\title{
Key Nuclear Data Impacting Reactivity in Advanced Reactors
}

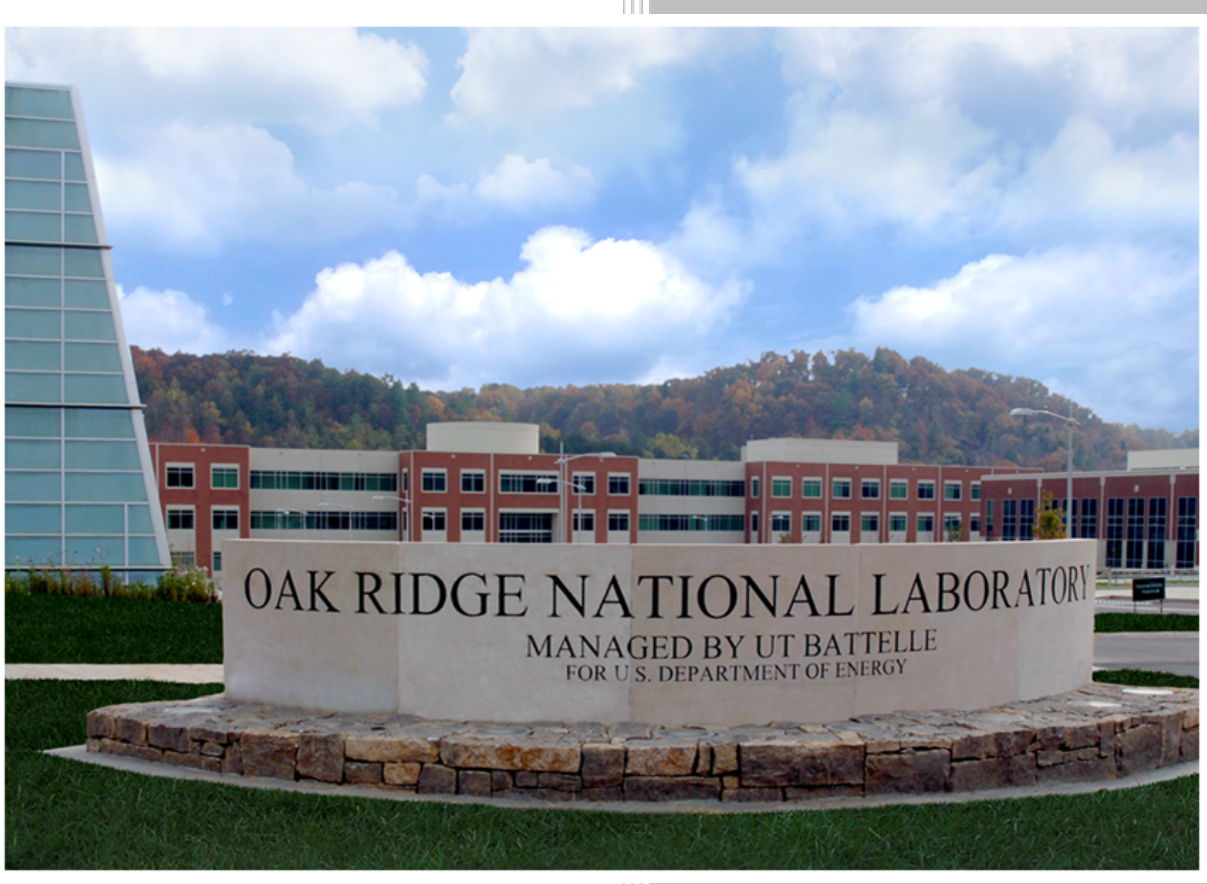

Approved for public release.

Distribution is unlimited.

Friederike Bostelmann Germina llas

William A. Wieselquist

June 2020 


\title{
DOCUMENT AVAILABILITY
}

Reports produced after January 1, 1996, are generally available free via US Department of Energy (DOE) SciTech Connect.

Website www.osti.gov

Reports produced before January 1, 1996, may be purchased by members of the public from the following source:

\author{
National Technical Information Service \\ 5285 Port Royal Road \\ Springfield, VA 22161 \\ Telephone 703-605-6000 (1-800-553-6847) \\ TDD 703-487-4639 \\ Fax 703-605-6900 \\ E-mail info@ntis.gov \\ Website http://classic.ntis.gov/
}

Reports are available to DOE employees, DOE contractors, Energy Technology Data Exchange representatives, and International Nuclear Information System representatives from the following source:

Office of Scientific and Technical Information

PO Box 62

Oak Ridge, TN 37831

Telephone 865-576-8401

Fax 865-576-5728

E-mail reports@osti.gov

Website http://www.osti.gov/contact.html

This report was prepared as an account of work sponsored by an agency of the United States Government. Neither the United States Government nor any agency thereof, nor any of their employees, makes any warranty, express or implied, or assumes any legal liability or responsibility for the accuracy, completeness, or usefulness of any information, apparatus, product, or process disclosed, or represents that its use would not infringe privately owned rights. Reference herein to any specific commercial product, process, or service by trade name, trademark, manufacturer, or otherwise, does not necessarily constitute or imply its endorsement, recommendation, or favoring by the United States Government or any agency thereof. The views and opinions of authors expressed herein do not necessarily state or reflect those of the United States Government or any agency thereof. 
Reactor and Nuclear Systems Division

\title{
KEY NUCLEAR DATA IMPACTING REACTIVITY IN ADVANCED REACTORS
}

Friederike Bostelmann, Germina Ilas, William A. Wieselquist

Date Published: June 2020

\author{
Prepared by \\ OAK RIDGE NATIONAL LABORATORY \\ Oak Ridge, TN 37831-6283 \\ managed by \\ UT-BATTELLE, LLC \\ for the \\ US DEPARTMENT OF ENERGY \\ under contract DE-AC05-00OR22725
}





\section{CONTENTS}

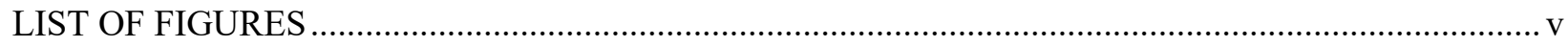

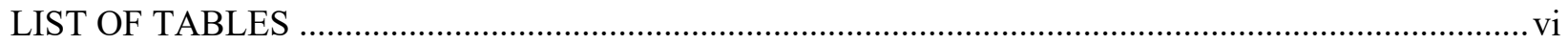

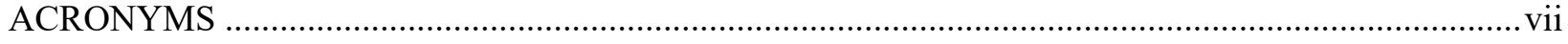

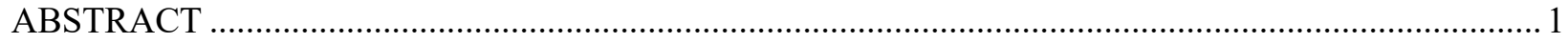

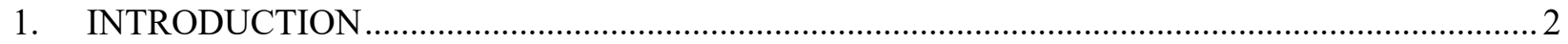

2. RELEVANT ADVANCED REACTOR TECHNOLOGIES …....................................................5

2.1 PEBBLE-BED HIGH TEMPERATURE GAS-COOLED REACTOR .................................... 5

2.2 FLUORIDE SALT-COOLED HIGH-TEMPERATURE REACTOR …................................. 6

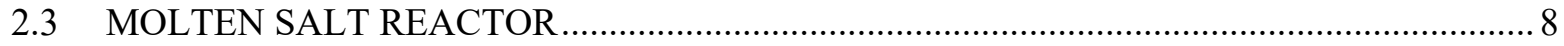

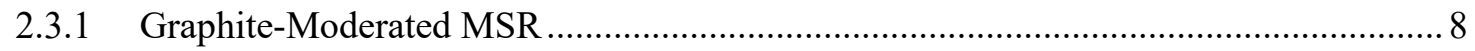

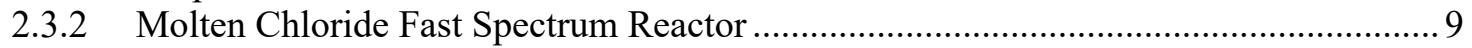

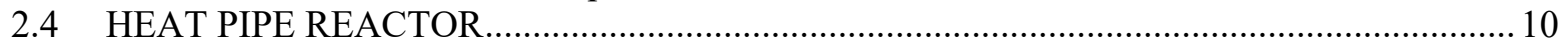

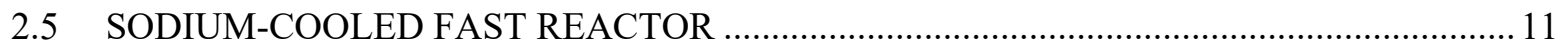

3. APPROACH TO IDENTIFY KEY NUCLEAR DATA AND TO ASSESS THEIR IMPACT.........13

3.1 COMPILATION OF GEOMETRICAL AND MATERIAL INFORMATION ....................... 13

3.2 INTERROGATION OF ENDF/B NUCLEAR DATA LIBRARIES ..................................... 13

3.3 CONSIDERATION OF LWR EXPERIENCE …......................................................... 13

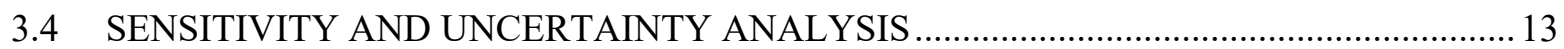

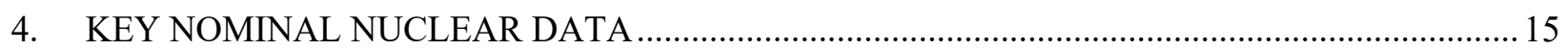

4.1 PEBBLE-BED HIGH TEMPERATURE GAS-COOLED REACTOR...................................... 15

4.2 FLUORIDE SALT-COOLED HIGH-TEMPERATURE REACTOR .................................... 17

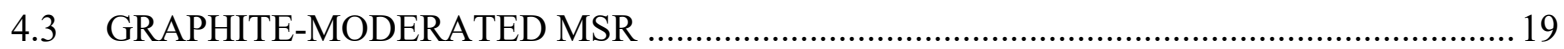

4.4 MOLTEN CHLORIDE FAST SPECTRUM REACTOR ...............................................20

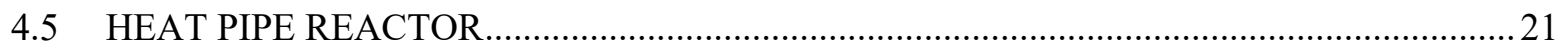

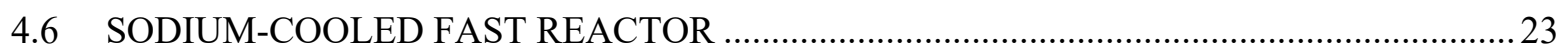

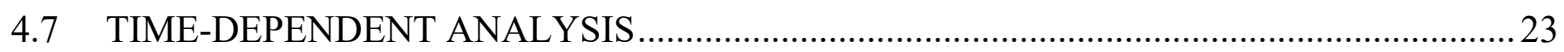

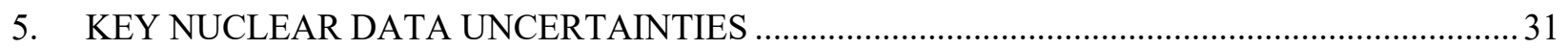

5.1 PEBBLE-BED HIGH TEMPERATURE GAS-COOLED REACTOR ................................. 31

5.2 FLUORIDE SALT-COOLED HIGH-TEMPERATURE REACTOR ..................................... 34

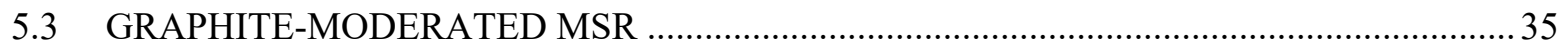

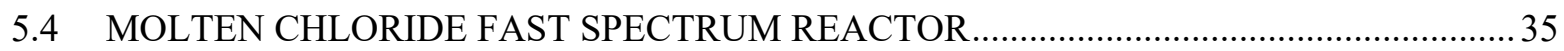

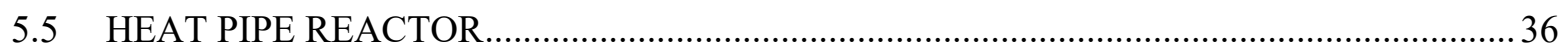

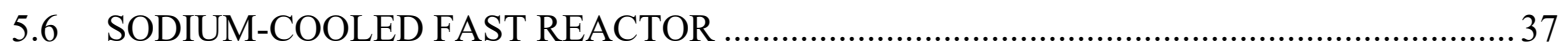

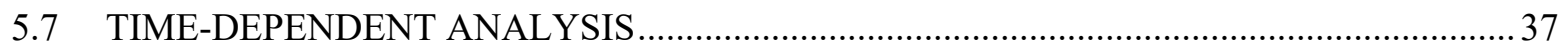

5.8 FURTHER COMMENTS ON THE AVAILABILITY AND USE OF COVARIANCE

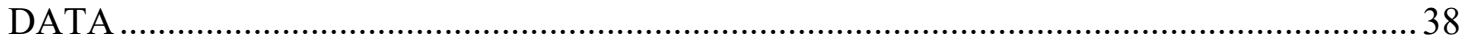

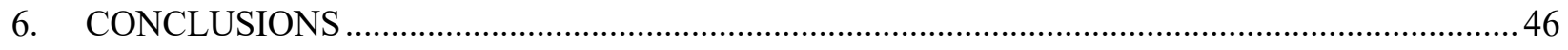

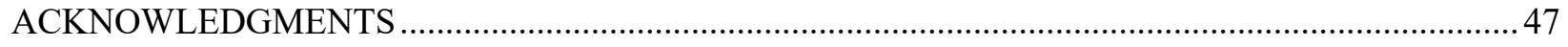

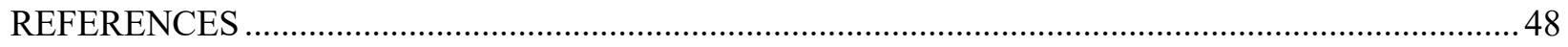





\section{LIST OF FIGURES}

Figure 1. Measured and evaluated ${ }^{23} \mathrm{Na}$ inelastic scattering cross section. ..............................................2

Figure 2. ${ }^{23} \mathrm{Na}$ inelastic scattering 17-group covariance matrix based on ENDF/B-VII.1. The energy ranges from $10^{-5}$ to $2 \cdot 10^{6} \mathrm{eV}$, with group 1 being the fastest group. Since inelastic scattering is a threshold reaction, the cross section and consequently the uncertainty for

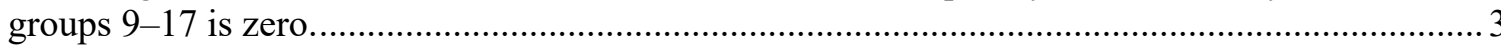

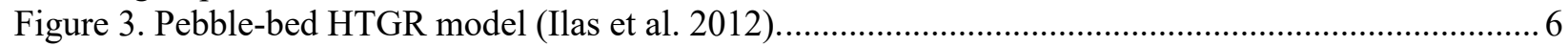

Figure 4. Representative TRISO fuel particle and pebble model............................................................. 6

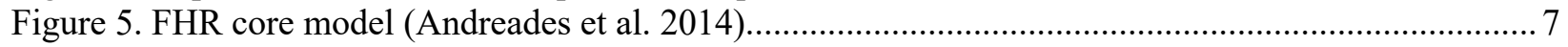

Figure 6. FHR fuel pebble model (Andreades et al. 2014) ................................................................ 8

Figure 7. Horizontal cross section of a graphite-moderated MSR (Shen et al. 2006) .............................. 9

Figure 8. Exemplary molten salt fast reactor model (Terrapower 2020) ............................................. 10

Figure 9. Cross section view of a heat pipe reactor with a hexagonal lattice of fuel cells (fuel red; heat pipe - yellow) surrounded by a reflector (blue), steel structure (green), and shield (gray) (Sterbentz et al. 2018).

Figure 10. Hexagonal lattice structure of fuel cells in a heat pipe reactor (fuel - red; heat pipe yellow, sodium pool - blue) (Sterbentz et al. 2018) .................................................................... 11

Figure 11. Fuel assembly model of a sodium-cooled fast reactor (OECD/NEA 2016) .......................... 12

Figure 12. Sodium-cooled fast reactor model cross section view (OECD/NEA 2016) ......................... 12

Figure 13. Comparison of carbon capture cross section in ENDF/B releases. ENDF/B-VII.0 and ENDF/B-VII.1 contain natural carbon data, while ENDF/B-VIII.0 contains isotopic data

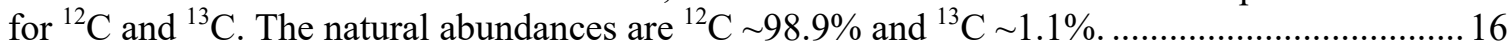

Figure 14. Relevant lithium cross sections (ENDF/B-VII.1) ........................................................ 18

Figure 15. Comparison of ${ }^{6} \mathrm{Li}(\mathrm{n}, \mathrm{t})$ cross section in ENDF/B releases................................................. 18

Figure 16. Comparison of ${ }^{35} \mathrm{Cl}(\mathrm{n}, \mathrm{p})$ cross section in ENDF/B releases. ............................................... 21

Figure 17. Comparison of ${ }^{9} \mathrm{Be}$ radiative neutron capture in ENDF/B releases. ........................................ 22

Figure 18. Comparison of ${ }^{16} \mathrm{O}$ elastic scattering cross section in ENDF/B releases. See Figure 20 for the relative difference between the cross sections of the ENDF/B-VII.1 and ENDF/B-

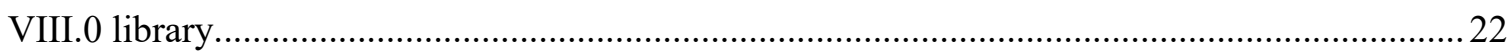

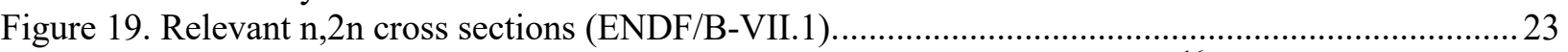

Figure 20. Relative differences between ENDF/B-VII.1 and ENDF/B-VIII.0 for ${ }^{16} \mathrm{O}$ cross

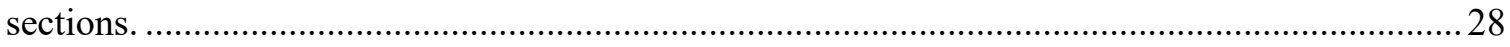

Figure 21. Relative differences between ENDF/B-VII.1 and ENDF/B-VIII.0 for ${ }^{56} \mathrm{Fe}$ cross

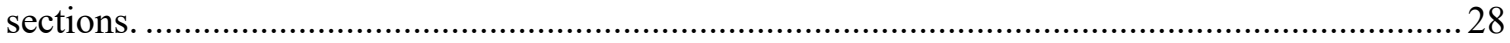

Figure 22. Relative differences between ENDF/B-VII.1 and ENDF/B-VIII.0 for ${ }^{235} \mathrm{U}$ cross sections.

Figure 23. Relative differences between ENDF/B-VII.1 and ENDF/B-VIII.0 for ${ }^{238} \mathrm{U}$ cross sections.

Figure 24. Relative differences between ENDF/B-VII.1 and ENDF/B-VIII.0 for ${ }^{239} \mathrm{Pu}$ cross sections

Figure 25. Relative differences of the ${ }^{235} \mathrm{U},{ }^{238} \mathrm{U}$, and ${ }^{239} \mathrm{Pu}$ neutron multiplicities between

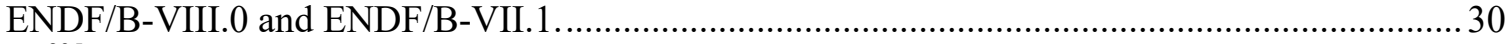

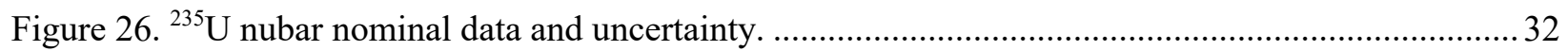

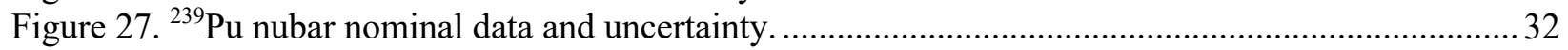

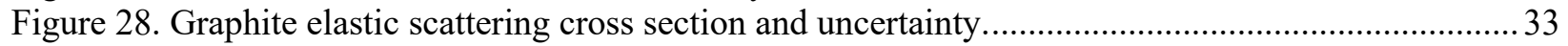

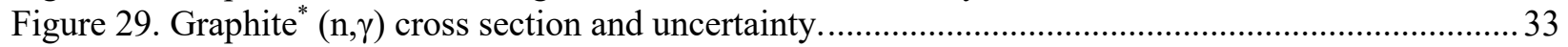

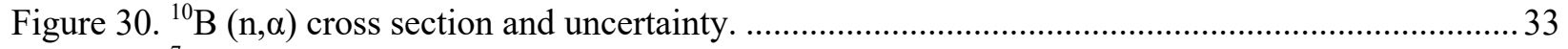

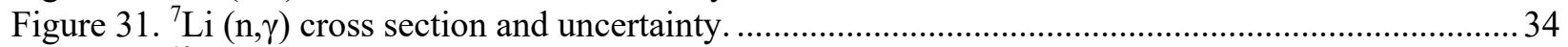

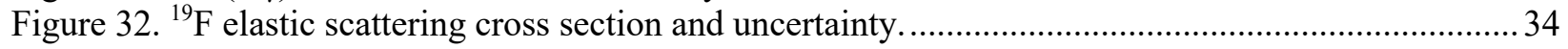




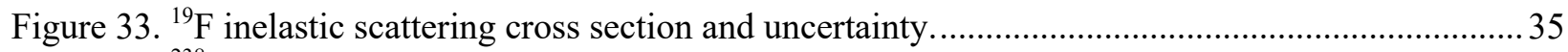

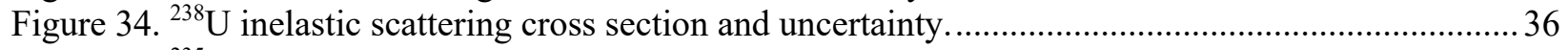

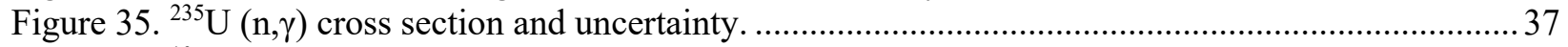

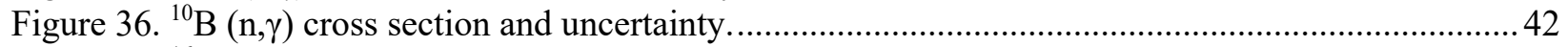

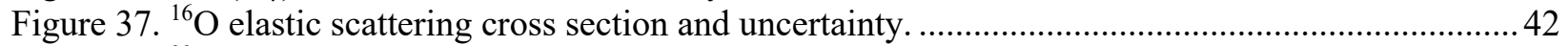

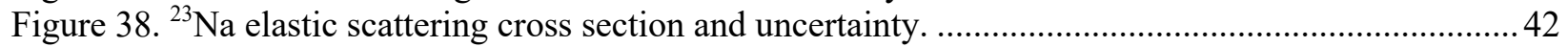

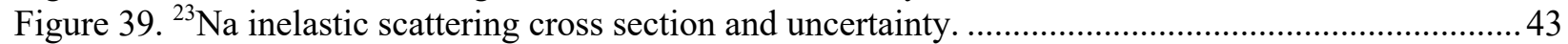

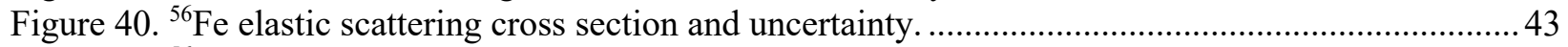

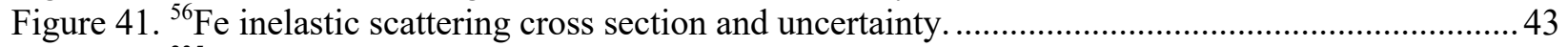

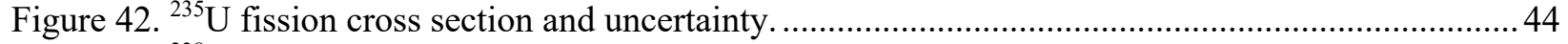

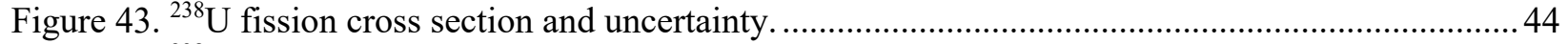

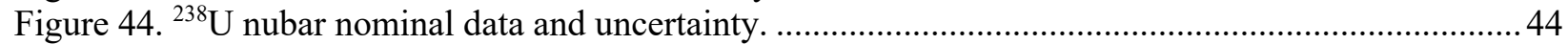

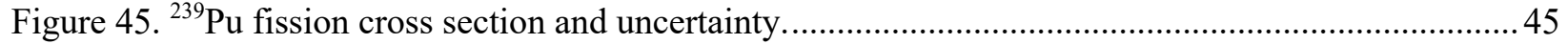

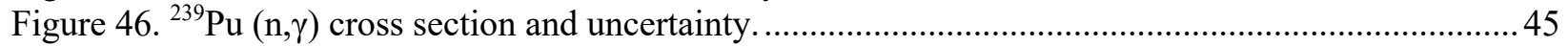

\section{LIST OF TABLES}

Table 1. Overview of selected advanced reactor technologies.......................................................... 5

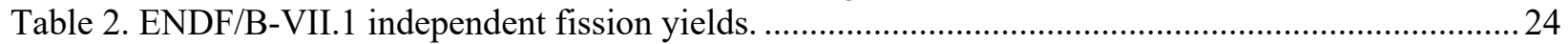

Table 3. Average energy of neutrons causing fission for a representative thermal (LWR) and fast

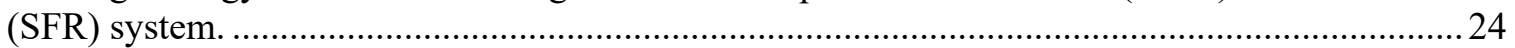

Table 4. Overview of key nominal nuclear data for the selected advanced reactor concepts ....................26

Table 5. Overview of key nuclear data uncertainties for the selected advanced reactor concepts. ............ 40 


\section{ACRONYMS}

$\begin{array}{ll}\text { EBC } & \text { equivalent boron concentration } \\ \text { ENDF/B } & \text { US Evaluated Nuclear Data File } \\ \text { FHR } & \text { fluoride salt-cooled high-temperature reactor } \\ \text { HTGR } & \text { high-temperature gas-cooled reactor } \\ \text { IAEA } & \text { International Atomic Energy Agency } \\ \text { JEFF } & \text { European Joint Evaluated Fission and Fusion File } \\ \text { JENDL } & \text { Japanese Evaluated Nuclear Data Library } \\ \text { LEU } & \text { low-enriched uranium } \\ \text { LWR } & \text { light-water reactor } \\ \text { MSR } & \text { molten-salt reactor } \\ \text { MW } & \text { megawatt } \\ \text { NRC } & \text { US Nuclear Regulatory Commission } \\ \text { OECD/NEA } & \text { Organisation for Economic Co-operation and Development Nuclear Energy Agency } \\ \text { ORNL } & \text { Oak Ridge National Laboratory } \\ \text { PyC } & \text { pyrolytic carbon } \\ \text { SFR } & \text { sodium-cooled fast reactor } \\ \text { SiC } & \text { silicon carbide } \\ \text { TRISO } & \text { tristructural isotropic }\end{array}$




\begin{abstract}
Advanced reactor concepts currently being developed throughout the industry are significantly different from light water reactor (LWR) designs with respect to geometry, materials, and operating conditions, and consequently, with respect to their reactor physics behavior. Given the limited operating experience with non-LWRs, the accurate simulation of reactor physics and the quantification of associated uncertainties are critical for ensuring that advanced reactor concepts operate within the appropriate safety margins.

Nuclear data are a major source of input uncertainties in reactor physics analysis. As part of an ongoing project at Oak Ridge National Laboratory (ORNL), the effects of nuclear data uncertainties on key figures of merit associated with advanced reactor safety are being assessed for selected advanced reactor technologies. Key nuclear data relevant for reactor safety analysis for each selected advanced reactor technology were identified, and their impact on important key figures of merit was assessed. Available advanced reactor specifications were reviewed, results from studies performed at ORNL and other research institutions were consulted, and available evaluated nuclear data libraries were analyzed.

This report summarizes the key nuclear data for nuclides in the fuel, as well as other significant data, including scattering and neutron capture in various materials for the moderator, coolant, and structure of the considered advanced reactors. For the considered advanced reactors that use low-enriched uranium (LEU) fuel, results from LWR studies provided insight into relevant nuclear data given the lack of available studies specifically addressing these new systems. The major nominal missing data that were identified consist of thermal scattering data and ${ }^{135 \mathrm{~m}}$ Xe cross section data for molten salt reactor (MSR) analysis. The identified major gaps with respect to nuclear data uncertainties are missing uncertainties of thermal scattering data for high temperature gas-cooled reactors and moderated MSR systems, and incomplete uncertainties on angular distributions in particular for fast spectrum systems, such as sodiumcooled fast reactors, fast molten salt reactors, and heat pipe reactors. Furthermore, it was found that special attention should be paid to cross section and uncertainty differences between different evaluated nuclear data library releases, because significant differences in nuclear data that can lead to major differences in reactivity calculations were found, even for well-known nuclides.
\end{abstract}




\section{INTRODUCTION}

Uncertainty analyses are an essential component in the design and analysis of advanced reactors, especially due to the growing interest in new reactor concepts that differ significantly from the designs for traditional light water reactors (LWRs). The advanced reactor concepts currently being developed throughout the industry are significantly different from LWR designs with respect to geometry, materials, and operating conditions, and consequently, with respect to their reactor physics behavior. Given the limited operating experience with non-LWRs, the accurate simulation of reactor physics and the quantification of associated uncertainties are critical for ensuring that advanced reactor concepts operate within the appropriate safety margins.

Nuclear data are a major source of input uncertainties in reactor physics analyses since they provide the basis for every reactor physics calculation. The nuclear interaction cross sections, fission yields, and decay data used in these calculations have uncertainty from measurements and from the data evaluations subsequent to the measurements. Nuclear data used with reactor physics codes result from extensive data evaluations, including validation studies performed with criticality experiments. The most common evaluated nuclear data libraries are the European Joint Evaluated Fission and Fusion File (JEFF) (Sublet et al. 2003), the Japanese Evaluated Nuclear Data Library (JENDL) (Shibata et al. 2012) files, and the US Evaluated Nuclear Data File (ENDF/B) (Chadwick et al. 2006, Chadwick et al. 2011, Brown et al. 2018). These libraries are undergoing continuous modifications based on additional measurements or improved evaluations, with new revisions being released on a regular basis. Figure 1 illustrates how cross section data for one nuclide and reaction - inelastic scattering in ${ }^{23} \mathrm{Na}$ - can differ significantly between different nuclear data libraries, including JENDL-4.0, JEFF-3.3, and ENDF/B-VII.1. Moreover, when comparing the data from these libraries with measurements from the EXFOR database (N. Otuka et al. 2014), significant disagreement between the individual measurements and between measurements and evaluations can be observed.

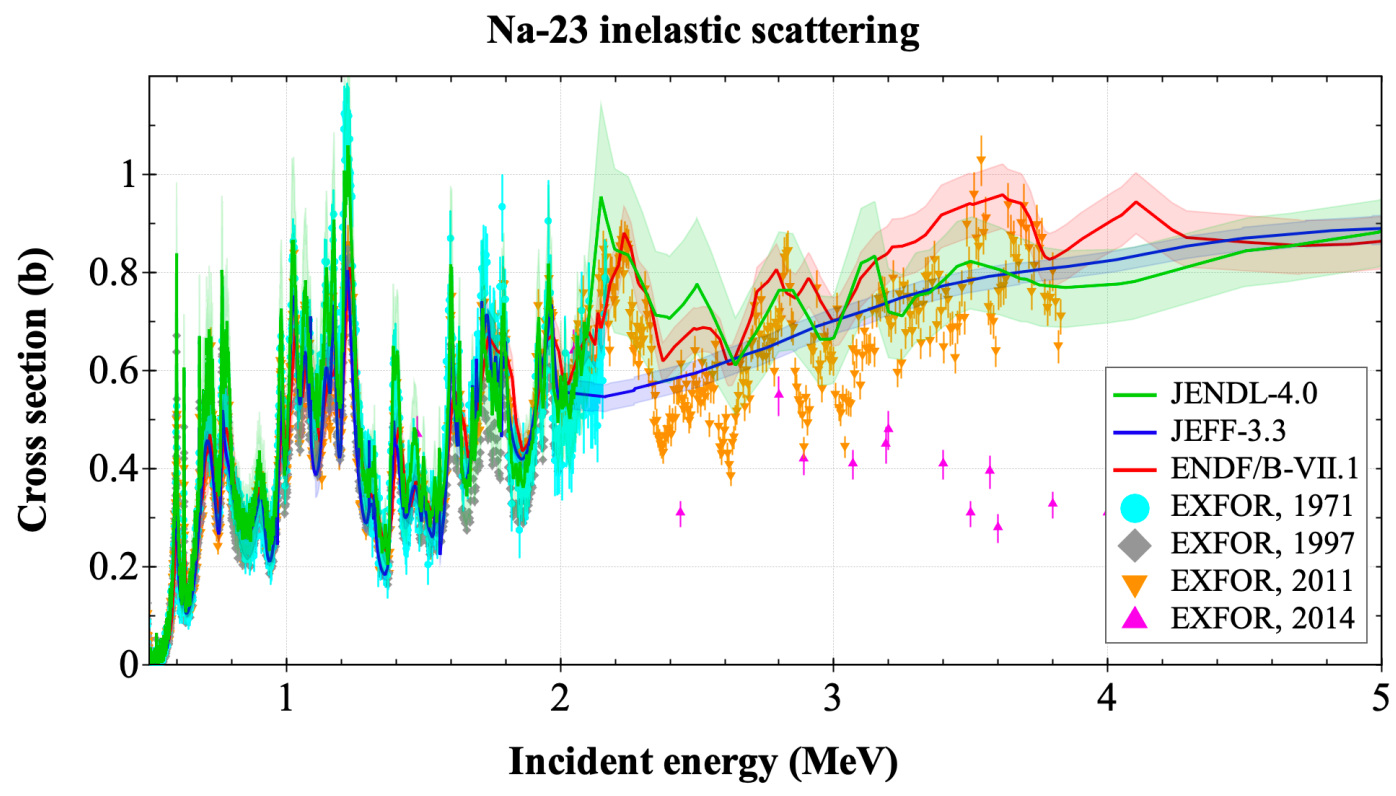

Figure 1. Measured and evaluated ${ }^{23} \mathrm{Na}$ inelastic scattering cross section. The bands represent the 1-sigma uncertainties as given in the evaluated nuclear data libraries. 
To express the uncertainty in the nominal cross section values, the evaluated nuclear data files contain information about the associated nuclear data uncertainties in the form of covariance matrices. The covariance is a measure of the joint variability of two cross sections. As an example, the energydependent covariance matrix in 17 neutron energy groups for ${ }^{23} \mathrm{Na}$ inelastic scattering based on ENDF/BVII.1 data is illustrated in Figure 2. The diagonal elements describe the variance of the cross sections in the individual energy groups. The square root of the variance is the standard deviation that is the uncertainty of the cross section. The value in the $\mathrm{i}^{\text {th }}$ row and $\mathrm{j}^{\text {th }}$ column is the covariance between the scattering cross section in the $i^{\text {th }}$ and $j^{\text {th }}$ energy group. In addition to covariance matrices of individual reactions, there are covariance matrices that include correlations between different reactions within a nuclide (e.g., between elastic scattering and neutron capture of ${ }^{238} \mathrm{U}$ ) and correlations between reactions of different nuclides (e.g., between fission of ${ }^{235} U$ and neutron capture of ${ }^{238} U$ ).

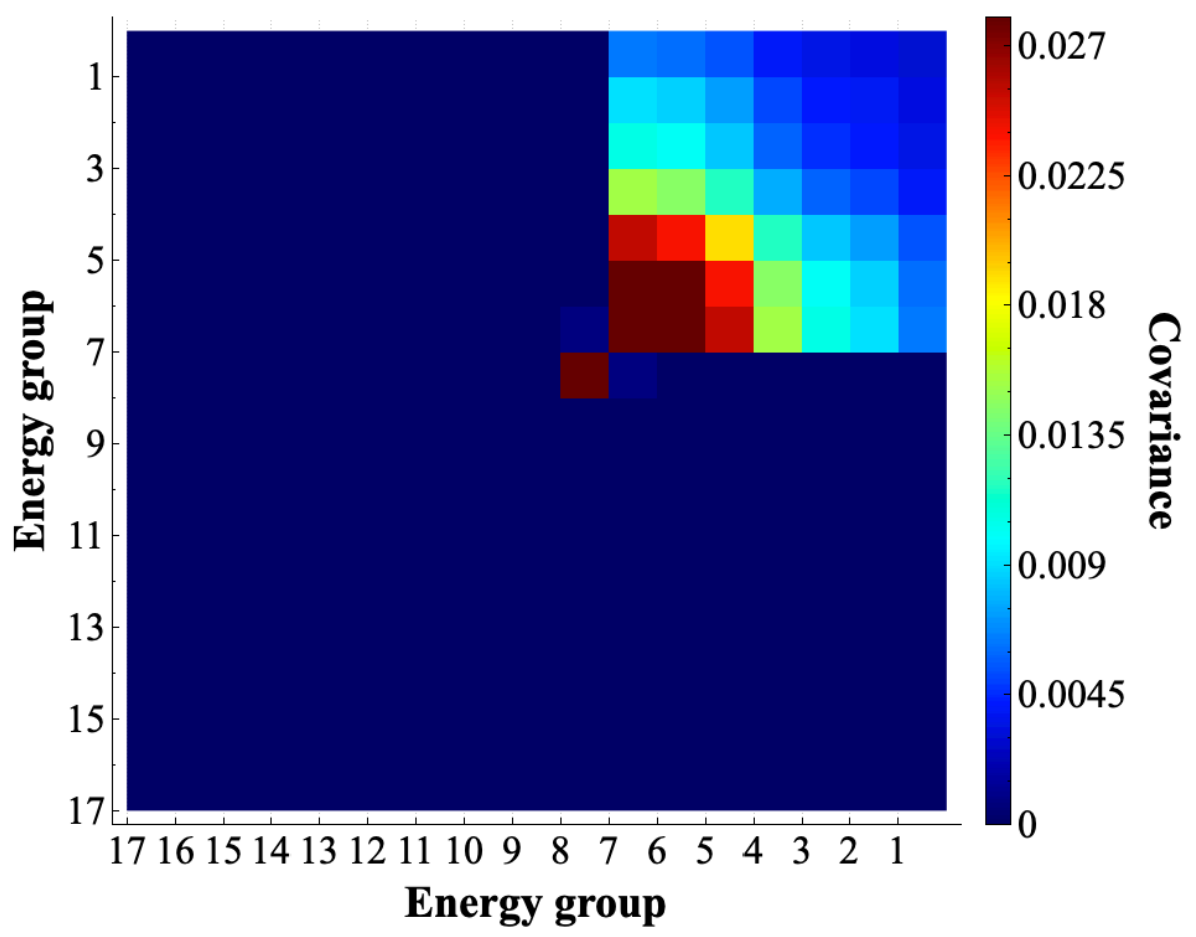

Figure 2. ${ }^{23} \mathrm{Na}$ inelastic scattering 17-group covariance matrix based on ENDF/B-VII.1. The energy ranges from $10^{-5}$ to $2 \cdot 10^{6} \mathrm{eV}$, with group 1 being the fastest group. Since inelastic scattering is a threshold reaction, the cross section and consequently the uncertainty for groups $9-17$ is zero.

To better understand uncertainties in the calculation of safety-relevant output quantities due to nuclear data and to decide where additional efforts should focus to reduce relevant nuclear data uncertainties, these data need to be propagated to key figures of merit impacting nuclear safety. This is a challenging task, because uncertainty information is not available for all nuclear data used in reactor physics analysis. For a thorough analysis, the missing data need to be identified, and the potential impact of missing nominal data, as well as the missing uncertainty information, needs to be assessed.

As part of the ongoing project, Nuclear Data Assessment for Advanced Reactors, which is funded by the US Nuclear Regulatory Commission (NRC), the impact of nuclear data uncertainties on key figures of merit associated with advanced reactor safety is assessed for selected advanced reactor technologies. The project includes four phases:

- Phase 1: Identify key nuclear data impacting reactivity in non-LWRs, 
- Phase 2: Assess key nuclear data impacting reactivity in non-LWRs,

- Phase 3: Assess relevant benchmark experiments applicable to the nuclear data identified in Phases 1 and 2 , and

- Phase 4: Assess the impact of nuclear data uncertainty through propagation to key figures of merit associated with reactor safety.

This report summarizes the findings of Phases 1 and 2. First, for each selected advanced reactor technology, key nuclear data that impact key figures of merit were identified. Second, the impact of the identified key nuclear data including their corresponding uncertainties on the key figures of merit was assessed. The following steps were included:

1. Explored publicly available literature to identify descriptions of representative geometrical and material definitions relevant for reactor physics analysis of the selected advanced reactor technologies.

2. Interrogated modern evaluated nuclear data libraries to identify important updates in nominal values and uncertainties of relevant nuclear data.

3. Reviewed results from previous studies performed by Oak Ridge National Laboratory (ORNL) and other research institutions with respect to the impact of nuclear data on key figures of merit associated with advanced reactor safety.

4. Based on the review of literature and previous studies, identified key nuclides and nuclear data impacting reactivity during operation - considering both fresh and irradiated fuel—and assessed their impact on the selected advanced reactor technologies.

The overall goal of the project is to study the following quantities of interest: (1) core reactivity, (2) the 4factor formula, (3) control rod worth, (4) temperature and expansion coefficients, (5) kinetic parameters, (6) spectral indices, and (7) power distribution, including peak pin power and peak power. The quantities' level of importance to reactor safety can differ between various advanced reactor concepts. Phases 1 and 2 mainly focus on reactivity effects.

The selected advanced reactor technologies are briefly described in Section 2. The approach used to identify key nuclear data impacting the mentioned quantities of interest is described in Section 3. Sections 4 and 5 present the key nominal nuclear data and nuclear data uncertainties, respectively, as well as their impact on quantities of interest as identified in this study. 


\section{RELEVANT ADVANCED REACTOR TECHNOLOGIES}

Based on current interest and relevant activities throughout the industry, several advanced reactor technologies were selected for consideration in this project. In the following section, the selected reactor concepts are briefly described with respect to the materials used, geometry, and temperatures. The fuel types, moderators, and coolants vary between the concepts, as shown in Table 1.

Table 1. Overview of selected advanced reactor technologies

\begin{tabular}{lllll}
\hline \multicolumn{1}{c}{ Reactor type } & \multicolumn{1}{c}{ Reactor technology } & \multicolumn{1}{c}{ Fuel } & Moderator & \multicolumn{1}{c}{ Coolant } \\
\hline $\begin{array}{l}\text { Thermal spectrum, high- } \\
\text { temperature gas-cooled } \\
\text { reactor (HTGR) }\end{array}$ & Pebble-bed HTGR & UCO or $\mathrm{UO}_{2}$ & Graphite & Helium \\
$\begin{array}{l}\text { Thermal spectrum, molten } \\
\text { salt reactor (MSR) }\end{array}$ & $\begin{array}{l}\text { Fluoride salt-cooled high- } \\
\text { temperature reactor } \\
\text { (FHR) }\end{array}$ & $\mathrm{UCO}$ or $\mathrm{UO}_{2}$ & Graphite & FLiBe \\
\hline Thermal spectrum MSR & Graphite-moderated MSR & $\mathrm{LiF-BeF}_{2}-\mathrm{UF}_{4}$ & Graphite & $\begin{array}{l}\text { Fuel serves as } \\
\text { coolant }\end{array}$ \\
\hline Fast spectrum MSR & $\begin{array}{l}\text { Molten chloride fast } \\
\text { spectrum reactor }\end{array}$ & $\begin{array}{l}\mathrm{PuCl}_{3}-\mathrm{NaCl}, \\
\mathrm{UCl}_{3}-\mathrm{NaCl}\end{array}$ & -- & $\begin{array}{l}\text { Fuel serves as } \\
\text { coolant }\end{array}$ \\
\hline $\begin{array}{l}\text { Fast spectrum, oxide and } \\
\text { metal fueled, stationary } \\
\text { microreactor }\end{array}$ & $\begin{array}{l}\text { Heat pipe reactor } \\
\mathrm{UO}_{2}, \mathrm{UN}, \\
\text { or U-10Zr }\end{array}$ & -- & Potassium, sodium \\
\hline $\begin{array}{l}\text { Fast spectrum, metal and } \\
\text { oxide fueled, sodium-cooled } \\
\text { reactor }\end{array}$ & $\begin{array}{l}\text { Sodium-cooled fast } \\
\text { reactor (SFR) }\end{array}$ & $\begin{array}{l}\mathrm{U} / \mathrm{TRU}-\mathrm{Zr} \text { or } \\
\mathrm{U} / \mathrm{TRU} \text { oxide }\end{array}$ & -- & Sodium \\
\hline
\end{tabular}

\subsection{PEBBLE-BED HIGH-TEMPERATURE GAS-COOLED REACTOR}

A high-temperature gas-cooled reactor (HTGR) is a graphite-moderated, helium-cooled reactor with a thermal neutron spectrum. An HTGR pebble-bed reactor operates at several hundred megawatts (MW) of power. Its core contains a large number of fuel pebbles and moderator (graphite) pebbles - on the order of hundreds of thousands. The core is surrounded by graphite reflector structures (Figure 3) (DOE Office of Nuclear Energy 2002, Zhang et al. 2006, International Handbook of Reactor Physics Experiments 2007, Ilas et al. 2012, IAEA 2013).

A fuel pebble consists of a fuel zone that is $\sim 5 \mathrm{~cm}$ in diameter, with many thousands of tristructural isotropic (TRISO) fuel particles distributed randomly in a graphite matrix, surrounded by a $5 \mathrm{~mm}$ graphite layer, resulting in an outer diameter of $6 \mathrm{~cm}$ (Figure 4). A representative TRISO fuel particle is roughly 1 $\mathrm{mm}$ in diameter and consists of a micro fuel kernel composed of uranium in oxide or carbide form. The fuel kernel is enclosed by four concentric coatings: a porous graphite buffer, an inner pyrolytic carbon $(\mathrm{PyC})$ layer, a ceramic silicon carbide (SiC) layer, and an outer PyC layer. The ${ }^{235} \mathrm{U}$ enrichment of the fuel reaches up to $19.75 \mathrm{wt} \%{ }^{235} \mathrm{U}$, depending on the reactor design. High inlet and outlet temperatures of the helium coolant $\left(640\right.$ and $1,000^{\circ} \mathrm{C}$, respectively) result in high fuel temperatures of up to $1,100^{\circ} \mathrm{C}$ under normal operating conditions. Reactivity control is achieved with absorber rods containing boron in the outer reflector. Burnups beyond $150 \mathrm{GWd}$ /MTHM are targeted (Mulder and Boyes 2020). 


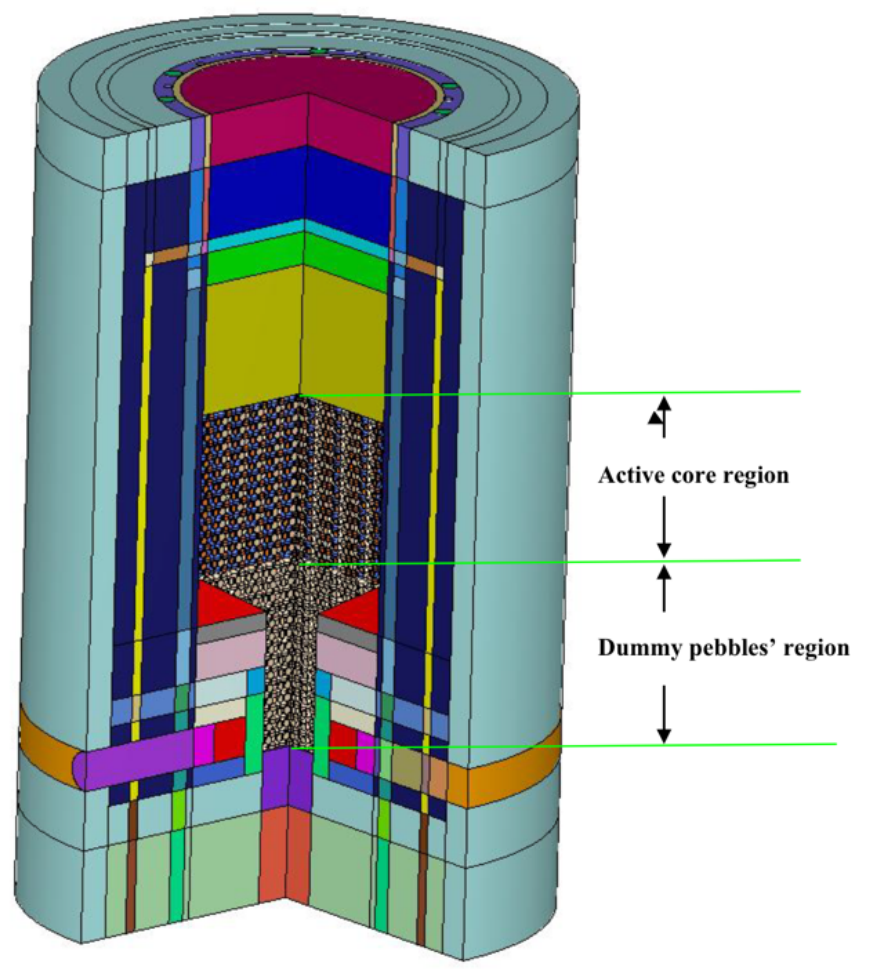

Figure 3. Pebble-bed HTGR model (Ilas et al. 2012).

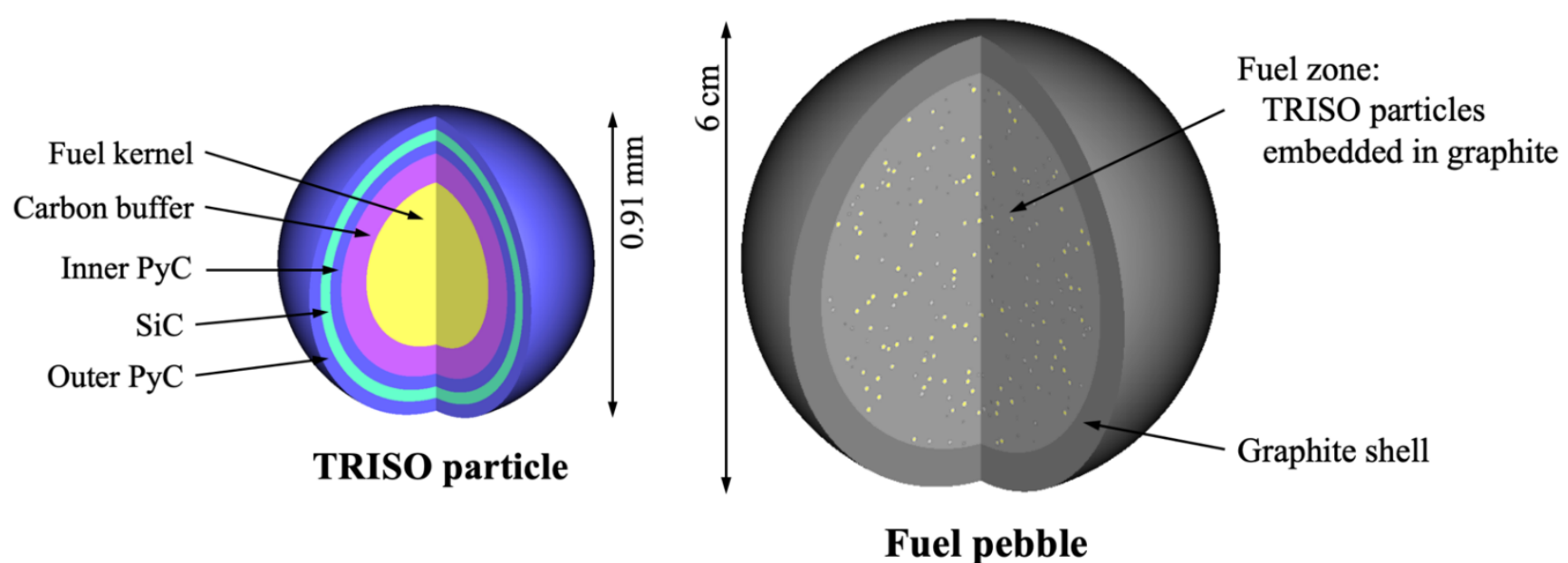

Figure 4. Representative TRISO fuel particle and pebble model.

\subsection{FLUORIDE SALT-COOLED HIGH-TEMPERATURE REACTOR}

A fluoride salt-cooled high-temperature reactor (FHR) combines the HTGR fuel form with liquid fluoride salt coolant in a graphite-moderated environment (Cisneros 2013). A pebble-bed FHR has an annular core filled with a large number of graphite moderator and fuel pebbles. This annular core is contained in graphite reflector structures (Figure 5). Like an HTGR, the fuel pebbles contain thousands of TRISO particles distributed in a graphite matrix. However, the pebbles in an FHR are significantly smaller, $\sim 3$ $\mathrm{cm}$ diameter, and the fuel particles within the pebble are tightly packed in an annulus that is $1.5 \mathrm{~mm}$ thick 
(Figure 6). The fuel material is either $\mathrm{UCO}$ or $\mathrm{UO}_{2}$ that is enriched up to $19.9 \mathrm{wt} \%{ }^{235} \mathrm{U}$. The coolant salt is $\mathrm{FLiBe}$, a mixture of $\mathrm{Li}_{2} \mathrm{~F}$ and $\mathrm{BeF}$. Core inlet and outlet temperatures are approximately 600 and $700^{\circ} \mathrm{C}$, respectively, and the fuel temperature ranges between 700 and $800^{\circ} \mathrm{C}$. Burnups reaching up to 180 $\mathrm{GWd} / \mathrm{MTHM}$ are intended. Reactivity control is achieved using control rods and blades containing boron carbide (Cisneros 2013, Andreades et al. 2014, Qualls et al. 2017, Latta et al. 2019).

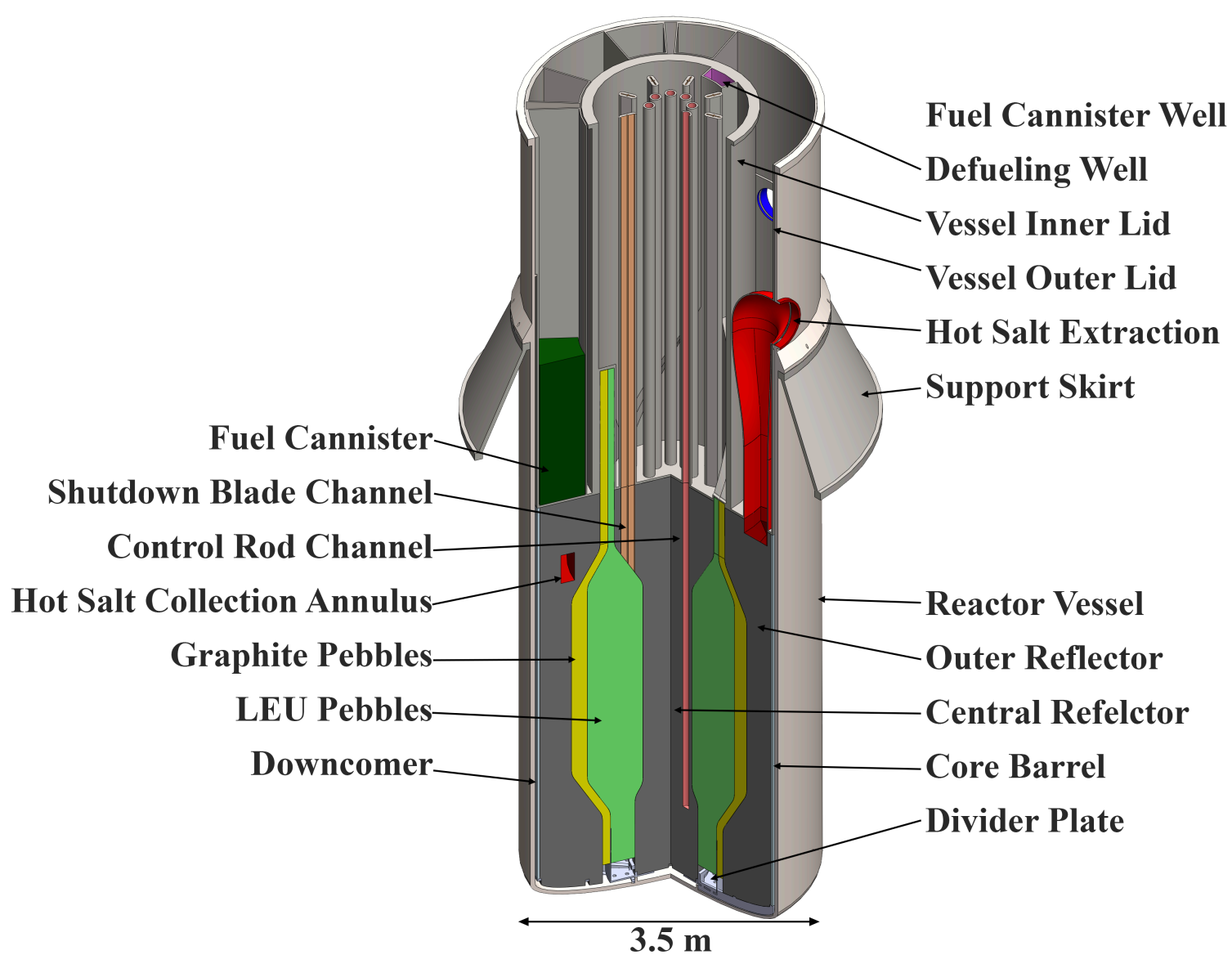

Figure 5. FHR core model (Andreades et al. 2014). 


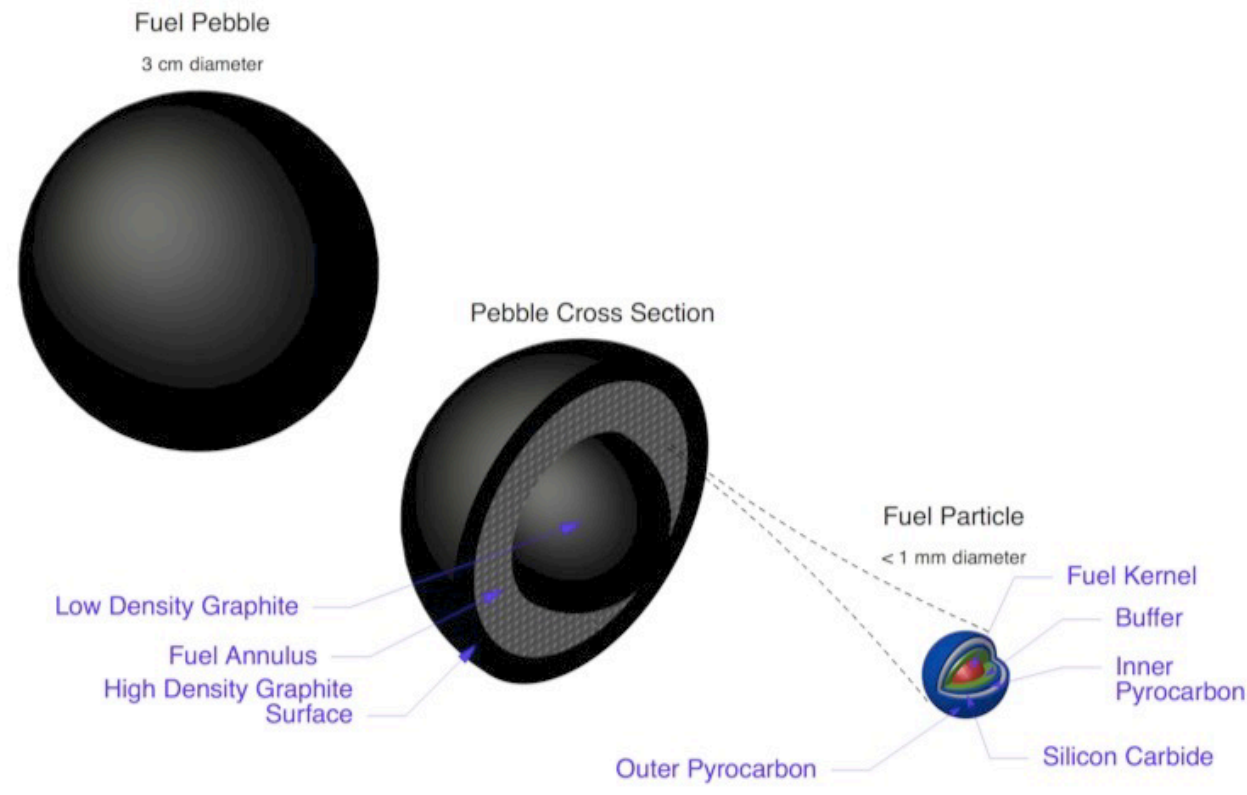

Figure 6. FHR fuel pebble model (Andreades et al. 2014).

\subsection{MOLTEN SALT REACTOR}

A number of different MSR systems that are currently pursued by industry vary widely with respect to the fuel salt and/or moderator. Therefore, MSRs have a variety of spectral conditions which can further change during fuel depletion. The FHR concept presented in Section 2.2 is also referred to in the literature as a molten salt system that uses solid fuel and molten salt as coolant. Two concepts in which the salt contains the fuel itself are briefly described in the following subsections.

\subsubsection{Graphite-Moderated MSR}

A graphite-moderated MSR core consists of a graphite structure within a cylindrical reactor vessel. The fuel salt is pumped through the graphite, building a plenum below and above the graphite structure. The salt is either a mixture of $\mathrm{LiF}-\mathrm{BeF}_{2}-\mathrm{UF}_{4}$ or a mixture of NaF-RbF-UF 4 that serves the dual purpose of carrying the low-enriched fuel (less than $5 \mathrm{wt} \%{ }^{235} \mathrm{U}$ ) and cooling the core. The fuel salt inlet and outlet temperatures are $\sim 560^{\circ} \mathrm{C}$ and $700^{\circ} \mathrm{C}$, respectively. Figure 7 provides an example of this type of MSR (Shen et al. 2006, Choe et al. 2018). 


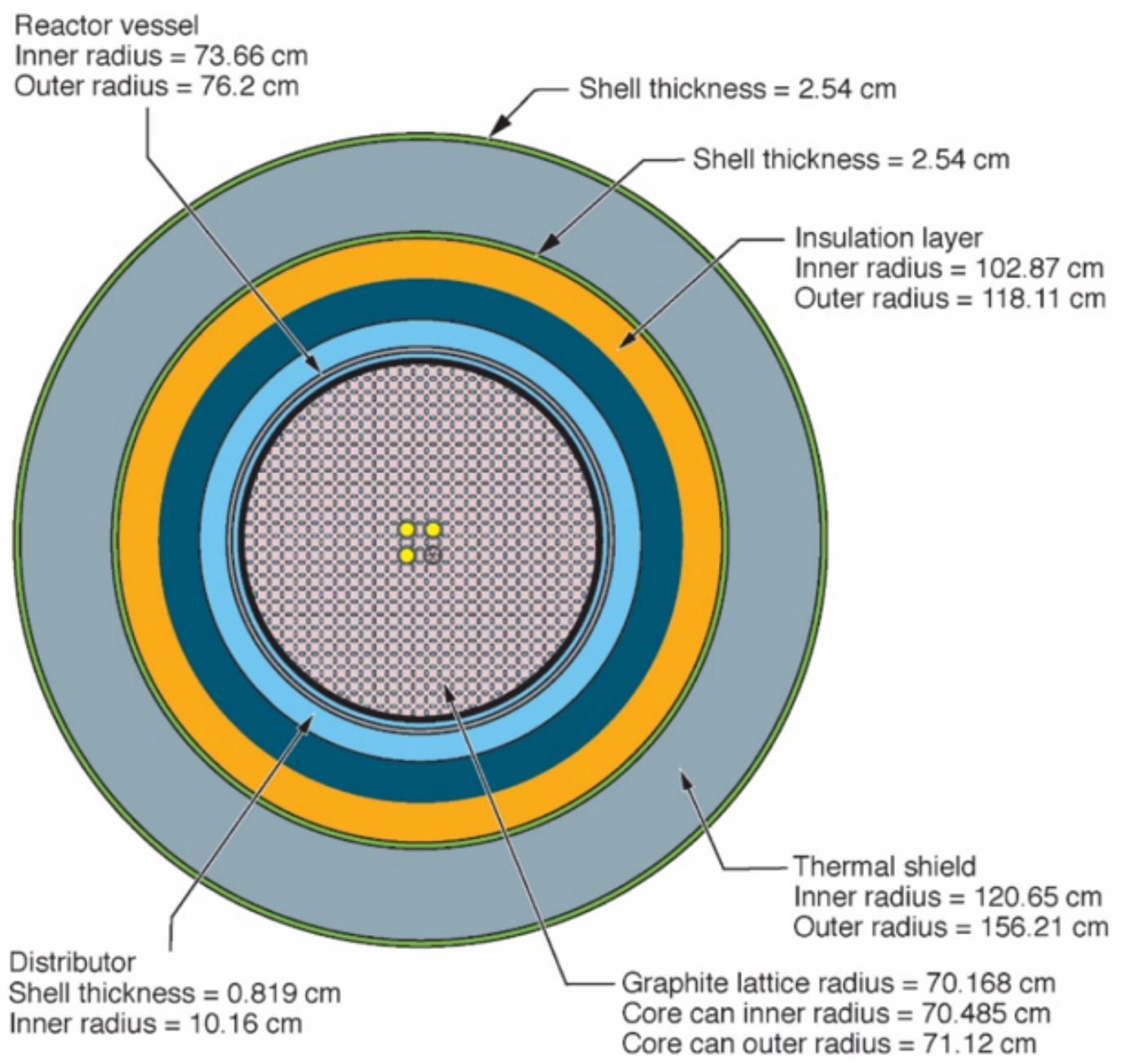

$15-6450499-148$

Figure 7. Horizontal cross section of a graphite-moderated MSR (Shen et al. 2006). Molten salt - light blue; graphite lattice - pink; reactor vessel, INOR (Ni-based alloy) - gray; void - dark blue; insulation, homogeneous mixture $(\mathrm{O}, \mathrm{Fe}, \mathrm{Al}, \mathrm{H}, \mathrm{Si}, \mathrm{Ca})$ - orange; stainless steel shells - green; mainly steel thermal shield - gray;

\subsubsection{Molten Chloride Fast Spectrum Reactor}

A molten chloride fast spectrum reactor uses $\mathrm{NaCl}$ as the carrier salt in $\mathrm{UCl}_{3}-\mathrm{NaCl}$ and $\mathrm{PuCl}_{3}-\mathrm{NaCl}$ fuel salts. The fuel salt is located at the center of the cylindrical reactor and circulates within the core region. In axial and radial directions, the core is surrounded by neutron reflectors made of steel. The fuel salt has an average temperature of $\sim 980^{\circ} \mathrm{C}$ (Holcomb et al. 2011, Betzler et al. 2017b). An example molten chloride reactor is shown in Figure 8. 


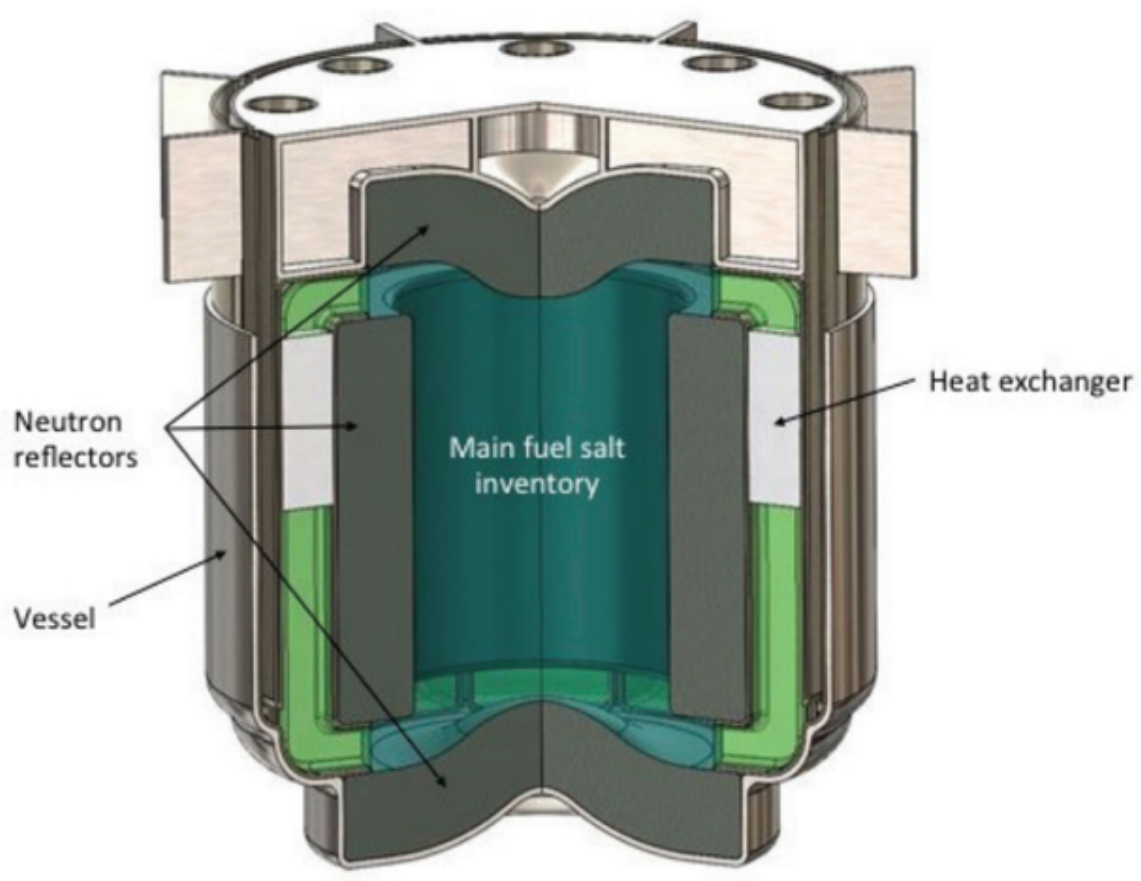

Figure 8. Exemplary molten salt fast reactor model (Terrapower 2020).

\subsection{HEAT PIPE REACTOR}

Heat pipe reactors are microreactors with small core diameters. These reactors mainly consist of a reactor core with a reflector, shielding, and a heat removal system. A stainless-steel monolithic core contains the fuel and the heat pipes. Many different heat pipe reactor concepts are currently under development. Most of these systems use $19.75 \mathrm{wt} \%{ }^{235} \mathrm{U}$ enriched $\mathrm{UO}_{2}, \mathrm{UN}$, or $\mathrm{U}-10 \mathrm{Zr}$ fuel with potassium $(\mathrm{K})$, sodium $(\mathrm{Na})$, or $\mathrm{NaK}$ as coolant. Reflector materials placed above the fuel and radially surrounding the core are $\mathrm{BeO}$, steel, and/or $\mathrm{Al}_{2} \mathrm{O}_{3}$. Reactivity control is performed using boron-containing control drums. Depending on the design, the temperature of the coolant in the heat pipes is $620-730^{\circ} \mathrm{C}$, and the fuel temperature is only slightly higher than that of the coolant and under $800^{\circ} \mathrm{C}$. Diagrams of a potassium-cooled $\mathrm{UO}_{2}$ fuel heat pipe reactor are provided in Figure 9 and Figure 10 (Yan et al. 2020, Sterbentz et al. 2018, Maoioli et al. 2019, Matthews et al. 2019, Clark et al. 2020). 


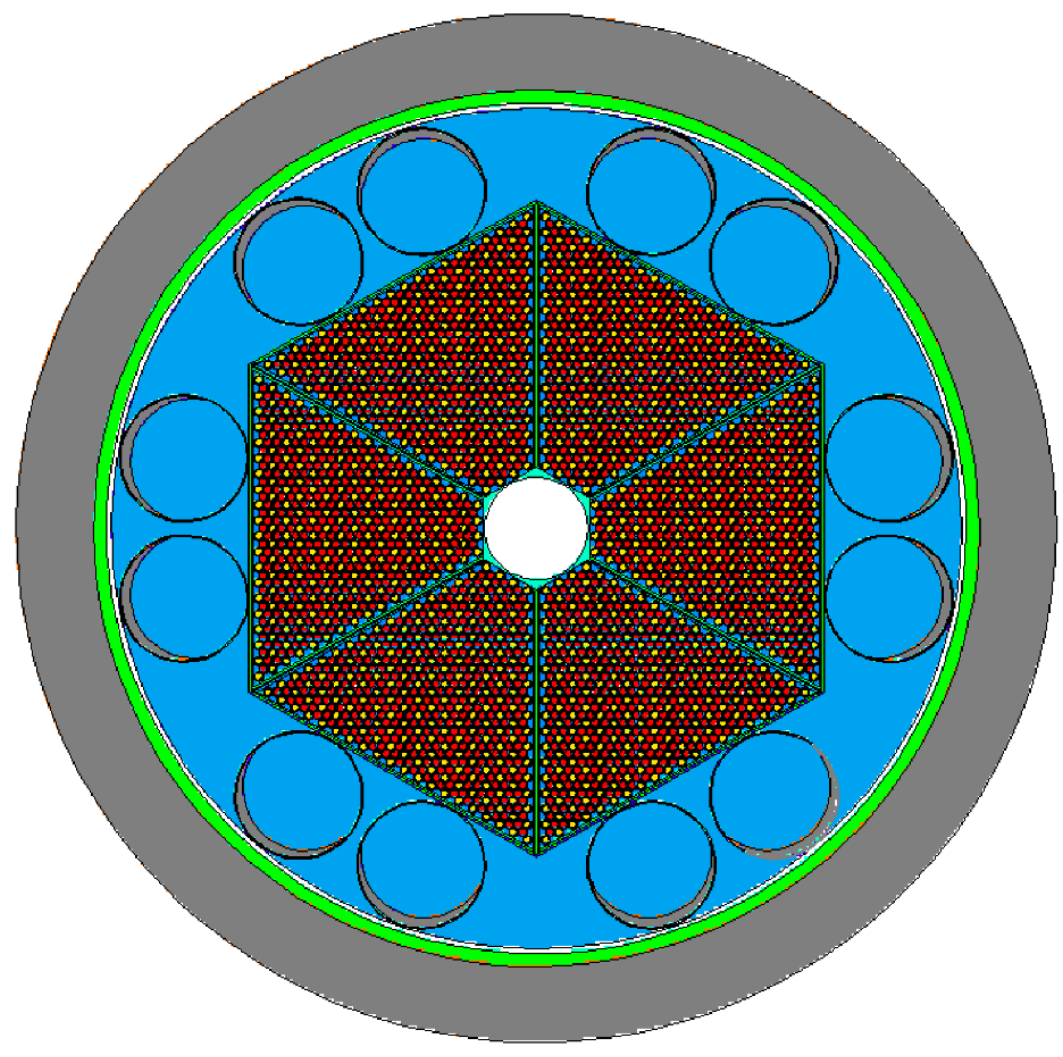

Figure 9. Cross section view of a heat pipe reactor with a hexagonal lattice of fuel cells (fuel - red; heat pipe - yellow) surrounded by a reflector (blue), steel structure (green), and shield (gray) (Sterbentz et al. 2018).

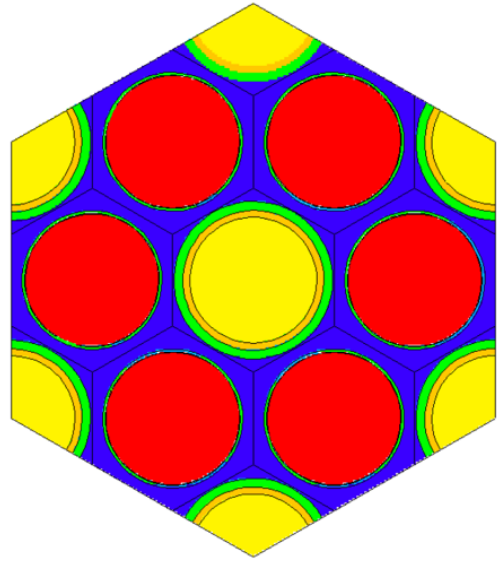

Figure 10. Hexagonal lattice structure of fuel cells in a heat pipe reactor (fuel - red; heat pipe yellow, sodium pool - blue) (Sterbentz et al. 2018).

\subsection{SODIUM-COOLED FAST REACTOR}

The core of a sodium-cooled fast reactor (SFR) (Figure 11 and Figure 12) consists of a grid of hexagonal assemblies. The fuel assemblies at the center of the core consist of fuel pins with an inner fuel zone surrounded by cladding. The fuel pins are arranged in a tight hexagonal lattice surrounded by a metal wrapper or duct (OECD/NEA 2016, Lum et al. 2006).

The fuel in an SFR can be mixed-oxide fuel or a mixed uranium-transuranic-zirconium (U-TRU-Zr) metal alloy. Axial reflectors and gas plenums are located above and below the fuel region. The structural materials, including the cladding and the wrapper, are made of iron-based alloys containing nickel, chromium, manganese, and/or molybdenum. Sodium is used as the coolant (Fast Reactor Working Group 2018).

A core can have multiple fuel zones with different fuel compositions. The fuel zone in the core is surrounded by hexagonal reflector assemblies, and an absorbing shield may also be included. Reactivity control is maintained by moving control and safety assemblies into locations not occupied by fuel assemblies.

The typical inlet and outlet temperatures of a metal core are 350 and $510^{\circ} \mathrm{C}$, respectively, and for an oxide core, they are $\sim 400$ and $550^{\circ} \mathrm{C}$, respectively. The metal fuel temperature is $\sim 530^{\circ} \mathrm{C}$, and the oxide fuel 
temperature is $\sim 1,200^{\circ} \mathrm{C}$. Burnups in the range of $150-200 \mathrm{GWd} / \mathrm{MTHM}$ have been experimentally demonstrated (DOE Office of Nuclear Science 2002).

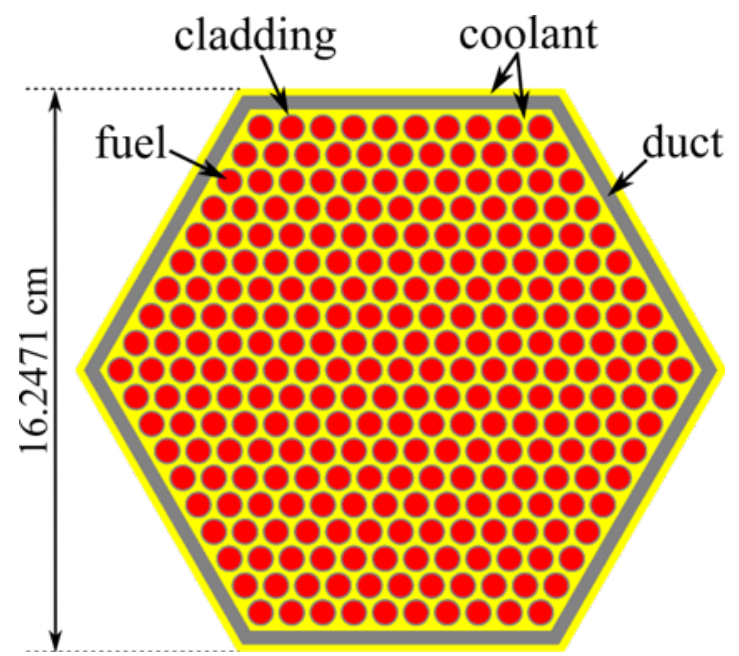

Figure 11. Fuel assembly model of a sodium-cooled fast reactor (OECD/NEA 2016).

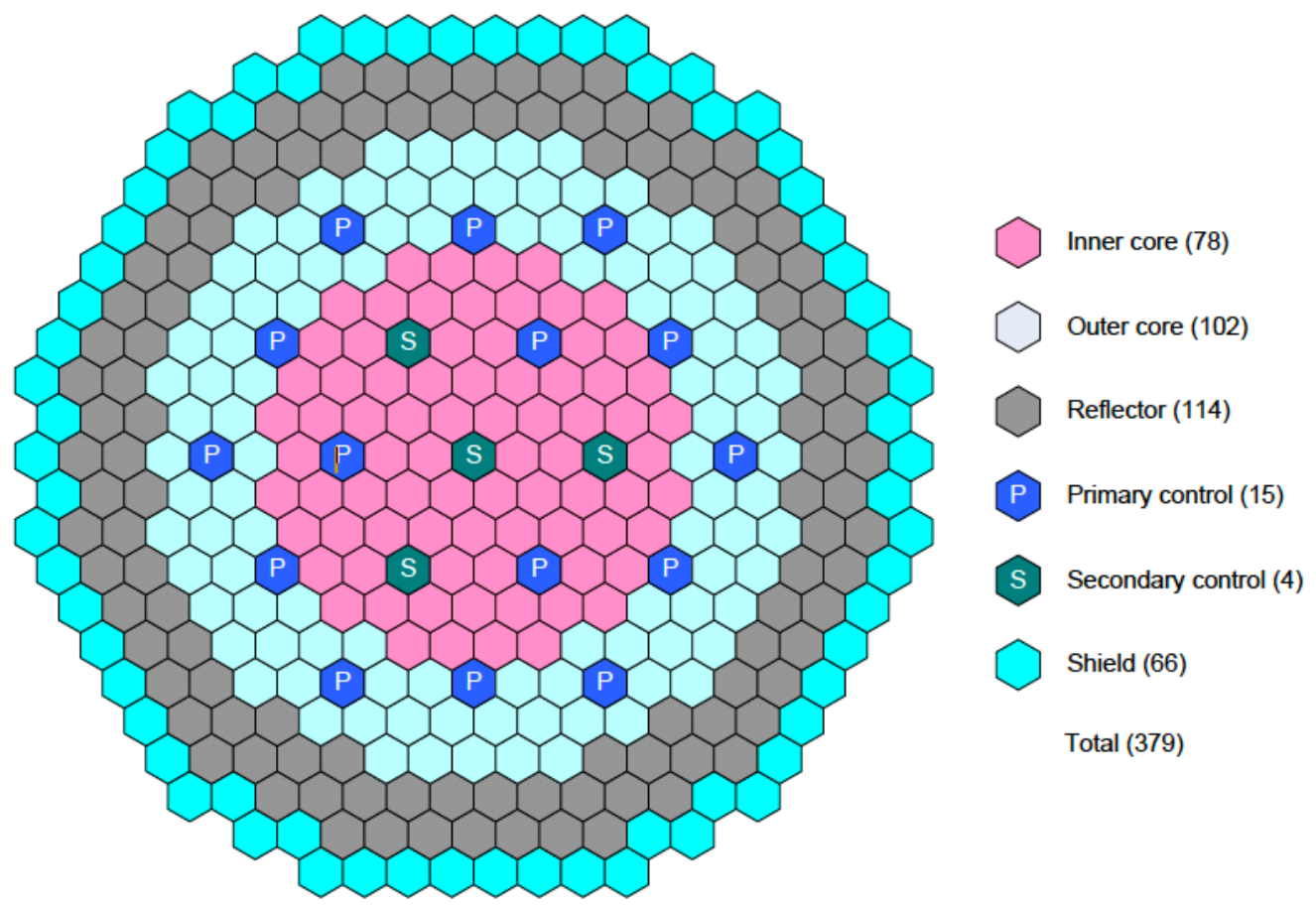

Figure 12. Sodium-cooled fast reactor model cross section view (OECD/NEA 2016). 


\section{APPROACH TO IDENTIFY KEY NUCLEAR DATA AND TO ASSESS THEIR IMPACT}

The key nuclear data relevant for simulation of the selected reactor technologies were identified, and their impact on important quantities of interested was assessed by reviewing available advanced reactor specifications, consulting the results from studies performed at ORNL and other research institutions, and studying the available evaluated nuclear data libraries. The steps for this process are described in the remaining sections of this chapter.

\subsection{COMPILATION OF GEOMETRICAL AND MATERIAL INFORMATION}

Publicly available literature was explored to find representative geometrical and material definitions of the advanced reactor technologies under investigation. The nuclides relevant for these systems were identified by considering the material compositions and the volumetric abundance of these materials in the reactor. Particular consideration was given to major differences in the fuel, moderator (if applicable), coolant, and structure materials.

\subsection{INTERROGATION OF ENDF/B NUCLEAR DATA LIBRARIES}

The nuclide reactions important for the relevant nuclides as identified in the literature search were determined by studying the nuclides' cross sections as provided in the ENDF/B libraries. In particular, the ENDF/B-VII.0, ENDF/B-VII.1, and ENDF/B-VIII.0 libraries were considered (Chadwick et al. 2006, Chadwick et al. 2011, Brown et al. 2018). The libraries' cross sections and uncertainties were compared to identify major differences that could result in a significant impact on reactor safety analysis.

The assessment of different materials used in the selected advanced reactor technologies led to identification of gaps within the evaluated nuclear data libraries. In particular, the comparison of available data (e.g., individual reactions) between various nuclides within a nuclear data library led to the identification of missing nominal data and missing uncertainty data.

\subsection{CONSIDERATION OF LWR EXPERIENCE}

Because many of the considered advanced reactor systems use ${ }^{235} \mathrm{U}$ as the primary fission power isotope, previous studies of LWR concepts were reviewed with respect to the impact of nuclear data on the quantities of interest. Fuel characteristics and operating conditions such as power density, initial enrichment, cycle length, etc., differ between LWRs and advanced reactor concepts. However, since ${ }^{235} \mathrm{U}$ is the major fissile material at the beginning of life in LWRs and in many advanced reactor concepts, some qualitative conclusions could be drawn to identify relevant fission products and actinides that build up in irradiated fuel during depletion. It must be noted that the spectral conditions differ between advanced reactor systems and traditional LWR systems and that advanced systems are expected to reach higher burnups than traditional LWRs.

\subsection{SENSITIVITY AND UNCERTAINTY ANALYSIS}

A common method for quantifying the importance of a nuclide reaction for an output quantity of interest is the calculation of sensitivity coefficients via linear perturbation theory. A sensitivity coefficient defines by how much an output quantity would change due to a change in a particular cross section. The larger the sensitivity is for a particular cross section, the greater the impact of a change of this cross section will be due to an update from one evaluated library release to the next, for example, or when considering this 
cross section's uncertainty. In fact, these sensitivity coefficients can be used to calculate the uncertainty of the investigated output due to nuclear data uncertainties. In the application of first order error propagation, the sensitivity coefficients of all relevant nuclide reactions are multiplied with the corresponding covariance matrices. In this way, the total uncertainty of an output quantity due to nuclear data uncertainties are determined, as well as contributions of individual nuclide reactions to the total uncertainty (Rearden 2010).

Another approach for determining the uncertainties in the output due to nuclear data uncertainties is the random sampling approach. This approach is especially useful for cases in which sensitivity coefficients cannot be easily determined for an output quantity of interest such as power distribution or with respect to a particular type of input nuclear data such as fission yields and decay data. In the random sampling approach, the nuclear data are randomly sampled based on their covariances to generate sets of perturbed nuclear data libraries. These perturbed nuclear data libraries are then used to perform the reactor physics calculation of interest - one calculation for each perturbed dataset. A statistical analysis of the multiple outputs provides the uncertainties in the output quantity of interest, and the analysis also identifies important nuclide reactions by means of correlation coefficients (Williams et al. 2013, Bostelmann 2020).

Publications documenting such sensitivity and uncertainty analyses were studied to identify relevant nuclear data and uncertainties for the systems of interest. 


\section{KEY NOMINAL NUCLEAR DATA}

This section summarizes key nominal nuclear data (i.e., cross section, decay data, fission yield mean values without their uncertainties) impactful for advanced reactor physics analysis that were identified based on the review of publicly available literature. The summary describes applicable conclusions from existing LWR studies, insights from various advanced reactor studies, important observations from evaluated nuclear data library comparisons, and relevant data not currently available for consideration in advanced reactor physics analysis. The section is structured according to the considered advanced reactor concept; relevant conclusions are repeated if applicable. Table 4 provides relevant nuclide reactions for each advanced reactor concept under consideration.

The latest ENDF/B-VIII.0 release shows major differences compared to the previous ENDF/B-VII.1 release for some nuclide reactions that are relevant for the investigated advanced reactor concepts. Relevant cross sections are presented throughout this section, and relative differences of relevant nuclide reactions are presented at the end of this section in Figure 20 through Figure 25.

\subsection{PEBBLE-BED HIGH-TEMPERATURE GAS-COOLED REACTOR}

For graphite-moderated systems such as pebbled-bed HTGRs, the capture cross section of carbon was significantly changed between ENDF/B-VII.0 and VII.1 (Figure 13). Due to the abundance of graphite in this reactor concept in the fuel material and the reflector, a change in a cross section of carbon is highly relevant. Depending on the size of the simulated reactor model, an impact of more than $1,000 \mathrm{pcm}$ on the multiplication factor can be observed. The ENDF/B-VII.1 calculations thereby show good agreement with measurements, while ENDF/B-VII.0 calculations show a significant overestimation (Bostelmann et al. 2016, Bostelmann et al. 2018b).

Prior to and including the ENDF/B-VII.1 release, available graphite evaluations considered graphite as a perfect crystal with respect to its thermal scattering cross sections. However, with the release of the ENDF/B-VIII.0 library, data for so-called reactor-grade graphite became available. In addition to an evaluation for graphite as a perfect crystal (i.e. $0 \%$ porosity), graphite evaluations assuming 10 and $30 \%$ porosity were made available (Hawari et al. 2014). Because of the amount of graphite in graphitemoderated systems and the importance of graphite as moderator, the availability of additional data is highly relevant to neutron moderation and therefore to reactivity. When changing the porosity of graphite in the fuel and dummy pebbles in criticality calculations of the HTR-10 benchmark (International Handbook of Reactor Physics Experiments 2007), an increase of the multiplication factor of several hundred pcm was observed at room temperature. In contrast, when changing the porosity only in the surrounding graphite reflector, the multiplication factor did not change (Bostelmann et al. 2018b). A similar study for the HTR-PM reactor came to similar conclusions (Zhang et al. 2020). For adequate consideration of the porosity, detailed information about the graphite porosity and the temperatures in the included materials is needed because (1) the impact at higher temperatures can be different than at lower temperatures, (2) the graphite porosity is a function of the neutron fluence (Campbell et al. 2016), and (3) the graphite porosity is not always known for each component of the reactor. 


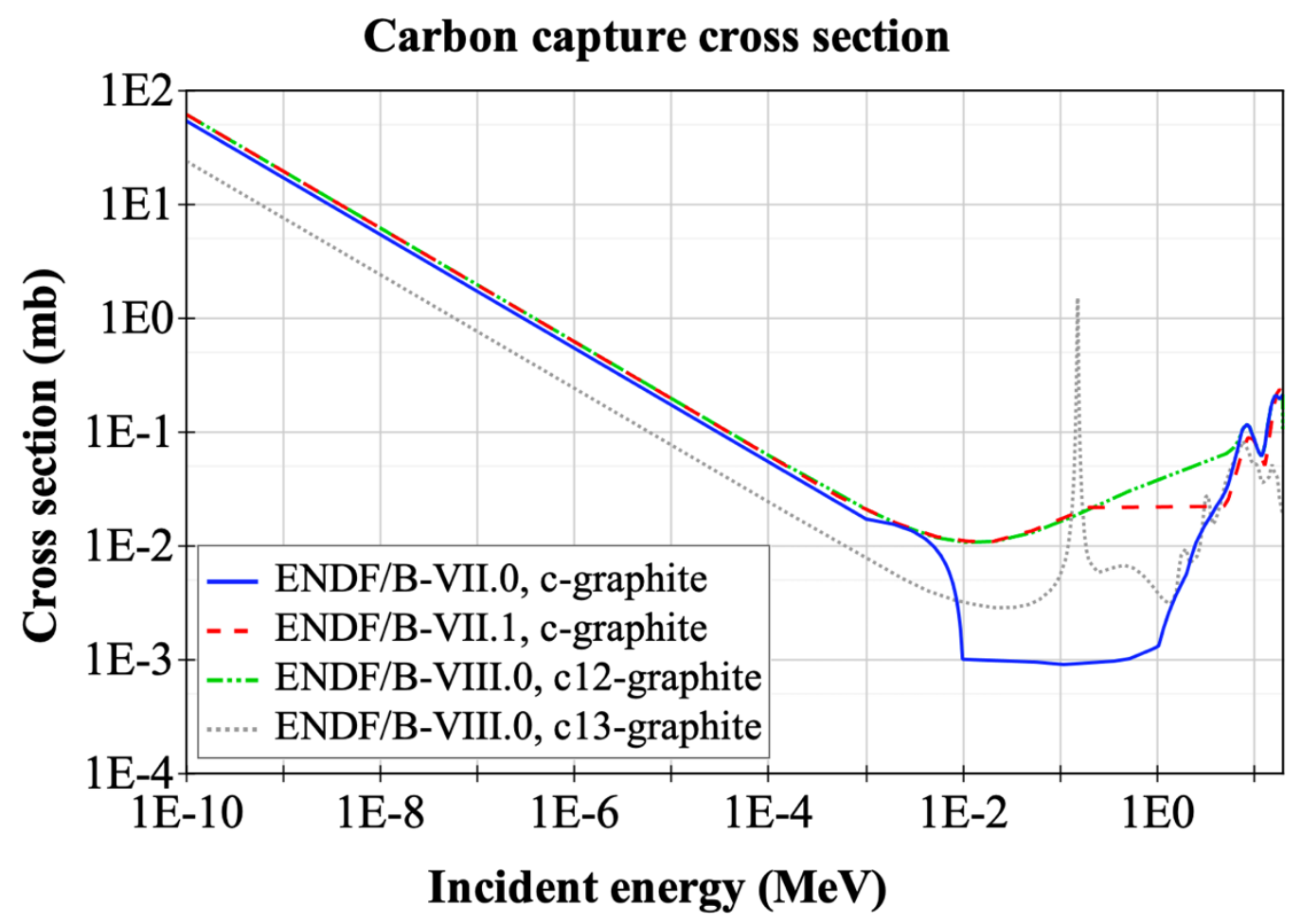

Figure 13. Comparison of carbon capture cross section in ENDF/B releases. ENDF/B-VII.0 and ENDF/B-VII.1 contain natural carbon data, while ENDF/B-VIII.0 contains isotopic data for ${ }^{12} \mathrm{C}$ and ${ }^{13} \mathrm{C}$. The natural abundances are ${ }^{12} \mathrm{C} \sim 98.9 \%$ and ${ }^{13} \mathrm{C} \sim 1.1 \%$.

For the first time in the ENDF evolution, the ENDF/B-VIII.0 library contains thermal scattering data for $\mathrm{SiC}$. These data could be significant for the analysis of systems fueled with TRISO with a SiC layer (see Figure 4). The impact of this additional data will be assessed in the next phases of this project.

For graphite-rich reactor configurations, the graphite impurities content is often provided as an equivalent boron concentration (EBC) quantifying their aggregate effect, and not as individual nuclide concentrations. Therefore, the nuclear data for boron become more relevant when simulating these systems. For example, a $2 \%$ change in EBC - which corresponds to a change of $2 \%$ in the total boron cross section in the reflector graphite-leads to a $100 \mathrm{pcm}$ change in the multiplication factor for the HTR-10 benchmark (International Handbook of Reactor Physics Experiments 2007). Accurate estimation of the EBC and the boron absorption cross section is relevant for HTGR analysis.

Additional relevant nuclide reactions that are important to the reactivity of HTGRs were identified based on a review of publications on uncertainty analysis using sensitivity coefficients. In addition to the analysis of the nuclides available in the various materials in a reactor's design, the importance of their individual reactions was captured in some of these studies. For the fuel material, the neutron multiplicity, fission, capture and scattering of uranium nuclides were found important for fresh fuel. Furthermore, the nuclear data of plutonium nuclides were deemed important for depleted fuel. In terms of the structural materials, the capture and scattering reactions in graphite and absorption in boron, as previously mentioned, were also found to be significant (Rochman et al. 2017, Bostelmann and Strydom 2017, Bostelmann et al. 2018a).

In a previous ORNL study, significant differences of a few hundred pcm in multiplication factors for advanced reactor models were noted when comparing results obtained with ENDF/B-VII.1 data to results 
obtained with ENDF/B-VIII.0 (Bostelmann et al. 2018b). Starting with an ENDF/B-VII.1 calculation and replacing the nuclear data of individual nuclides with data from ENDF/B-VIII.0 one nuclide at a time, it was found that updates in the cross sections of ${ }^{235} U$ and ${ }^{238} U$ were responsible for most observed differences in multiplication factors (Bostelmann et al. 2019). Even though these are among the most common nuclides in traditional reactor fuel and their nuclear data are therefore assumed to be very well known, significant changes in the capture, fission, and scattering cross sections were introduced in the latest ENDF/B-VIII.0 release compared to ENDF/B-VII.1.

HTGR concepts are intended to achieve burnups that are significantly higher than those in traditional LWRs. The importance of the nuclear data for higher actinides, in addition to that for uranium and plutonium, is potentially amplified. However, the available benchmarks involving neutron interaction reactions of minor actinides - particularly capture, fission, and inelastic scattering reactions - are scarce in the literature (Salvatores 2002, Bernstein et al. 2019).

\subsection{FLUORIDE SALT-COOLED HIGH-TEMPERATURE REACTOR}

FHRs are graphite-moderated systems, so the same conclusions regarding carbon/graphite as identified for the pebble-bed HTGR (Section 4.1) generally apply. In particular, the change of the carbon capture cross section from ENDF/B-VII.0 to ENDF/B-VII.1 and the use of different graphite porosities in ENDF/B-VIII.0 will have a significant impact on the reactivity.

For nuclides acting as moderators like the carbon in graphite just mentioned, improved thermal scattering data are available, including upscattering on these nuclides. However, thermal scattering data are not yet available for the various salts used in FHRs. Thermal scattering data for FLiBe - a compound combining $\mathrm{LiF}$ and $\mathrm{BeF}_{2}$ - is currently under preparation and is intended to be included with the next ENDF/B release (Zhu and Hawari 2017). In reported test calculations in which researchers processed their own FLiBe data, an impact in the range 260-800 pcm was found for the multiplication factor in a molten salt system containing FLiBe, the magnitude of the effect being dependent on the temperature (Mei et al. 2013).

The data for individual salt components are relevant and must be considered. For example, there are no data for $\mathrm{LiF}$ and $\mathrm{BeF}_{2}$ in $\mathrm{FLiBe}$; there are only data for the individual nuclides. Furthermore, it needs to be assured that the thermal scattering data are available for the entire temperature range applicable to the systems of interest. For example, in ENDF/B-VII.1 graphite scattering data are available for temperatures up to $2,000 \mathrm{~K}$. The presently available thermal scattering data were mostly developed without sufficient comparison to experimental data. 


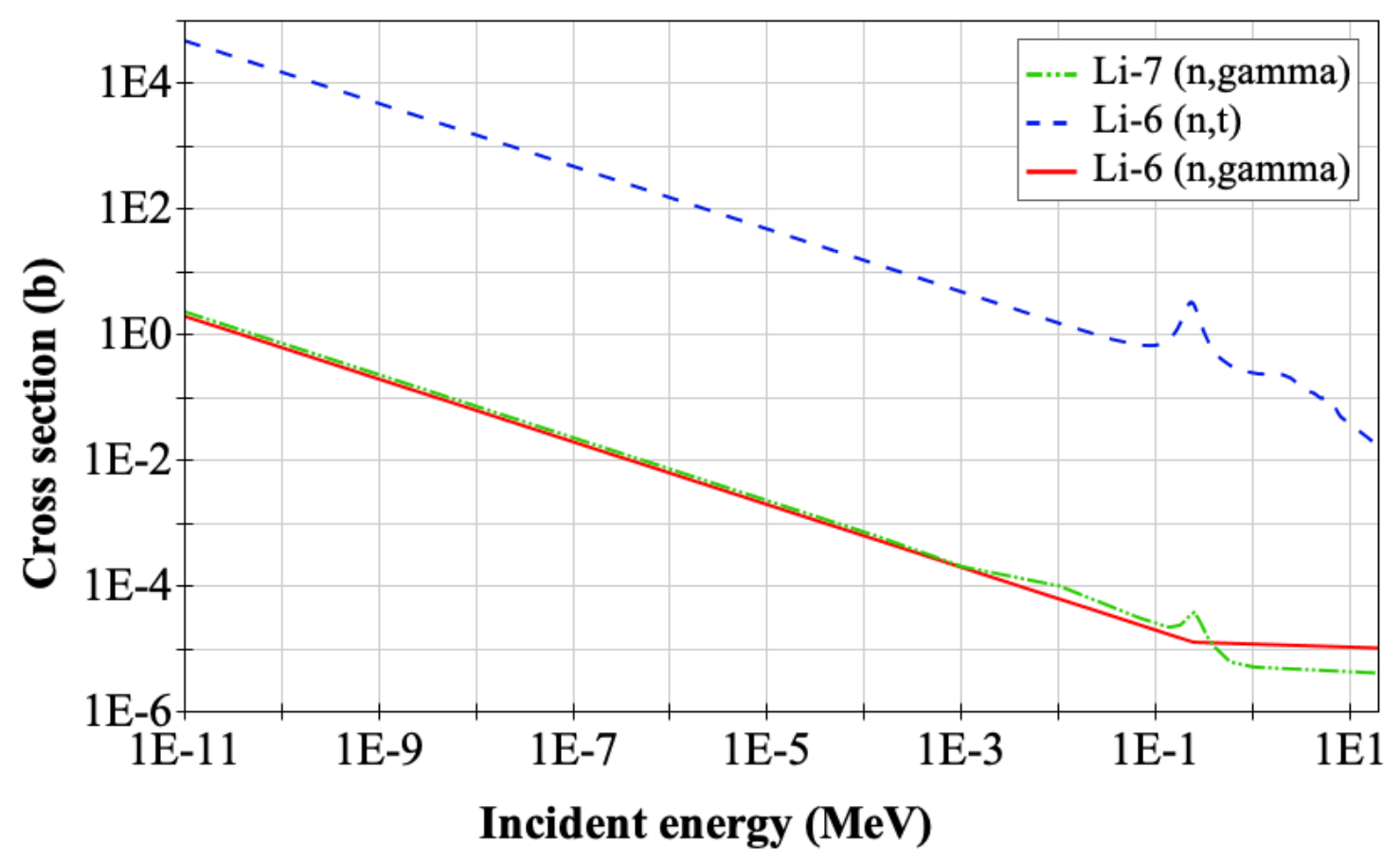

Figure 14. Relevant lithium cross sections (ENDF/B-VII.1).

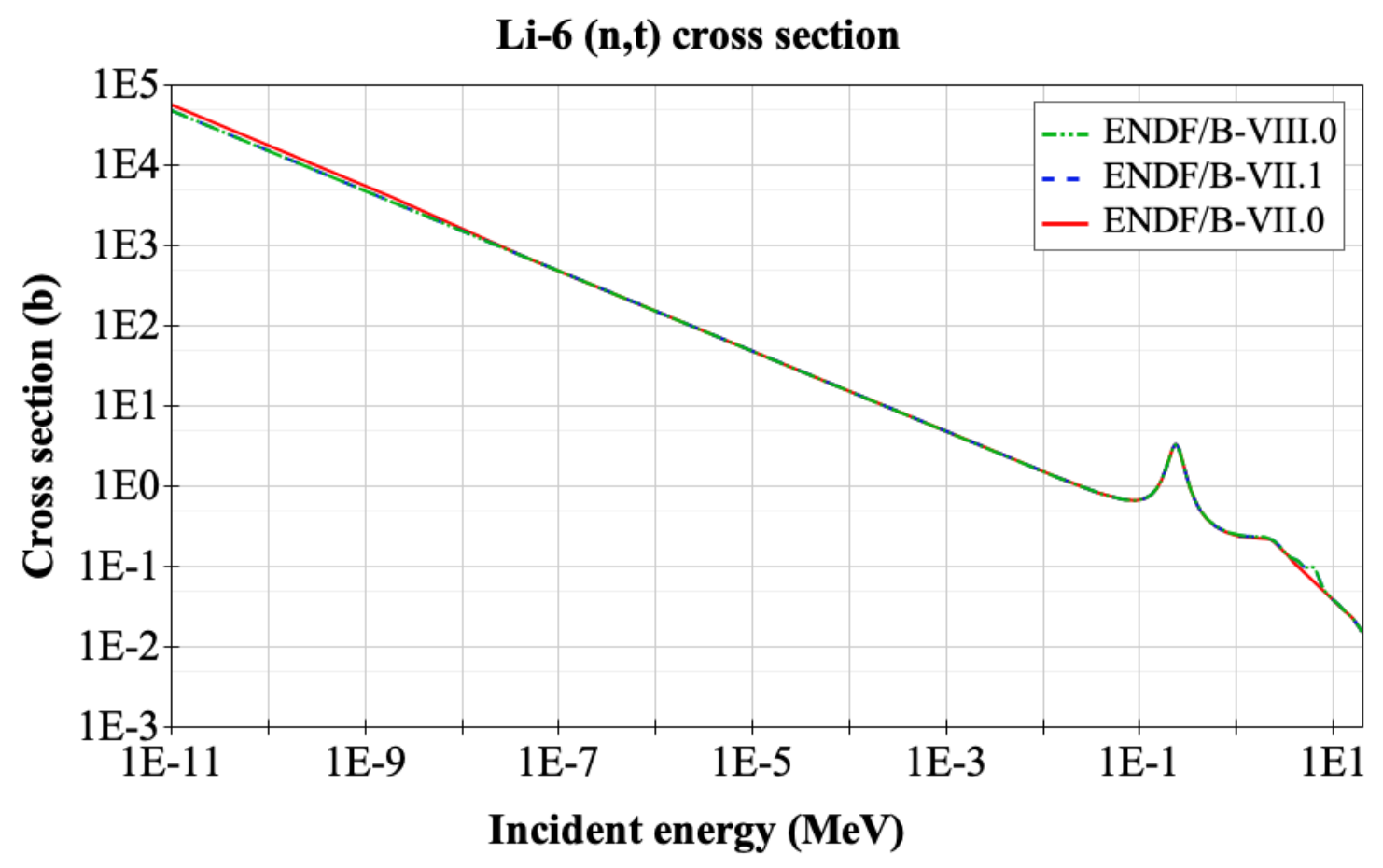

Figure 15. Comparison of ${ }^{6} \mathrm{Li}(\mathrm{n}, \mathrm{t})$ cross section in ENDF/B releases. 
Naturally occurring lithium is composed of two stable isotopes $-{ }^{6} \mathrm{Li}$ with $7.59 \%$ abundance, and ${ }^{7} \mathrm{Li}$ with 92.41\% abundance. When lithium is part of the salt mixture, particularly LiF, the concentration of the isotope ${ }^{6} \mathrm{Li}$ can have a significant impact on reactivity. ${ }^{6} \mathrm{Li}$ is a strong neutron absorber with a significant cross section for radiative neutron capture $(\mathrm{n}, \gamma)$ and in particular a very large cross section for neutron capture with subsequent decay leading to emission of tritium $(n, t)$ (Figure 14). To avoid this strong neutron absorption even for small concentrations of ${ }^{6} \mathrm{Li}$, lithium in MSRs is usually enriched to contain an abundance of ${ }^{7} \mathrm{Li}$ above $99.995 \%$ (Andreades et al. 2014). The radiative neutron capture in ${ }^{7} \mathrm{Li}$ (Figure 14) is also highly relevant due to the large amount of this nuclide in the reactor coolant (Fratoni 2019).

Inspection of the ${ }^{6} \mathrm{Li}(\mathrm{n}, \mathrm{t})$ cross section in different ENDF/B library releases reveals a visible difference in the thermal range: the ENDF/B-VII.0 data provide a cross section almost twice as large as that in ENDF/B-VII.1 in the thermal energy range below $0.01 \mathrm{eV}$ (Figure 15). No studies on the potential impact of this difference have been found in the open literature. In contrast, the ${ }^{6} \mathrm{Li}(\mathrm{n}, \mathrm{t})$ cross section is almost identical between ENDF/B-VII.1 and ENDF/B-VIII.0 with relative differences below $0.1 \%$ in the thermal energy range.

Similar to the pebble-bed HTGR, additional relevant nuclide reactions for FHRs were identified through the review of publications on uncertainty analysis using sensitivity coefficients. Fission, capture, and scattering of uranium (and plutonium nuclides in case of depleted fuel) were significant. Furthermore, various capture and scattering reactions of $\mathrm{Li}, \mathrm{F}$, and Be nuclides were deemed relevant due to the high abundance of FLiBe salt in this reactor (Rochman et al. 2017, Bostelmann and Strydom 2017, Powers et al. 2018, Bostelmann et al. 2018a).

FHRs are intended to achieve burnups significantly higher than those of traditional LWRs. As in the high burnup fuel in the previously discussed pebble-bed HTGR, the importance of the nuclear data for higher actinides is also amplified for FHRs. The available nuclear data are often insufficiently compared with benchmarks for neutron reactions of minor actinides, particularly capture, fission, and inelastic scattering reactions (Bernstein et al. 2019, Salvatores 2002).

\subsection{GRAPHITE-MODERATED MSR}

For graphite-moderated MSRs, the same conclusions with respect to carbon/graphite apply as described for the pebble-bed HTGR in Section 4.1. Notably, as shown in the update of the carbon capture cross section from ENDF/B-VII.0 to ENDF/B-VII.1, the different graphite porosities in ENDF/B-VIII.0 can have a significant impact on reactivity.

As pointed out for the FHR concept in Section 4.2, thermal scattering data for the salt are not available. The impact on the reactivity can potentially be in the hundreds of pcm (Bostelmann et al. 2018b, Zhang et al. 2020). Additionally, these systems also include a significant amount of lithium as part of the salt mixture. Thus, neutron capture in ${ }^{6} \mathrm{Li}$ and ${ }^{7} \mathrm{Li}$ is highly relevant for MSRs, as discussed for FHRs (Mei et al. 2013).

In contrast to the stationary fuel concept of an FHR, graphite-moderated MSR concepts have fuel salt circulating through the reactor during operation, including the fission products that occur during fuel depletion. There are several processes to strip fission products from the circulating salt, but not all of it is removed. Radioactive nuclides with short half-lives, which are not usually relevant in a reactor with stationary fuel, become important in systems with moving fuel. ${ }^{135 \mathrm{~m}} \mathrm{Xe}$ is one of these fission products. No data are available in the ENDF/B libraries for metastable ${ }^{135 m} \mathrm{Xe}$ that decays to ${ }^{135} \mathrm{Xe}$ with a half-life of $\sim 15$ minutes. The consideration of ${ }^{135 \mathrm{~m}} \mathrm{Xe}$ is important when calculating the steady-state xenon worth in thermal MSRs. Based on a cross section estimate in the TENDL-2015 nuclear data library, a study assumed the neutron capture cross section of ${ }^{135 \mathrm{~m}} \mathrm{Xe}$ as $\sim 4$ times greater than that for ${ }^{135} \mathrm{Xe}$ and calculated 
a MSR a xenon worth that was approximately 1.6 times higher than in the case when ${ }^{135 \mathrm{~m}} \mathrm{Xe}$ was not considered in the analysis (Eades et al. 2016).

The review of various uncertainty analysis studies using sensitivity coefficients was especially useful in identifying nuclide reactions relevant for reactivity of graphite-moderated MSRs. The relevant nuclide reactions for the fuel salt show a significant overlap with the reactions found to be relevant for FHRs (Rochman et al. 2017, Bostelmann and Strydom 2017, Power et al. 2018, Bostelmann et al. 2018a). Additionally, relevant nickel cross sections were included for cases in which Ni-based alloys are used as structural materials (Shen et al. 2006).

\subsection{MOLTEN CHLORIDE FAST SPECTRUM REACTOR}

For MSR systems in which chloride $(\mathrm{Cl})$ is part of the salt, the ${ }^{35} \mathrm{Cl}(\mathrm{n}, \mathrm{p})$ reaction is highly relevant when determining reactivity effects. New evaluations (not measurements) of this cross section resulted in a major change from ENDF/B-VII.0 to ENDF/B-VII.1 (Figure 16). Due to the large amount of chlorine in the fast MSR system, this change is highly relevant to reactivity and can cause differences in the multiplication factor of more than 1,000 pcm (Betzler et al. 2017a).

With respect to chlorine as a salt component, scattering on ${ }^{37} \mathrm{Cl}$ becomes relevant. The concentration of ${ }^{35} \mathrm{Cl}$ in the salt is usually decreased by design since neutron absorption in ${ }^{35} \mathrm{Cl}$ results in the generation of large amounts of the long-lived beta emitter ${ }^{36} \mathrm{Cl}$, which must be minimized as much as possible due to its significant contribution to the total dose (Holcomb et al. 2011).

For MSRs in which fluoride is a component of the salt, the literature mentions that a large inconsistency between JENDL-4.0 compared to ENDF/B-VII.1 and ENDF/B-VIII.0 data was found for inelastic scattering of ${ }^{19} \mathrm{~F}$. JENDL-4.0 appears to show better agreement with experimental data. In a reactivity comparison of a fast spectrum molten salt reactor between and JENDL-4.0 and ENDF/B-VII.1, a difference of almost $2,000 \mathrm{pcm}$ in reactivity was ascribed to the difference in only the inelastic scattering reaction of ${ }^{19} \mathrm{~F}$ (Van Rooijen et al. 2015, Neudecker et al. 2020).

Since molten chloride fast-spectrum reactors have fuel salt circulating through the reactor during operation, the same relevance of missing ${ }^{135 \mathrm{~m}} \mathrm{Xe}$ data for the determination of the xenon worth as noted in Section 4.3 for the graphite moderated MSR applies.

The review of uncertainty analysis studies using sensitivity coefficients for this reactor type led to the identification of the neutron multiplicity, fission cross section, and capture cross section of various uranium and plutonium isotopes as important for analysis of this reactor type. Due to the large amount of the carrier salt $\mathrm{NaCl}$ in the reactor, the scattering and capture reactions of $\mathrm{Na}$ and $\mathrm{Cl}$ nuclides were also identified as relevant for the reactivity (Bostelmann et al. 2018a). Updates of these $\mathrm{Na}$ and $\mathrm{Cl}$ cross sections as well as for uranium and plutonium cross sections between the ENDF/B-VII.1 and ENDF/BVIII.0 release can cause reactivity differences of a few hundred pcm (Bostelmann et al. 2018a,

Bostelmann et al. 2019). 


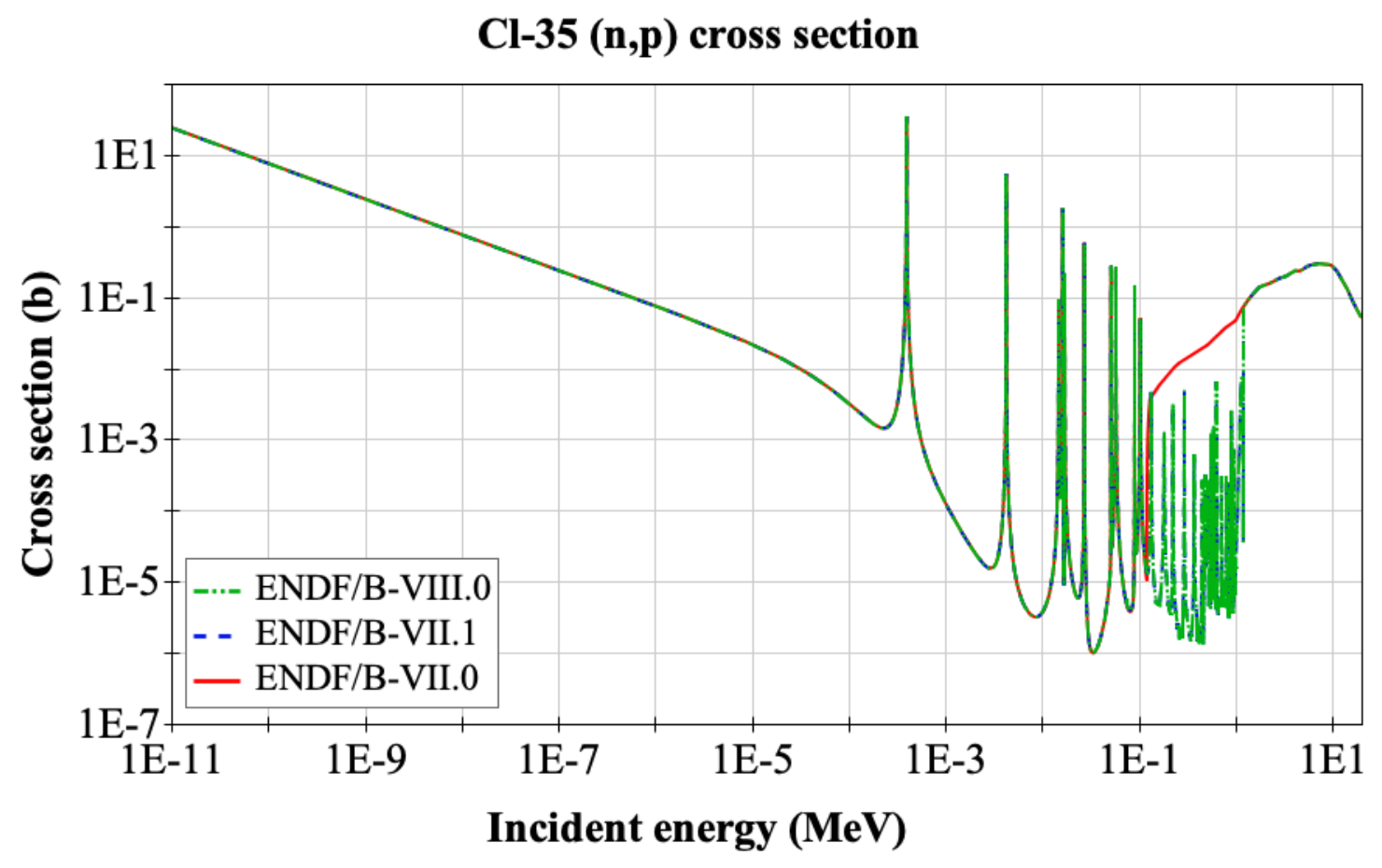

Figure 16. Comparison of ${ }^{35} \mathrm{Cl}(\mathrm{n}, \mathrm{p})$ cross section in ENDF/B releases.

\subsection{HEAT PIPE REACTOR}

Nuclide reactions of importance for the reactivity were identified for heat pipe reactions based on uncertainty analysis publications coefficients for similar reactors with fast neutron spectra. For the fuel material, the neutron multiplicity, fission, capture and scattering of uranium and plutonium nuclides was found important for both fresh and depleted fuel. As mentioned for the previously discussed HTGR and FHR thermal reactor concepts, and as further discussed for fast systems in Section 4.6, there are major differences for various uranium and plutonium cross sections between ENDF/B-VII.1 and ENDF/BVIII.0 that could cause changes in calculated reactivities (see Figure 22 through Figure 25), including for the heat pipe reactor concept. Regarding metal fuel, the large amount of zirconium present in the fuel increases the importance of scattering and capture reactions of several zirconium isotopes.

With respect to the coolant, the elastic and inelastic scattering reactions of $\mathrm{Na}$ and $\mathrm{K}$ were found relevant for this system. Nuclides present in the structural $(\mathrm{Fe})$ or reflector $\left(\mathrm{Al}_{2} \mathrm{O}_{3}, \mathrm{BeO}\right)$ materials are also important. The scattering and capture reactions of $\mathrm{Fe}, \mathrm{Be}, \mathrm{Al}$ and $\mathrm{O}$, and the thermal scattering data for $\mathrm{BeO}$ were identified as relevant for this type of fast system (OECD/NEA 2016, Bostelmann et al. 2018a). Although neutron capture in $\mathrm{Be}$ was found to have a small impact on reactivity, it is noted that there are major differences between its cross section in ENDF/B-VII.0, ENDF/B-VII.1 and ENDF/B-VIII.0. The difference for energies below $100 \mathrm{eV}$ in which the cross section is the greatest is approximately $14 \%$ (Figure 17). Relevant changes from ENDF/B-VII.1 to ENDF/B-VIII.0 are observed in the ${ }^{16} \mathrm{O}$ elastic scattering cross section, showing a difference of approximately $2 \%$ in the energy range up to $10^{5} \mathrm{eV}$, and larger differences in the resonances within the fast energy range (Figure 18). 


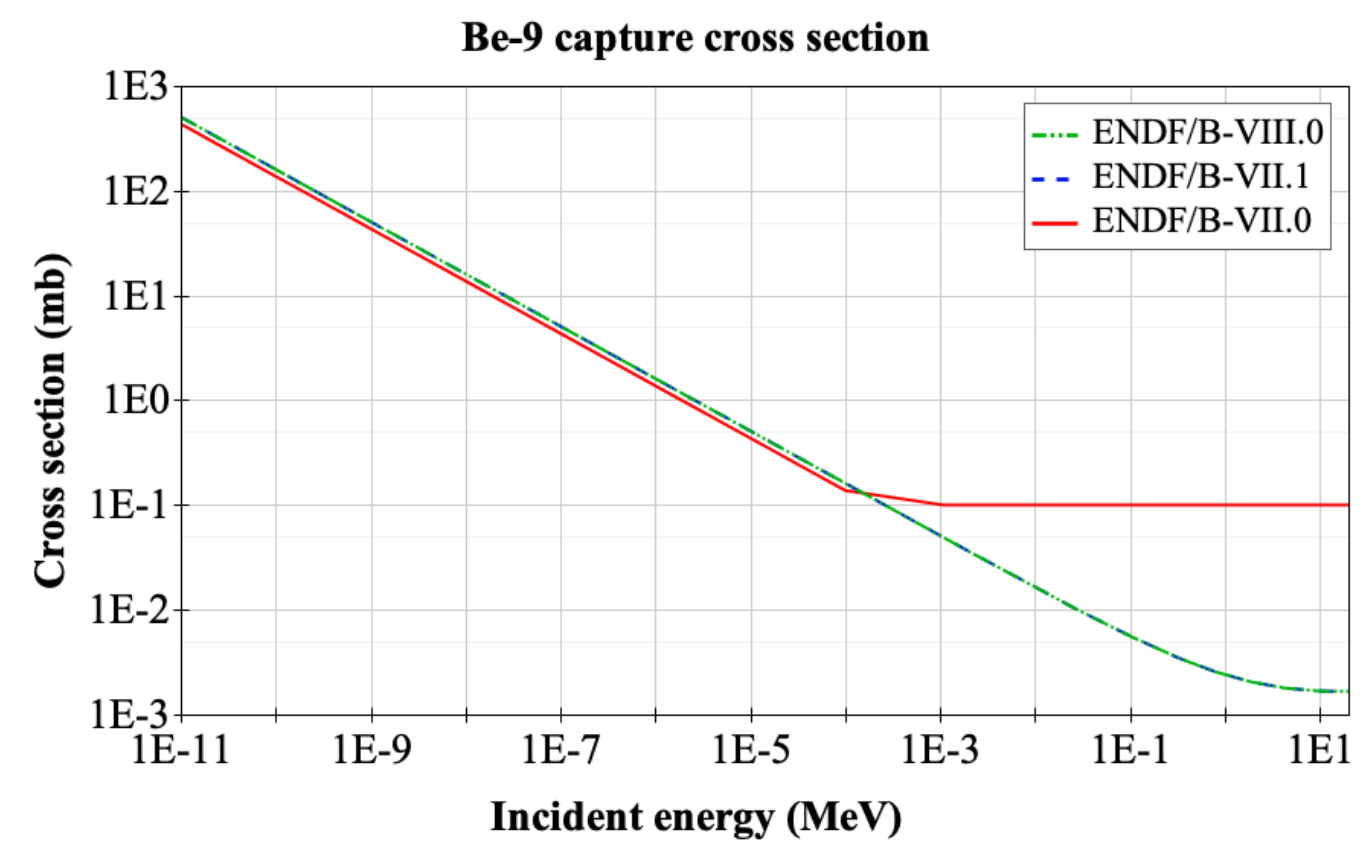

Figure 17. Comparison of ${ }^{9} \mathrm{Be}$ radiative neutron capture in ENDF/B releases.

O-16 elastic scattering cross section
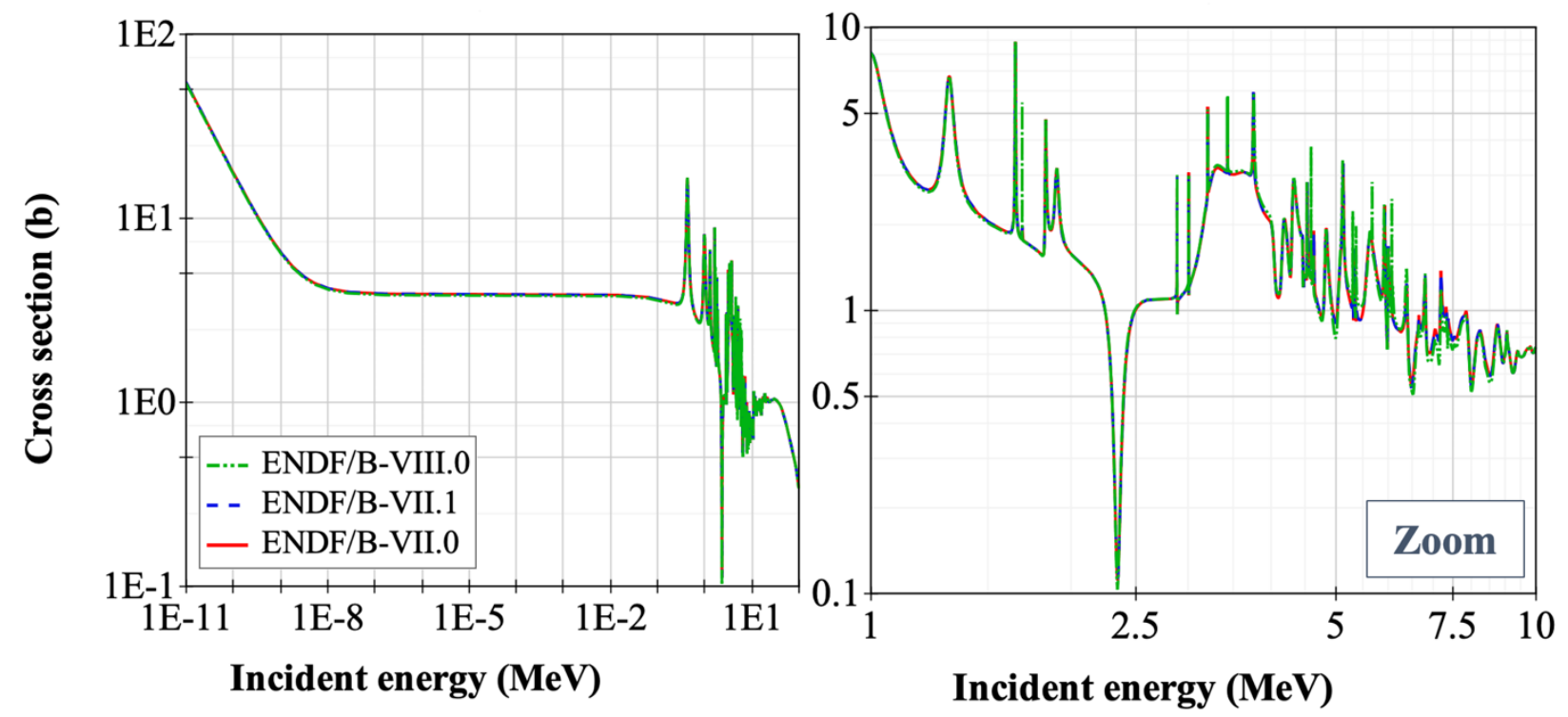

Figure 18. Comparison of ${ }^{16} \mathrm{O}$ elastic scattering cross section in ENDF/B releases. See Figure 20 for the relative difference between the cross sections of the ENDF/B-VII.1 and ENDF/B-VIII.0 library.

For the analysis of fast spectrum systems with a high relevance of scattering reactions and neutron leakage, it is especially important to know the angular distributions of neutron scattering data. Differences of more than $100 \mathrm{pcm}$ were found in highly enriched uranium and plutonium fast spectrum systems (Hill 
2017). Notably, the $(\mathrm{n}, 2 \mathrm{n})$ reaction has a greater importance in fast systems than in LWR systems (Figure 19; Yang 2012).

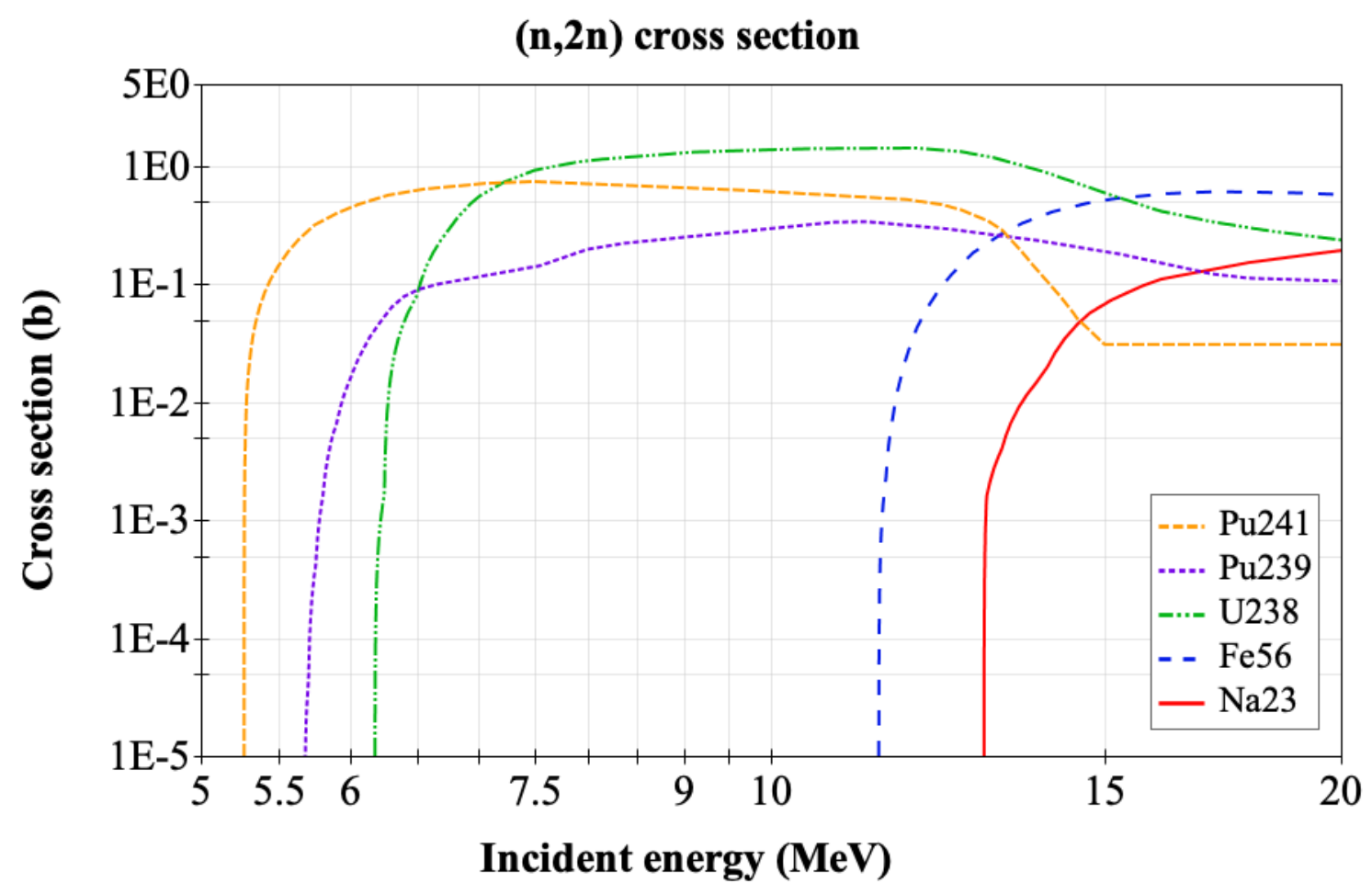

Figure 19. Relevant n,2n cross sections (ENDF/B-VII.1).

\subsection{SODIUM-COOLED FAST REACTOR}

SFRs show similar important nuclide reactions for reactor physics analysis as discussed regarding the fast spectrum heat pipe reactor. However, the initial fuel composition is different for SFRs. It consists of a mixture of $\mathrm{U}, \mathrm{Pu}$, and minor actinides, leading to an increased relevance of cross section data for minor actinides at the beginning of cycle.

The review of uncertainty analysis studies using sensitivity coefficients for SFRs revealed a large significance of scattering reactions of the coolant $(\mathrm{Na})$ and structural materials $\left({ }^{56} \mathrm{Fe}\right.$, in particular) (OECD/NEA 2016, Bostelmann et al. 2018a, Bostelmann 2020). Furthermore, for fast spectrum systems, the $(n, 2 n)$ reaction has a greater importance than in LWR systems (Yang 2012). In case of oxide fuel, elastic scattering of ${ }^{16} \mathrm{O}$ is relevant because of its resonances in the fast energy range (Bostelmann et al. 2018a, Bostelmann 2020).

As applicable to the other discussed reactor concepts, the updates between the ENDF/B-VII.1 and ENDF/B-VIII.0 releases of relevant cross sections of ${ }^{16} \mathrm{O},{ }^{56} \mathrm{Fe},{ }^{238} \mathrm{U}$, and ${ }^{239} \mathrm{Pu}$, for example, cause differences in reactivity results. Reactivity differences of up to $200 \mathrm{pcm}$ were observed in previous studies due to updates in ${ }^{238} \mathrm{U}$ data (Bostelmann et al. 2018a, Bostelmann et al. 2019).

\subsection{TIME-DEPENDENT ANALYSIS}

As in the analysis of the time-dependent behavior of LWRs, the time-dependent behavior of conceptual advanced reactors requires more than just cross section data. Fission product yield data, decay constants, 
and branching fractions are also important factors in the buildup of fission products and higher actinides (Rochman et al. 2017, Martines et al. 2014, Leray et al. 2017).

The fission product yields provided with ENDF/B-VII.0 and ENDF/B-VII.1 show only minor differences for ${ }^{239} \mathrm{Pu}$, and the fission product yields provided with ENDF/B-VIII.0 are identical to the ones provided with ENDF/B-VII.1. However, it was found that calculated fission product concentrations using the branching fraction and independent yield data from the ENDF/B-VII.1 were inconsistent with cumulative yield measurements (Pigni et al. 2015). This was traced to ENDF/B evaluators using an earlier version of the decay data to determine independent yields from measured cumulative yields. For SCALE 6.2, the independent yields of ${ }^{235} \mathrm{U},{ }^{238} \mathrm{Uand}{ }^{239} \mathrm{Pu},{ }^{241} \mathrm{Pu}$ were adjusted to improve the internal consistency with the decay data, leading to improved agreement with cumulative fission yields measurements.

The ENDF/B nuclear data libraries provide fission product yields for up to four incident neutron energies (Table 2) and suggest using linear interpolation between these points. Since the average energy of neutrons causing fission for major fissionable nuclides is in the range of $10^{4}$ and $10^{5} \mathrm{eV}$ (Table 3), the interpolated yields for both fast and thermal systems are primarily based on the $10^{5} \mathrm{eV}$ data point. It is unknown if the interpolation of these few data points is sufficient or if additional data points would cause significant differences in depletion calculations. As shown in Table 2, the yield of important fission products can easily vary by $10 \%$ with incident fission neutron energy. For thermal systems, the use of these fission yields in depletion calculations generally leads to good agreement of fission product concentrations with measurements. However, for fast spectrum systems, the average energy of fission is higher and therefore the fission yields for the highest energy point play an increased role. To provide increased confidence using this data for fast spectrum reactors, additional destructive assay data are desired.

Table 2. ENDF/B-VII.1 independent fission yields.

\begin{tabular}{|l|c|c|c|c|c|c|c|c|}
\hline Energy [eV] & \multicolumn{2}{|c|}{ U-235 } & \multicolumn{2}{c|}{ U-238 } & \multicolumn{2}{c|}{ Pu-239 } & \multicolumn{2}{c|}{ Pu-241 } \\
\hline & Sr-96 & Te-135 & Sr-96 & Te-135 & Sr-96 & Te-135 & Sr-96 & Te-135 \\
\hline $2.53 \mathrm{E}-02$ & $3.57 \mathrm{E}-02$ & $3.22 \mathrm{E}-02$ & & & $1.82 \mathrm{E}-02$ & $2.19 \mathrm{E}-02$ & $2.45 \mathrm{E}-02$ & $3.73 \mathrm{E}-02$ \\
\hline $5.00 \mathrm{E}+05$ & $4.38 \mathrm{E}-02$ & $2.47 \mathrm{E}-02$ & $4.13 \mathrm{E}-02$ & $4.62 \mathrm{E}-02$ & $1.95 \mathrm{E}-02$ & $2.05 \mathrm{E}-02$ & $2.73 \mathrm{E}-02$ & $3.75 \mathrm{E}-02$ \\
\hline $2.00 \mathrm{E}+06$ & & & & & $1.77 \mathrm{E}-02$ & $1.68 \mathrm{E}-02$ & & \\
\hline $1.40 \mathrm{E}+07$ & $1.81 \mathrm{E}-02$ & $1.04 \mathrm{E}-02$ & $3.20 \mathrm{E}-02$ & $2.66 \mathrm{E}-02$ & $1.27 \mathrm{E}-02$ & $8.11 \mathrm{E}-03$ & & \\
\hline
\end{tabular}

Table 3. Average energy of neutrons causing fission for a representative thermal (LWR) and fast (SFR) system*.

\begin{tabular}{|l|c|c|}
\hline \multirow{2}{*}{ Nuclide } & \multicolumn{2}{|c|}{ Energy [eV] } \\
\cline { 2 - 3 } & $\begin{array}{c}\text { thermal } \\
\text { (LWR) }\end{array}$ & $\begin{array}{c}\text { fast } \\
\text { (SFR) }\end{array}$ \\
\hline${ }^{235} \mathrm{U}$ & $1.9 \mathrm{E}+04$ & $3.4 \mathrm{E}+05$ \\
\hline${ }^{238} \mathrm{U}$ & $3.2 \mathrm{E}+06$ & $2.9 \mathrm{E}+06$ \\
\hline${ }^{239} \mathrm{Pu}$ & $1.3 \mathrm{E}+04$ & $4.5 \mathrm{E}+05$ \\
\hline${ }^{241} \mathrm{Pu}$ & $9.8 \mathrm{E}+03$ & $3.3 \mathrm{E}+05$ \\
\hline
\end{tabular}

\footnotetext{
${ }^{*}$ Values estimated for simple unit cells via SCALE/COUPLE.
} 
In transient analysis, the effective delayed neutron fraction is important (Kodeli 2013), as are the fission spectra of individual actinides, with their dependence on the energy of the neutron causing fission. Furthermore, the decay constants are also of high importance (Aliberti et al. 2017). In all advanced reactor analysis, power normalization requires adequate knowledge of the recoverable fission and capture energy. 
Table 4. Overview of key nominal nuclear data for the selected advanced reactor concepts

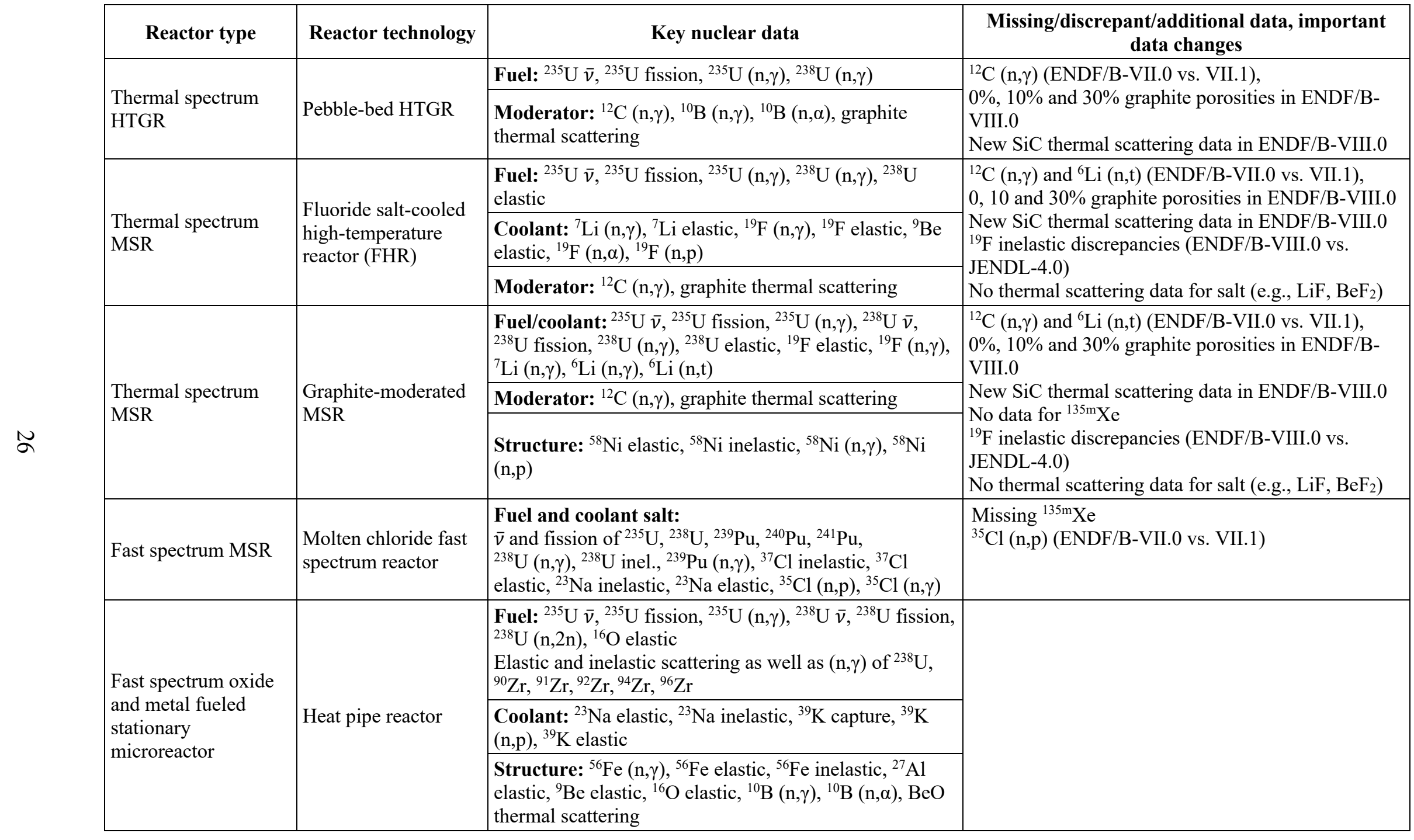


Table 4. Overview of key nominal nuclear data for the selected advanced reactor concepts (continued).

\begin{tabular}{|c|c|c|c|}
\hline Reactor type & Reactor technology & Key nuclear data & $\begin{array}{c}\text { Missing/discrepant/additional data, important } \\
\text { data changes }\end{array}$ \\
\hline \multirow{3}{*}{$\begin{array}{l}\text { Fast-spectrum metal } \\
\text { and oxide fueled SFR }\end{array}$} & \multirow{3}{*}{ SFR } & $\begin{array}{l}\text { Fuel: } \bar{v} \text { and fission of }{ }^{238} \mathrm{U},{ }^{238} \mathrm{Pu},{ }^{239} \mathrm{Pu},{ }^{240} \mathrm{Pu},{ }^{241} \mathrm{Pu}, \\
{ }^{242} \mathrm{Pu},{ }^{241} \mathrm{Am},{ }^{242 \mathrm{~m}} \mathrm{Am},{ }^{243} \mathrm{Am},{ }^{245} \mathrm{Cm} ; \\
{ }^{238} \mathrm{U}(\mathrm{n}, \gamma),{ }^{238} \mathrm{U} \text { inelastic, }{ }^{239} \mathrm{Pu}(\mathrm{n}, \gamma),{ }^{241} \mathrm{Am}(\mathrm{n}, \gamma),{ }^{243} \mathrm{Am} \\
(\mathrm{n}, \gamma),{ }^{16} \mathrm{O} \text { elastic }\end{array}$ & \\
\hline & & Coolant: ${ }^{23} \mathrm{Na}$ elastic, ${ }^{23} \mathrm{Na}$ inelastic & \\
\hline & & $\begin{array}{l}\text { Structure: }{ }^{52} \mathrm{Cr} \text { elastic } \\
\text { Elastic and inelastic scattering as well as }(\mathrm{n}, \gamma) \text { of }{ }^{56} \mathrm{Fe} \text {, } \\
{ }^{52} \mathrm{Cr},{ }^{90} \mathrm{Zr},{ }^{91} \mathrm{Zr},{ }^{92} \mathrm{Zr},{ }^{94} \mathrm{Zr},{ }^{96} \mathrm{Zr}\end{array}$ & \\
\hline All concepts & & $\begin{array}{l}\text { Fission yields, decay constants, branching ratios, energy } \\
\text { release per fission, fission spectra, fission products (e.g., } \\
\text { Xe, Sm, Gd), fission and capture of actinides that build } \\
\text { up during depletion }\end{array}$ & \\
\hline
\end{tabular}




\section{6}

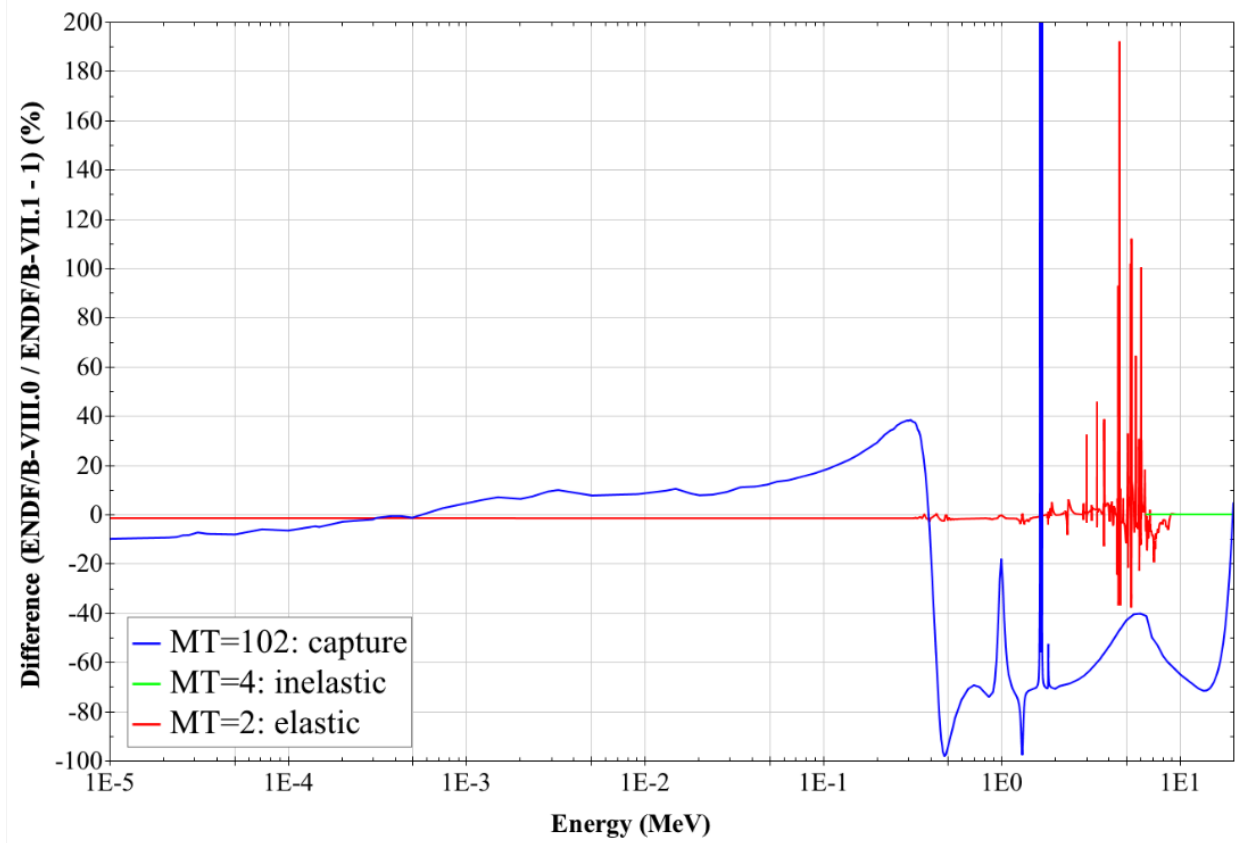

Figure 20. Relative differences between ENDF/B-VII.1 and ENDF/B-VIII.0 for ${ }^{16} \mathrm{O}$ cross sections.

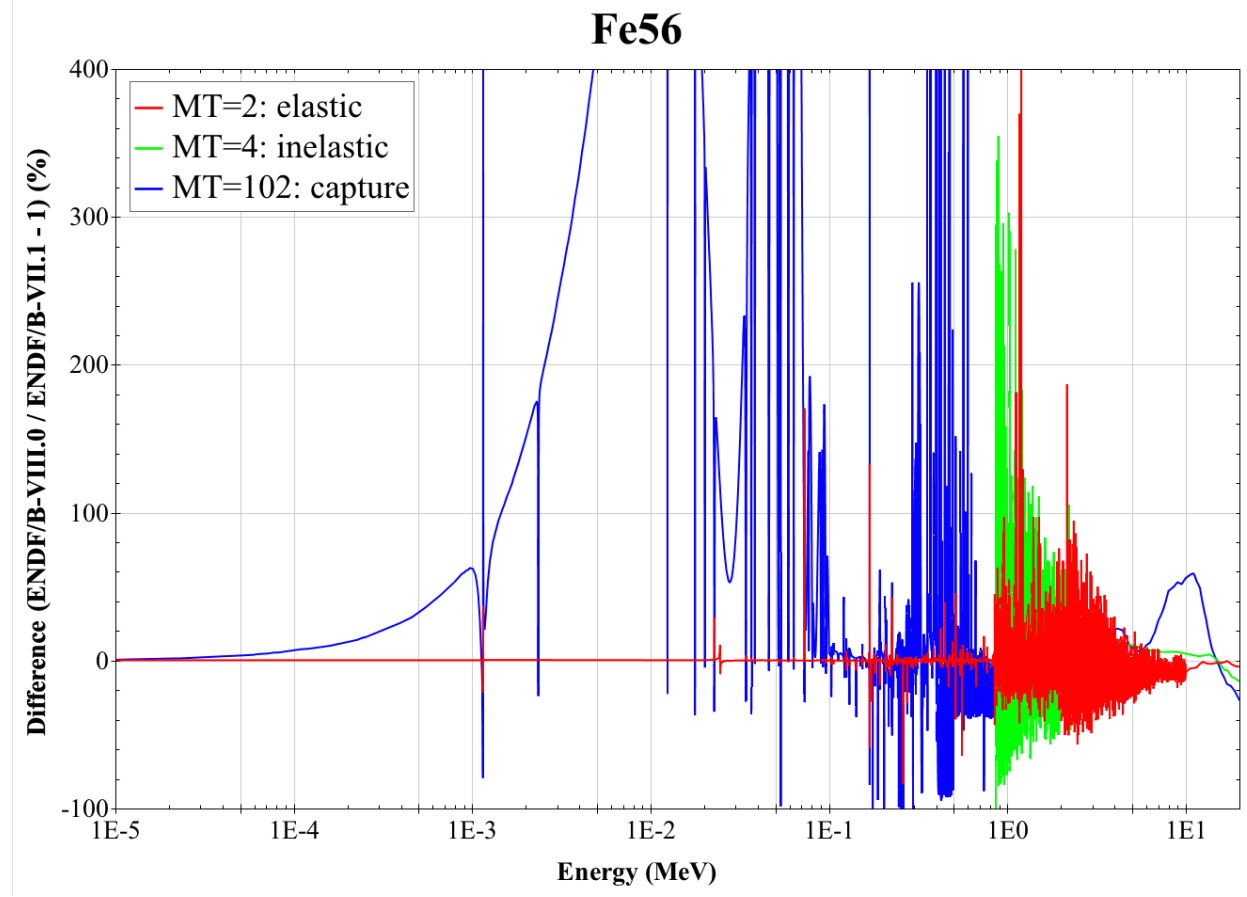

Figure 21. Relative differences between ENDF/B-VII.1 and ENDF/B-VIII.0 for ${ }^{56} \mathrm{Fe}$ cross sections. 


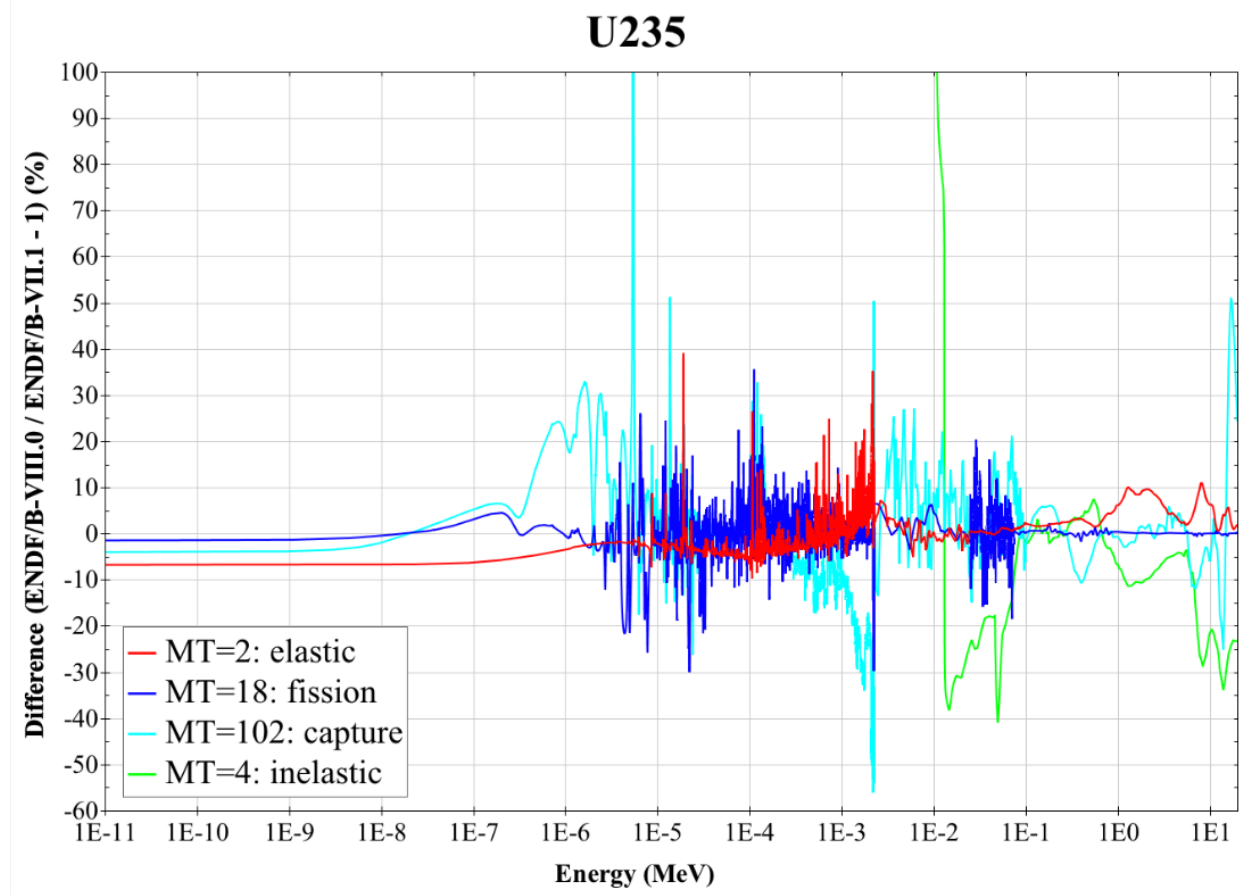

Figure 22. Relative differences between ENDF/B-VII.1 and ENDF/B-VIII.0 for ${ }^{235} \mathrm{U}$ cross sections.

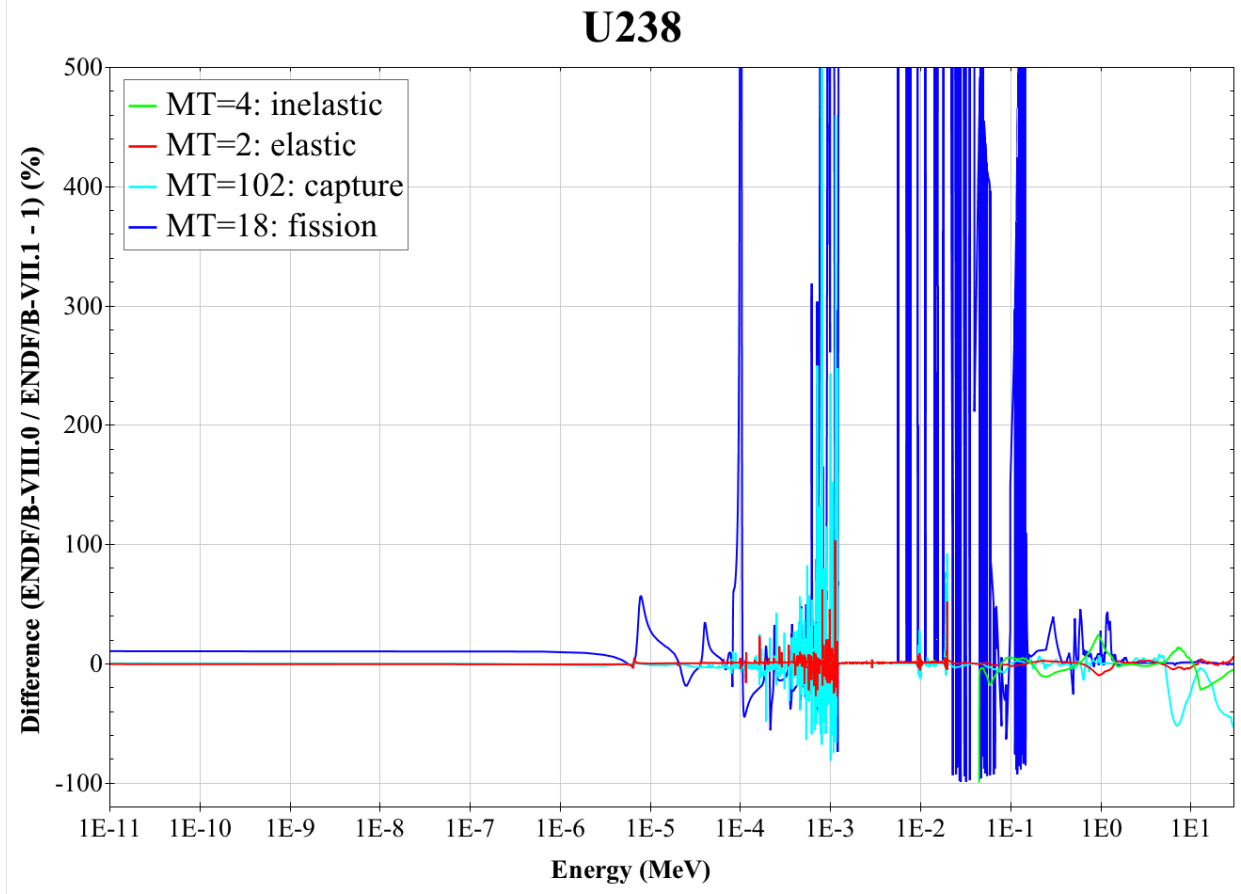

Figure 23. Relative differences between ENDF/B-VII.1 and ENDF/B-VIII.0 for ${ }^{238} \mathrm{U}$ cross sections. 


\section{Pu239}

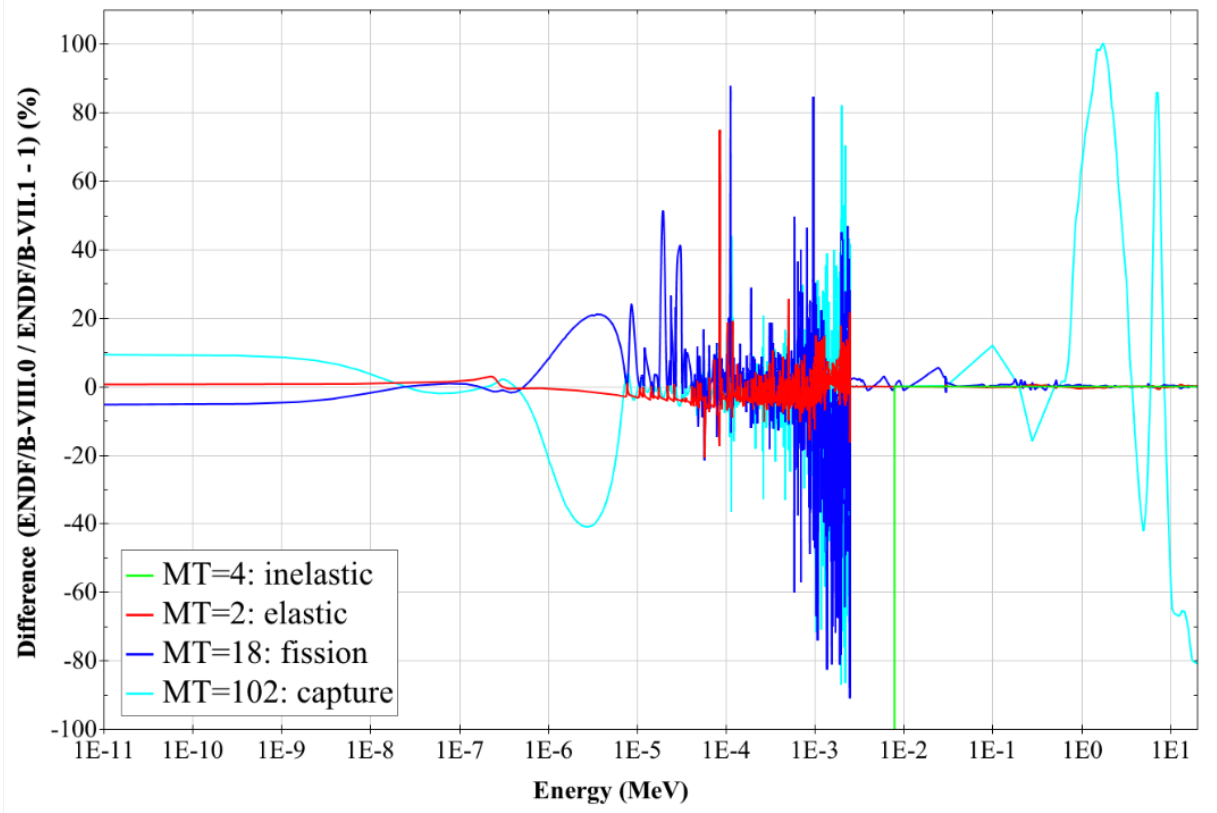

Figure 24. Relative differences between ENDF/B-VII.1 and ENDF/B-VIII.0 for ${ }^{239} \mathrm{Pu}$ cross sections.

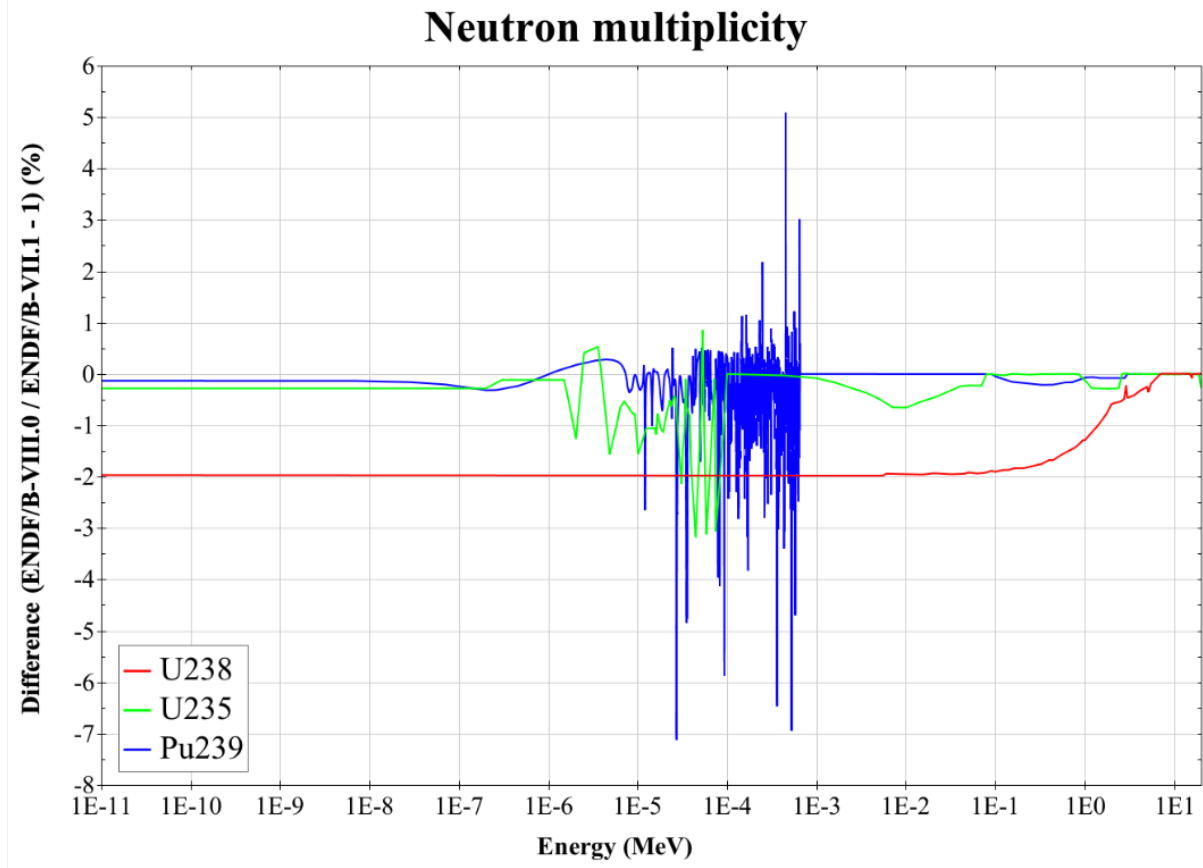

Figure 25. Relative differences of the ${ }^{235} \mathrm{U},{ }^{238} \mathrm{U}$, and ${ }^{239} \mathrm{Pu}$ neutron multiplicities between ENDF/B-VIII.0 and ENDF/B-VII.1. 


\section{KEY NUCLEAR DATA UNCERTAINTIES}

This section summarizes key nuclear data uncertainties that affect advanced reactor physics analysis. These uncertainties were identified based on the review of publicly available literature. The summary describes applicable conclusions from existing LWR analysis, insights from various available advanced reactor publications, important observations from evaluated nuclear data library comparisons, and relevant data that are currently not available for use in advanced reactor physics analysis. The section is structured according to the selected advanced reactor concepts included in Table 1; relevant conclusions are repeated as applicable. Table 5 provides relevant uncertainties for each advanced reactor concept under consideration.

Uncertainties of selected relevant cross sections are presented below. The plots shown here were generated using data from SCALE covariance libraries, which have been provided with SCALE 6.1, 6.2, and 6.3 beta. These libraries are mainly based on ENDF/B-VII.0, ENDF/B-VII.1, and ENDF/B-VIII.0 evaluated data, respectively, with some ORNL additions or modifications (Rearden and Jessee 2016). Added or modified data are labeled with the SCALE release instead of the ENDF/B release. SCALE 6.1 covariance data are presented in a 44-group structure, while SCALE 6.2 and 6.3 data are presented in a 56-group structure. Nominal data are presented with corresponding 2-sigma uncertainty bands. Additional relevant nuclear data uncertainties that apply to more than one of the considered reactor concepts are presented at the end of this section.

\subsection{PEBBLE-BED HIGH-TEMPERATURE GAS-COOLED REACTOR}

Studies on the impact of nuclear data uncertainties on HTGRs have mainly been published with respect to reactivity impacts. Reported eigenvalue uncertainties for a fresh core of the Very High Temperature Reactor Critical experiment are between 0.5 and $0.7 \%$; eigenvalue uncertainties for a core with depleted fuel are slightly larger due to the impact of higher actinides uncertainties, such as in plutonium cross sections (Bostelmann and Strydom 2017, Bostelmann et al. 2018a). The top contributing nuclide reactions to these uncertainties are the neutron multiplicity of ${ }^{235} \mathrm{U}$ for the fresh fuel core and the neutron multiplicity of ${ }^{239} \mathrm{Pu}$ for a depleted fuel core (Figure 26 and Figure 27). Other relevant contributors are fission and neutron capture in uranium and plutonium isotopes, as well as capture and scattering in graphite (Figure 28 and Figure 29).

Currently there are no published studies on the impact of uncertainties in ENDF/B-VIII.0 for the reactivity of HTGR. However, differences between the nuclear data uncertainties given in ENDF/B-VII.0 and ENDF/B-VII.1 have been shown to cause relevant differences in calculated output uncertainties. In particular, it has been shown that updates in the released uncertainties for fission cross sections and neutron multiplicities can cause significant changes in eigenvalue uncertainties. For example, for a small HTGR experiment, the eigenvalue uncertainty increased from $0.58 \%$ with SCALE 6.1 covariance data (mainly based on ENDF/B-VII.0) to $0.67 \%$ with SCALE 6.2 covariance data (mainly based on ENDF/BVII.1) (Bostelmann and Strydom 2017). Furthermore, a significant increase of the ${ }^{10} \mathrm{~B}(\mathrm{n}, \alpha)$ cross section uncertainty in ENDF/B-VIII.0 was observed (Figure 30) that could potentially increase the impact on the reactivity uncertainty of the equivalent boron content in the graphite reflector.

Consideration of uncertainties in graphite thermal scattering data would potentially have an impact on the output uncertainties in pebble-bed HTGRs. While such data are currently not available for use in uncertainty analysis, a very rough estimate of the impact for a $100 \%$ uncertainty can be assessed by determining the difference between calculations that exclude or include thermal scattering data. A maximum impact of a several hundred pcm on the reactivity is expected since this is the determined 
impact of the consideration of graphite thermal scattering data in reflector graphite in two studied HTGR systems (Bostelmann et al. 2018b, Zhang et al. 2020, Section 4.1).
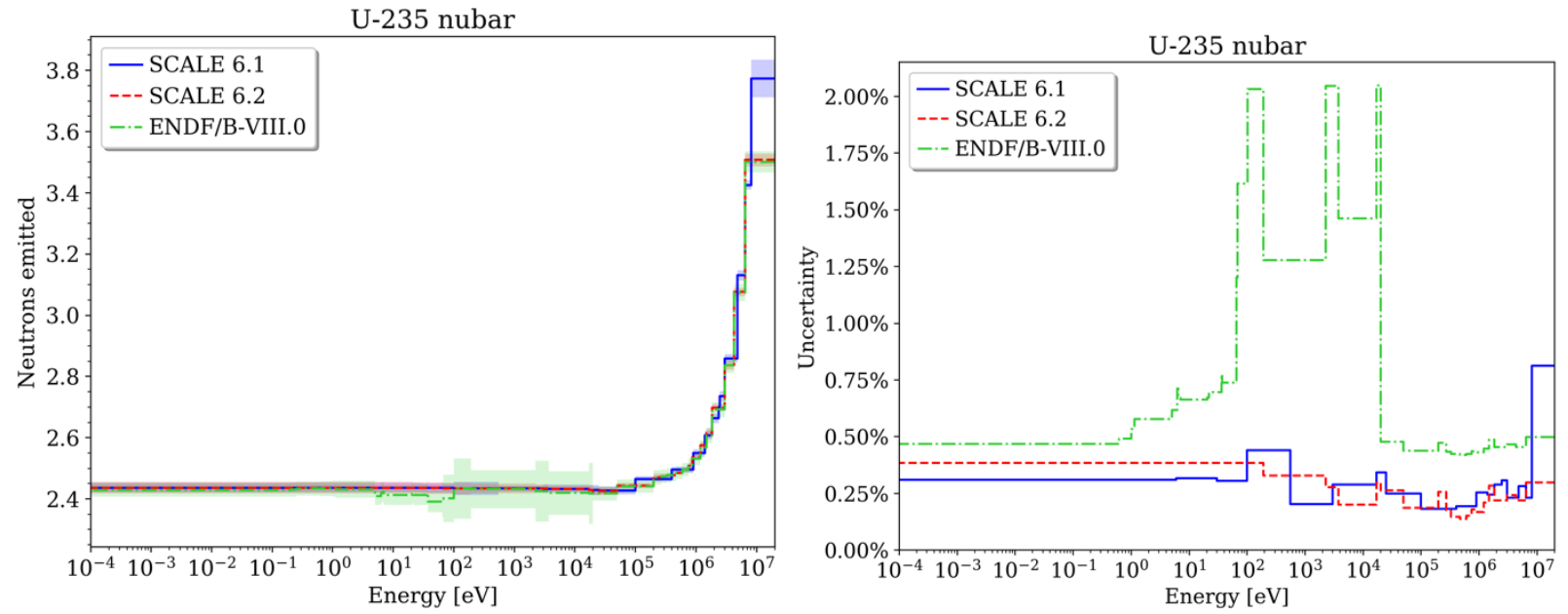

Figure 26. ${ }^{235} \mathrm{U}$ nubar nominal data and uncertainty.
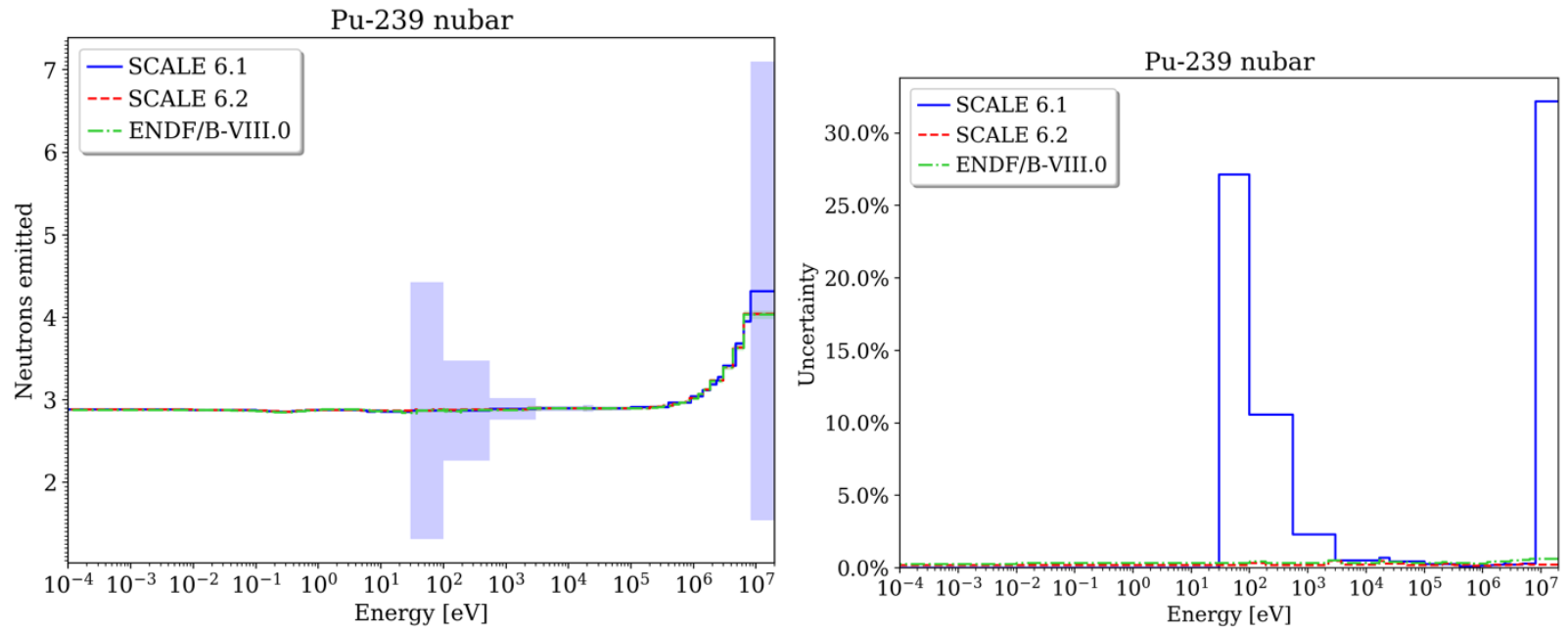

Figure 27. ${ }^{239} \mathrm{Pu}$ nubar nominal data and uncertainty. 

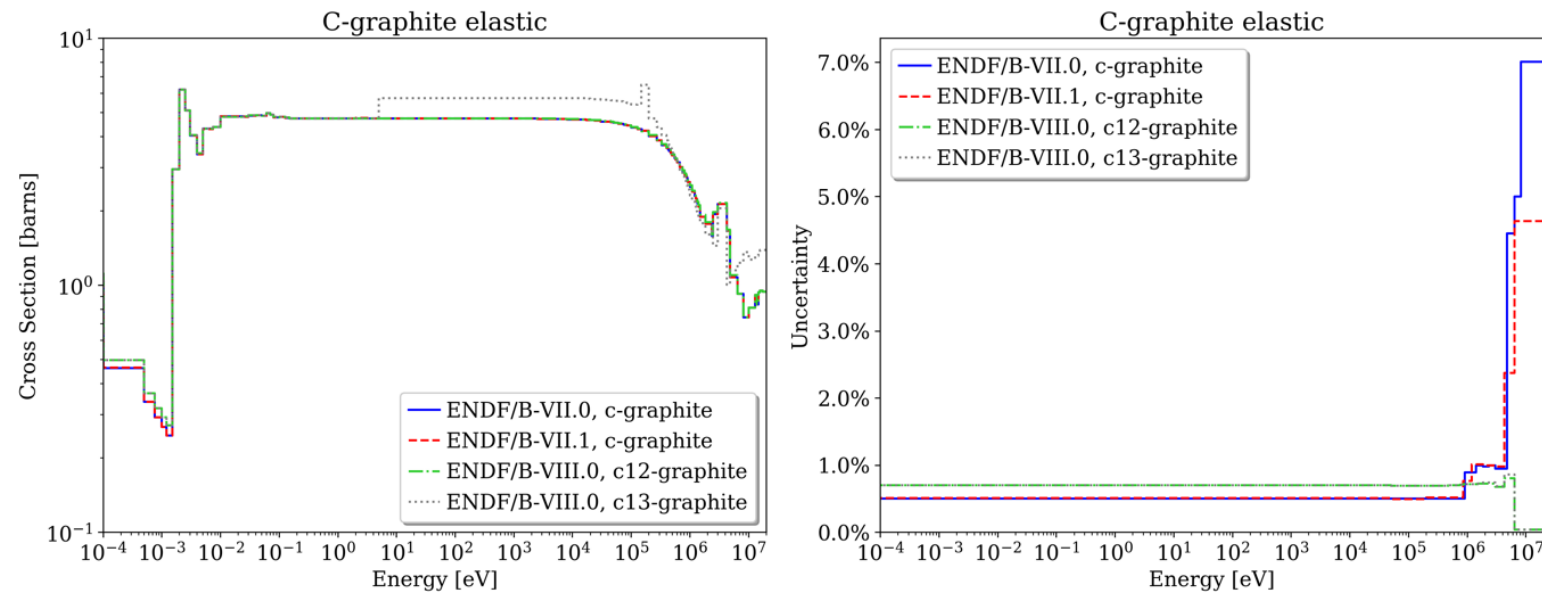

Figure 28. Graphite ${ }^{\dagger}$ elastic scattering cross section and uncertainty.
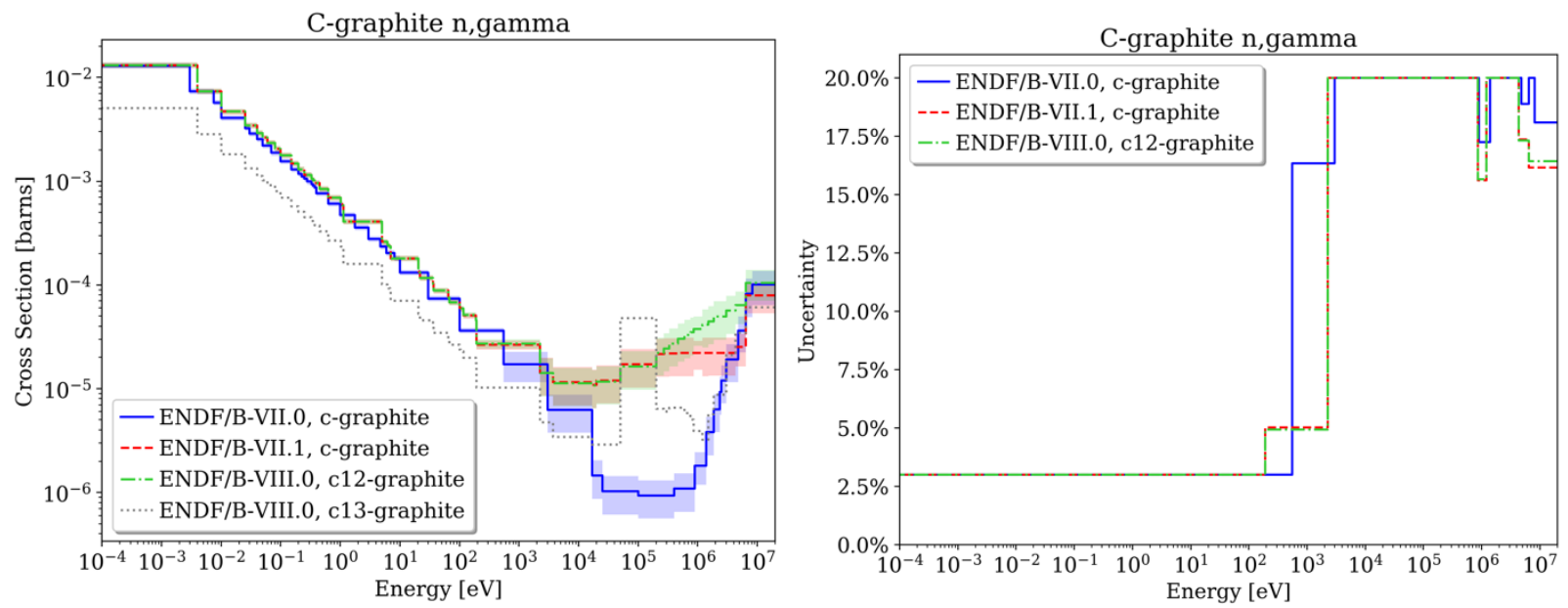

Figure 29. Graphite* $(n, \gamma)$ cross section and uncertainty.
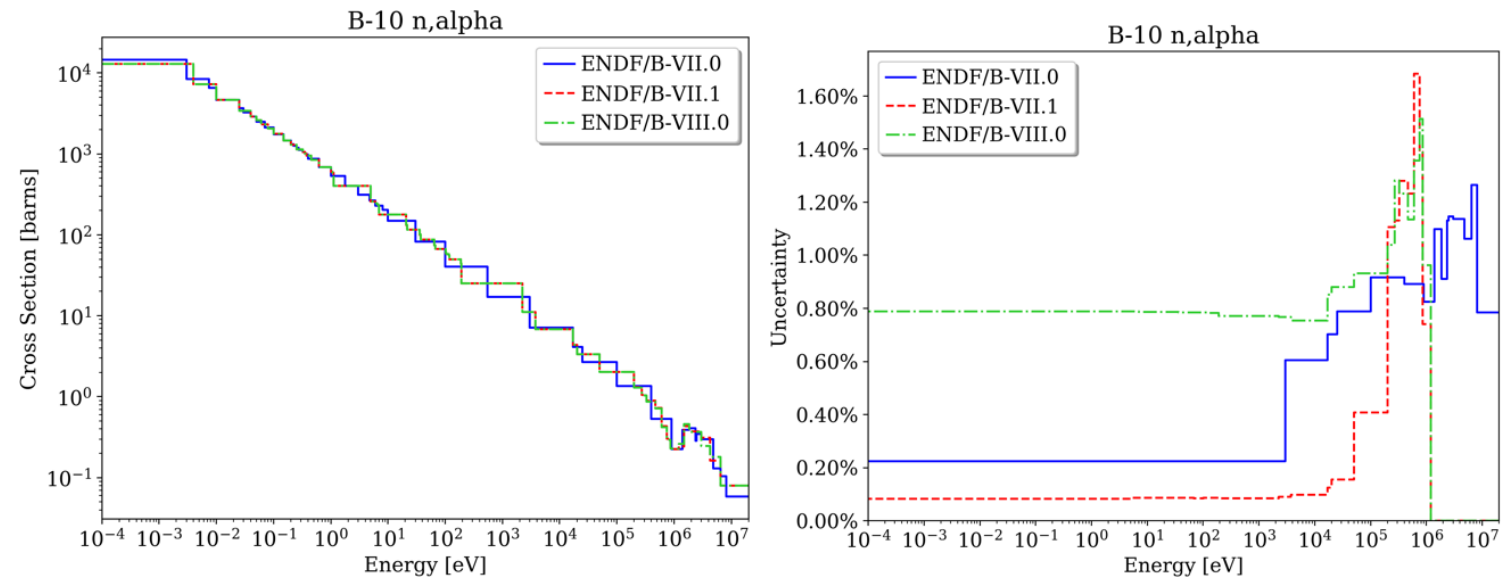

Figure 30. ${ }^{10} \mathrm{~B}(\mathrm{n}, \boldsymbol{\alpha})$ cross section and uncertainty.

${ }^{\dagger}$ ENDF/B-VII.0 and ENDF/B-VII.1 contain natural carbon data, while ENDF/B-VIII.0 contains isotopic data for ${ }^{12} \mathrm{C}$ and ${ }^{13} \mathrm{C}$. The natural abundances are ${ }^{12} \mathrm{C} \sim 98.9 \%$ and ${ }^{13} \mathrm{C} \sim 1.1 \%$. ENDF/B-VIII.0 does not contain uncertainties for ${ }^{13} \mathrm{C}(\mathrm{n}, \gamma)$. 


\subsection{FLUORIDE SALT-COOLED HIGH-TEMPERATURE REACTOR}

Graphite-moderated systems containing enriched ${ }^{235} \mathrm{U}$ fuel such as FHRs show similar reactivity uncertainties as described for the pebble-bed HTGRs. The multiplication factor uncertainty was shown to be $\sim 0.6 \%$, with the top contributor to this uncertainty the neutron multiplicity of ${ }^{235} \mathrm{U}$, in case of an FHR fresh fuel core (Powers et al. 2018). In addition to neutron capture reactions of ${ }^{235} \mathrm{U}$ and ${ }^{238} \mathrm{U}$, due to the large amount of $\mathrm{FLiBe}$ in the reactor, other relevant reactions are neutron capture and scattering for ${ }^{7} \mathrm{Li}$ and scattering for ${ }^{19} \mathrm{~F}$ as shown in Figure 32 and Figure 33 (Powers et al. 2018, Fratoni 2019). Neutron capture of ${ }^{7} \mathrm{Li}$ is especially relevant due to the large uncertainty of this reaction (Figure 31).

The consideration of uncertainties for graphite thermal scattering data and FLiBe thermal scattering data would potentially have an impact on the output uncertainties for FHRs. As previously mentioned in Section 5.1, only an estimate for an assumed $100 \%$ uncertainty in this data can be made now, because no uncertainty is available for these thermal scattering data in the evaluated released libraries. A maximum impact of several hundred pcm on reactivity is expected since an impact of the consideration of FLiBe thermal scattering data in the range of $260-800 \mathrm{pcm}$ was found for the multiplication factor in a molten salt system (Mei et al. 2013, Section 4.2).
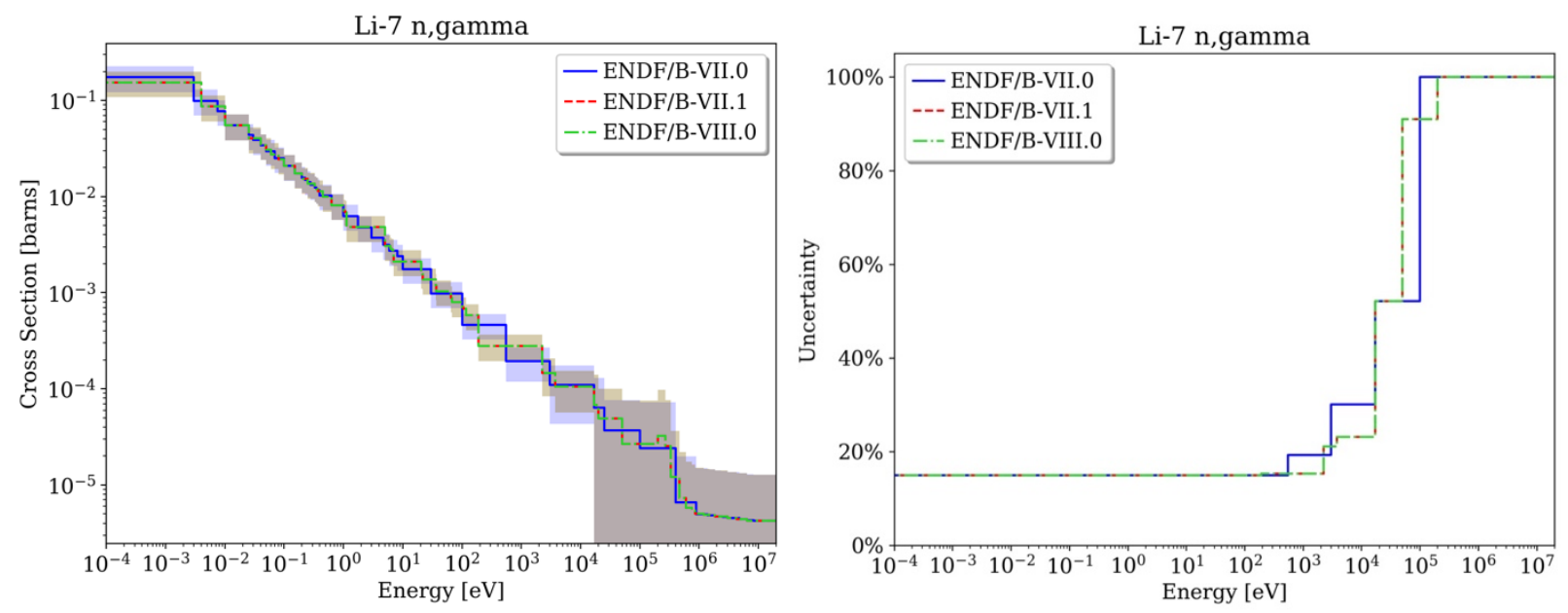

Figure $31 .{ }^{7} \mathbf{L i}(\mathrm{n}, \gamma)$ cross section and uncertainty.
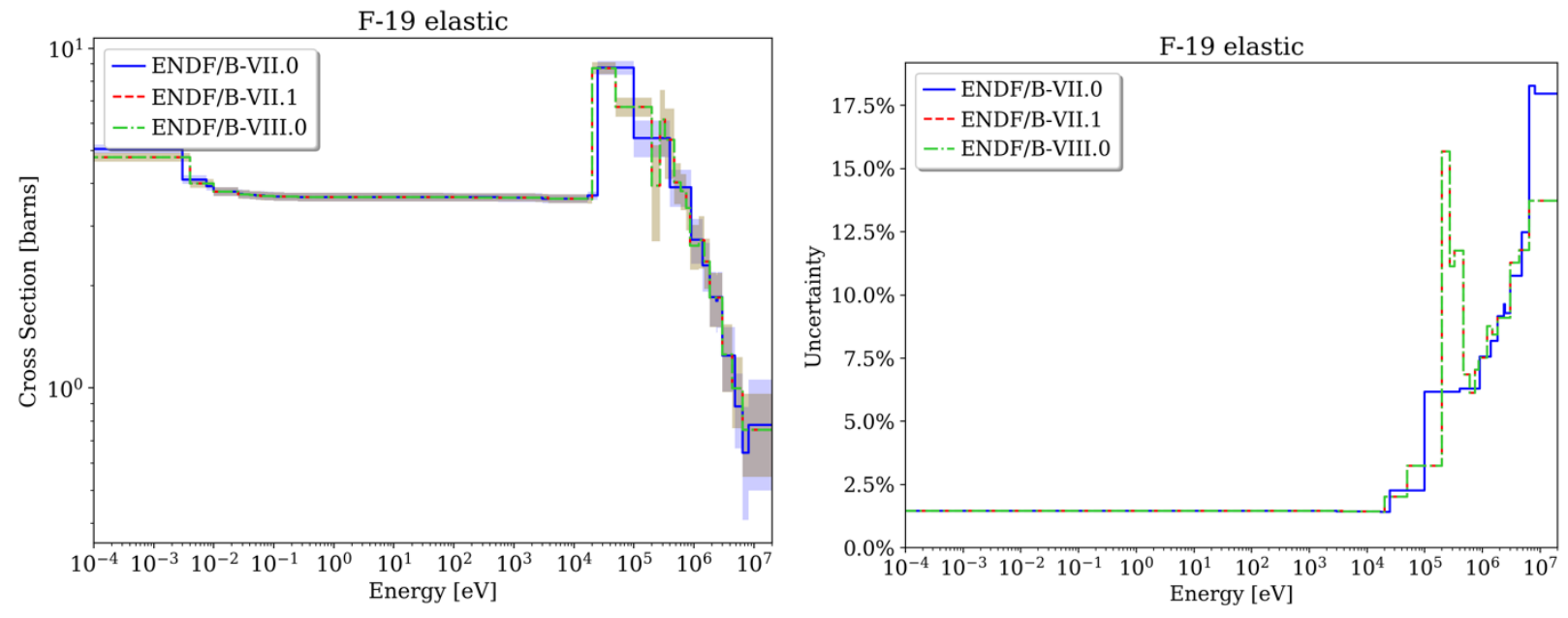

Figure 32. ${ }^{19} \mathrm{~F}$ elastic scattering cross section and uncertainty. 

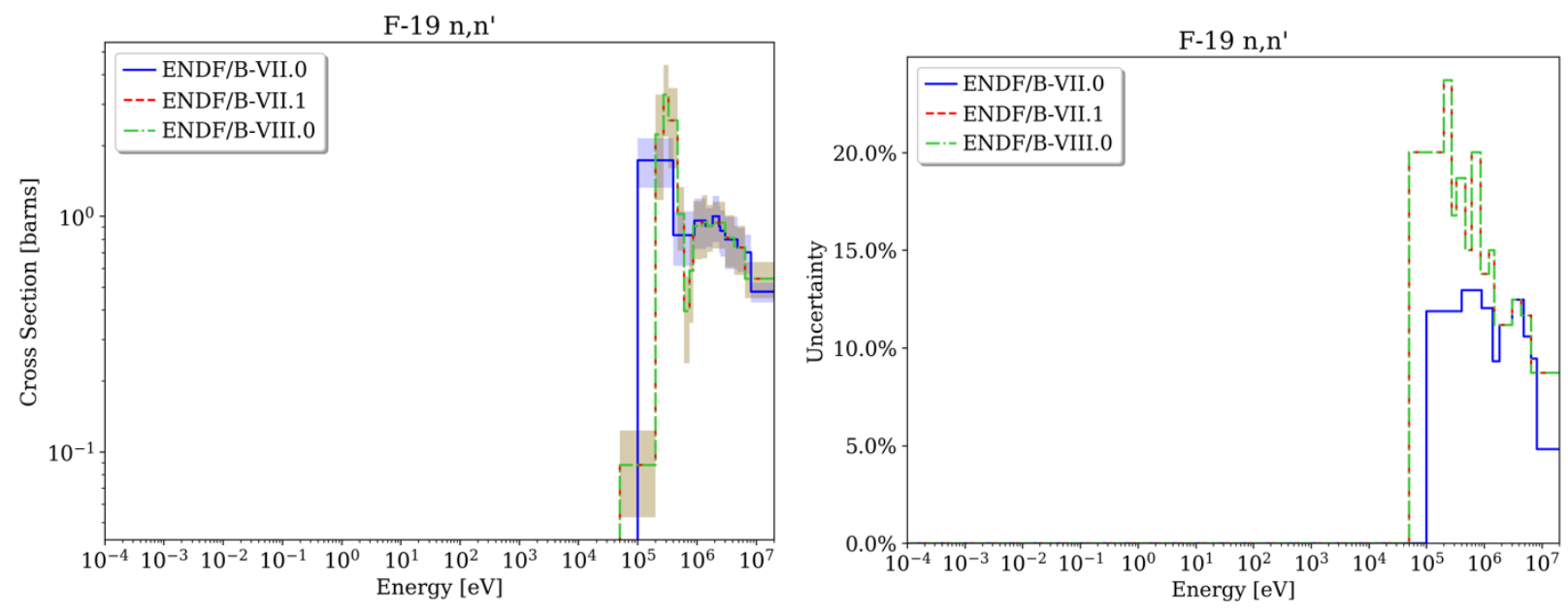

Figure 33. ${ }^{19} \mathrm{~F}$ inelastic scattering cross section and uncertainty.

\subsection{GRAPHITE-MODERATED MSR}

Relevant nuclear data uncertainties for graphite-moderated MSRs are very similar to those identified for FHRs (Section 5.2). The neutron multiplicity, fission, and capture cross section of ${ }^{235} \mathrm{U}$, neutron capture of ${ }^{238} \mathrm{U}$, and neutron capture and scattering of ${ }^{7} \mathrm{Li},{ }^{19} \mathrm{~F}$, and graphite play the most important role for reactivity uncertainty analysis (Powers et al. 2018, Bostelmann et al. 2018a, Fratoni 2019). As noted for the FHRs, the large uncertainty of neutron capture of ${ }^{7} \mathrm{Li}$ is also especially relevant (Figure 31 ) for graphite-moderated MSRs.

Uncertainties of graphite and FLiBe thermal scattering data would potentially have a significant impact on the output uncertainties for graphite-moderated MSRs. Since these uncertainty data are missing in the released libraries, a specific quantification of the impact cannot be performed. However, an impact on the order of few hundred pcm can be inferred since an impact of the consideration of FLiBe thermal scattering data in the range $260-800 \mathrm{pcm}$ was found for the multiplication factor in a molten salt system as described in Section 4.2 (Mei et al. 2013).

\subsection{MOLTEN CHLORIDE FAST SPECTRUM REACTOR}

The uncertainties of quantities of interest in fast spectrum MSR analyses that are due to nuclear data uncertainties can be significantly larger than those in thermal systems. Most previous studies and evaluations for nuclear data have focused on traditional thermal systems, while fewer have focused on fast spectrum systems. Therefore, many cross sections show a large uncertainty in the fast energy range for all ENDF/B releases. The eigenvalue uncertainty for fast spectrum systems can be up to 2-3 times larger than for LWRs. For example, the reactivity uncertainty in a fast system is in the $1-2 \%$ range when using ENDF/B-VII.1 data (Bostelmann et al. 2018a). The major contributor to the uncertainty in many reactivity coefficients is the ${ }^{238} \mathrm{U}$ inelastic scattering cross section, which has a large uncertainty in the fast energy range. Other relevant contributors to reactivity uncertainties are the fission cross section, the capture cross section and fission spectrum of ${ }^{239} \mathrm{Pu}$, the capture cross section of ${ }^{238} \mathrm{U}$, and the scattering cross sections of ${ }^{23} \mathrm{Na}$.

The uncertainty of ${ }^{238} \mathrm{U}$ inelastic scattering was decreased in the ENDF/B-VIII.0 release compared to the ENDF/B-VII.1 release (Figure 34). Since this inelastic reaction is a dominant contributor to output uncertainties in ENDF/B-VII.1 calculations, its change in uncertainty has a major impact on fast reactor uncertainty analyses that use ENDF/B-VIII.0 data. The uncertainties of other relevant reactions, such as 
${ }^{239} \mathrm{Pu}$ fission and ${ }^{238} \mathrm{U}$ neutron capture, were also significantly changed in ENDF/B-VIII.0, therefore causing differences in output uncertainties and their top contributing nuclides.

The non-consideration of angular scattering distributions was shown to have an impact of several hundred pcm on the multiplication factor for high enriched uranium and plutonium fast spectrum systems (Hill 2017).
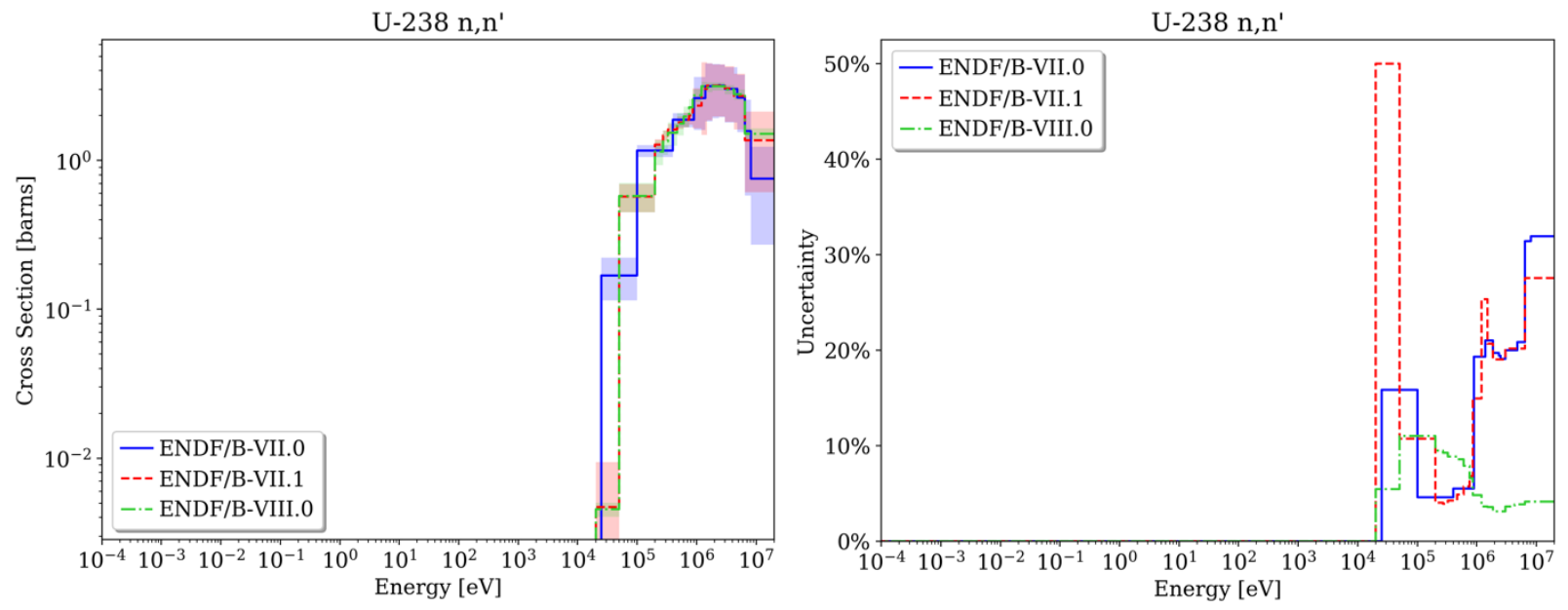

Figure 34. ${ }^{238} \mathrm{U}$ inelastic scattering cross section and uncertainty.

\subsection{HEAT PIPE REACTOR}

Given the large uncertainties in relevant cross sections within the fast energy range, uncertainty for fast neutron spectrum systems such as heat pipe reactors are expected to be significant. The ${ }^{235} \mathrm{U}$ cross section data are well known in the thermal energy range due to the extensive experience of measurements and evaluations that target traditional LWRs. However, in the fast energy range, the neutron capture cross section of ${ }^{235} \mathrm{U}$ shows a large uncertainty of over $30 \%$ in the ENDF/B-VII.0 and ENDF/B-VII.1 releases (Figure 35). Due to its importance for reactivity, this large uncertainty is expected to cause a large reactivity uncertainty. A significant reduction in reactivity uncertainty is expected when using ENDF/BVIII.0 data because of a significantly reduced uncertainty for this reaction in the recent library release. Other relevant expected contributors to reactivity uncertainty are various scattering reactions for selected nuclides in fuel and in structural and coolant materials as applicable for uncertainty analyses of other SFR systems that have been previously studied (Bostelmann 2020).

The impact of missing thermal scattering uncertainties for $\mathrm{BeO}$ is expected to be small, as this is a fast spectrum system. Only a limited set of uncertainties for angular scattering data is available. Since the neglect of angular scattering distributions was shown to have an impact of several hundred pcm on the multiplication factor of high enriched uranium and the plutonium fast spectrum system (Hill 2017, CSWEG 2019), the impact of missing angular scattering uncertainties is expected to be in the same range as that for fast spectrum heat pipe reactor systems. 

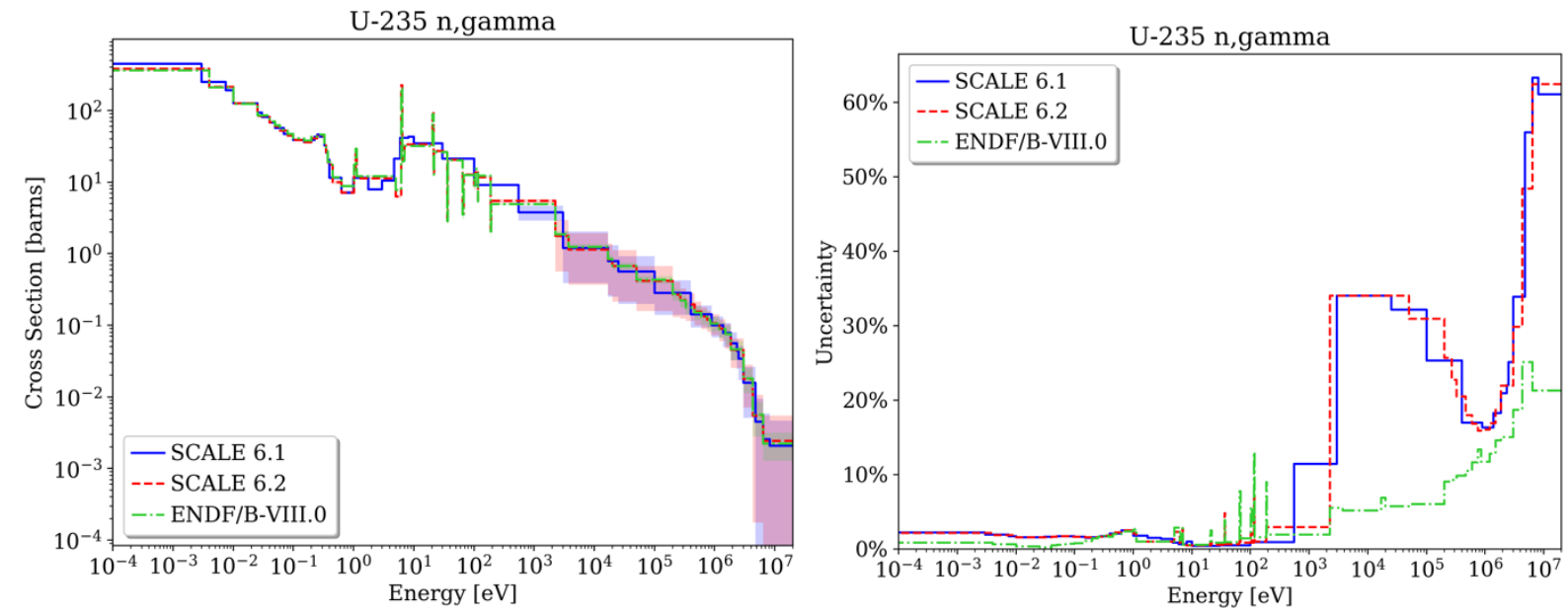

Figure $35 .{ }^{235} \mathrm{U}(\mathrm{n}, \gamma)$ cross section and uncertainty.

\subsection{SODIUM-COOLED FAST REACTOR}

As described for fast spectrum MSR systems, the uncertainties of important quantities in SFR analyses that are due to nuclear data uncertainties can be significantly larger than in thermal systems. The eigenvalue uncertainty for SFRs can be 2-3 times greater than for LWR, depending on the libraries used. For example, the reactivity uncertainty for a typical SFR is in the range $1-1.5 \%$ when using ENDF/BVII.1 data. The uncertainties of important reactivity coefficients such as the sodium void coefficient can be as high as $5 \%$. The major contributor to the uncertainty of many reactivity coefficients is ${ }^{238} \mathrm{U}$ inelastic scattering due to its large uncertainty in the fast energy range. Other relevant contributors to reactivity coefficients uncertainties, as well as uncertainty in the power distribution, are the scattering reactions of ${ }^{56} \mathrm{Fe}$ and ${ }^{23} \mathrm{Na}$ (Bostelmann 2020).

The uncertainty of ${ }^{238} \mathrm{U}$ inelastic scattering was shown to be a dominant contributor to output uncertainties in SFR uncertainty analyses using ENDF/B-VII.1 data. In the ENDF/B-VIII.0 release, this uncertainty was decreased compared to the ENDF/B-VII.1 release (Figure 34). SFR uncertainty analyses based on the ENDF/B-VIII.0 release are therefore expected to show major differences with respect to output uncertainties and their top contributing nuclide reactions when compared with ENDF/B-VII.1 calculations. The uncertainties of other relevant reactions such as ${ }^{56} \mathrm{Fe}$ scattering, ${ }^{239} \mathrm{Pu}$ fission, and ${ }^{238} \mathrm{U}$ neutron capture were also significantly changed in ENDF/B-VIII.0, so they will contribute to these differences as well (Bostelmann et al. 2019).

The neglect of angular scattering distributions and their uncertainties was shown to have an impact of several hundred pcm on the multiplication factor of highly enriched uranium and the plutonium fast spectrum system (Hill 2017, CSWEG 2019).

\subsection{TIME-DEPENDENT ANALYSIS}

The time-dependent behavior of advanced reactor concepts, as discussed in Section 4.7, requires data on fission yields, decay constants, branching ratios, recoverable energy for capture and fission, and effective delayed neutron fraction ( $\beta_{\mathrm{eff}}$ ) in the case of transient analysis.

The current ENDF/B format does not allow correlations for fission product yields or decay data. However, correlations for fission product yields can be determined via constraints such as a limited number of fission products per fission event. Such correlation matrices were generated for use in the 
SCALE code system (Pigni et al. 2015). Additionally, updates were implemented in SCALE for ${ }^{235} \mathrm{U}$, ${ }^{238} \mathrm{U},{ }^{239} \mathrm{Pu}$, and ${ }^{241} \mathrm{Pu}$ to ensure consistency between the measured cumulative fission yields and the independent fission yields taken from ENDF/B-VII.1. The consideration of fission yield uncertainties and details on their constraints can have a noticeable impact on the fission product evolution in depletion calculations, as shown previously for LWR systems (Aures et al. 2017a).

The literature review did not reveal the consideration or availability of branching ratio uncertainties by any computational tool or data library. If they were available and accounted for, then additional correlations would be introduced to the independent fission yields since they are always required to sum up to 2. No data for uncertainties in the recoverable fission and capture energy were found in the literature. In fact, the energy release per fission is often hard coded in many of the computational tools. If such uncertainties were available and considered, then they could affect the power distribution calculation.

The propagation of cross section uncertainties to $\beta_{\text {eff }}$ in an LWR lattice calculation revealed significant $\beta_{\text {eff }}$ uncertainties of approximately $7 \%$ for fresh fuel and approximately $15 \%$ for depleted fuel (Radaideh et al. 2019). Different studies found $\beta_{\text {eff }}$ uncertainties of up to $4 \%$ for thermal and fast spectrum systems (Kodeli 2013, Aures et al. 2017b). The ${ }^{238} \mathrm{U}$ scattering reactions were identified as major contributors to the uncertainty for fast spectrum systems, and, the delayed neutron multiplicity of ${ }^{235} \mathrm{U}$ and ${ }^{239} \mathrm{Pu}$ for thermal systems.

Due to the buildup of Pu during depletion in an LWR, the value of $\beta_{\text {eff }}$ decreases over time; consequently, the uncertainty in this value becomes even more relevant for safety analyses. Advanced reactor systems such as SFRs that are fueled with a mixture of $U$ and $P u$ fuel show a smaller value $\beta_{\text {eff }}$ than LWR systems; the impact of nuclear data uncertainties on $\beta_{\text {eff }}$ in these systems is expected to be significant.

With respect to $\beta_{\text {eff, }}$ some correlations are expected between inherently correlated data such as fission cross section, neutron multiplicity, and fission spectrum. However, the correlations are assumed to be independent - not correlated - in ENDF/B. In fact, the current ENDF/B format cannot even store correlations between these reactions. In a recent ORNL study, the existing covariance library was augmented with such correlations (Sobes et al. 2018). It was demonstrated that the consideration of these additional correlations is relevant and that they have a visible impact on uncertainty analysis. Since all the above mentioned data are used in the calculation of $\beta_{\text {eff }}$, a significant impact on the uncertainty of $\beta_{\text {eff }}$ is expected when such correlations are included in the analysis.

\subsection{FURTHER COMMENTS ON THE AVAILABILITY AND USE OF COVARIANCE DATA}

While ENDF/B provides a large number of uncertainty data, there are other nuclear data libraries that contain uncertainty data that are not yet included in ENDF/B. The SCALE covariance library contains not only ENDF/B data, but also data for missing fission spectrum uncertainties from JEFF. Furthermore, SCALE's libraries contain low-fidelity uncertainty data generated during the Low-Fidelity Covariance Project, which used simple procedures to estimate data uncertainties in the absence of high-fidelity covariance data (Little et al. 2008, Rearden and Jessee 2016). The available nuclear data libraries are still missing a significant number of uncertainties for various materials and reactions. For example, covariance data of inelastic scattering, $(\mathrm{n}, 2 \mathrm{n})$ and other neutron interactions are often missing for relevant isotopes such as ${ }^{197} \mathrm{Au}$ (Bailey 2020).

Covariance matrices as provided in the ENDF/B libraries sometimes do not show their intrinsic attributes. For example, they may be not positive semi-definite (sometimes caused by limited precision when storing them in a particular format), they can show unphysically large correlations, or have correlations that seem 
incorrect because the data in certain energy ranges are independent (Wiarda et al. 2018). Depending on the application need (e.g., required matrix inversion), it may be necessary to modify the matrices to be able to perform the uncertainty calculations.

Even if all relevant uncertainty data were available, the following three requirements must be met before the data can be used:

1. The tools for nuclear data processing must be able to handle the provided data.

2. The data must be stored in adequate format for subsequent use in uncertainty/sensitivity analysis tools.

3. The uncertainty/sensitivity analysis tools must be able to read and use the data.

For some of the provided covariance data, it is not yet possible to process it with the processing code of choice, to store it in a processing codes' output format, or to use it with the desired analysis tools.

The perturbation theory-based approach relies on calculation of sensitivity coefficients for an output quantity with respect to the input data uncertainty. However, such sensitivity coefficients are not yet implemented for all available input nuclear data in commonly used sensitivity analysis tools. In the random sampling approach, data provided in two dimensions (e.g., fission spectrum) cannot necessarily be sampled. Furthermore, many tools can only consider data in multigroup representation, but not in continuous energy representation.

For example, the AMPX code used to process data for use with SCALE cannot currently store available angular scattering uncertainties. Furthermore, it is not yet possible to consider the incident neutron energy dependence of the fission spectrum; uncertainties are currently included only for mean incident energies (Wiarda et al. 2016).

During the challenging process of developing ENDF/B libraries, the nuclear data mean values are adjusted during the evaluation process based on data from criticality experiments in the International Criticality Safety Benchmark Experiment Project (ICSBEP) Handbook. As a result of this adjustment, the mean values allow for an accurate prediction of the multiplication factor values for such experiments. The covariance data development does not include or reflect this type of adjustment, leading in some cases to an inconsistent approach in predicting uncertainties for integral quantities such as the multiplication factor. The variation of calculated vs. experimental $(\mathrm{C} / \mathrm{E})$ multiplication factors for large sets of ICSBEP experiments was shown to be significantly smaller than that predicted by using ENDF/B covariance data (Williams et al. 2017). However, methods are available to account for available information on the experiments in the generation of adjusted covariance data, enabling a better consistency approach in calculating $\mathrm{C} / \mathrm{E}$ distributions (Salvatores et al. 2013). The nuclear data community is currently engaged in discussing an optimal approach to address the adjustment of the covariance data to better represent uncertainty in integral quantities (CSEWG 2018, CSEWG 2019). 
Table 5. Overview of key nuclear data uncertainties for the selected advanced reactor concepts.

\begin{tabular}{|c|c|c|c|}
\hline Reactor type & $\begin{array}{l}\text { Reactor } \\
\text { technology }\end{array}$ & Key nuclear data & $\begin{array}{l}\text { Missing/discrepant data, important } \\
\text { data changes, caveats }\end{array}$ \\
\hline \multirow{2}{*}{$\begin{array}{l}\text { Thermal spectrum } \\
\text { HTGR }\end{array}$} & \multirow{2}{*}{ Pebble-bed HTGR } & $\begin{array}{l}\text { Fuel: }{ }^{235} \mathrm{U} \bar{v},{ }^{235} \mathrm{U} \text { fission, }{ }^{235} \mathrm{U} \chi,{ }^{235} \mathrm{U}(\mathrm{n}, \gamma),{ }^{238} \mathrm{U}(\mathrm{n}, \gamma),{ }^{28} \mathrm{Si}(\mathrm{n}, \gamma),{ }^{28} \mathrm{Si} \\
\text { elastic }\end{array}$ & \multirow[t]{2}{*}{$\begin{array}{l}\text { No thermal scattering data uncertainties } \\
\text { for graphite }\end{array}$} \\
\hline & & $\begin{array}{l}\text { Moderator: }{ }^{12} \mathrm{C} / \text { graphite }(\mathrm{n}, \gamma),{ }^{12} \mathrm{C} / \text { graphite elastic, }{ }^{12} \mathrm{C} / \text { graphite } \\
\text { inelastic }\end{array}$ & \\
\hline \multirow{3}{*}{$\begin{array}{l}\text { Thermal spectrum } \\
\text { MSR }\end{array}$} & \multirow{3}{*}{$\begin{array}{l}\text { Fluoride salt- } \\
\text { cooled high- } \\
\text { temperature reactor } \\
\text { (FHR) }\end{array}$} & Fuel: ${ }^{235} \mathrm{U} \bar{v},{ }^{235} \mathrm{U}$ fission, ${ }^{235} \mathrm{U}(\mathrm{n}, \gamma),{ }^{238} \mathrm{U}(\mathrm{n}, \gamma),{ }^{238} \mathrm{U}$ elastic & \multirow{3}{*}{$\begin{array}{l}\text { No thermal scattering data uncertainties } \\
\text { for graphite and molten salts }\end{array}$} \\
\hline & & $\begin{array}{l}\text { Coolant: }{ }^{7} \mathrm{Li}(\mathrm{n}, \gamma),{ }^{7} \mathrm{Li} \text { elastic, }{ }^{19} \mathrm{~F}(\mathrm{n}, \gamma),{ }^{19} \mathrm{~F} \text { elastic, }{ }^{9} \mathrm{Be} \text { elastic, }{ }^{19} \mathrm{~F} \\
(\mathrm{n}, \alpha),{ }^{19} \mathrm{~F}(\mathrm{n}, \mathrm{p})\end{array}$ & \\
\hline & & Moderator: ${ }^{12} \mathrm{C}(\mathrm{n}, \gamma),{ }^{12} \mathrm{C}$ elastic & \\
\hline \multirow{3}{*}{$\begin{array}{l}\text { Thermal spectrum } \\
\text { MSR }\end{array}$} & \multirow{3}{*}{$\begin{array}{l}\text { Graphite- } \\
\text { moderated MSR }\end{array}$} & $\begin{array}{l}\text { Fuel/coolant: }{ }^{235} \mathrm{U} \bar{v},{ }^{235} \mathrm{U} \text { fission, }{ }^{235} \mathrm{U}(\mathrm{n}, \gamma),{ }^{238} \mathrm{U} \bar{v},{ }^{238} \mathrm{U} \text { fission, }{ }^{238} \mathrm{U} \\
(\mathrm{n}, \gamma),{ }^{238} \mathrm{U} \text { elastic, }{ }^{19} \mathrm{~F} \text { elastic },{ }^{19} \mathrm{~F}(\mathrm{n}, \gamma),{ }^{7} \mathrm{Li}(\mathrm{n}, \gamma),{ }^{6} \mathrm{Li}(\mathrm{n}, \gamma),{ }^{6} \mathrm{Li}(\mathrm{n}, \mathrm{t})\end{array}$ & \multirow[t]{3}{*}{$\begin{array}{l}\text { No thermal scattering data uncertainties } \\
\text { for graphite and molten salts }\end{array}$} \\
\hline & & Moderator: ${ }^{12} \mathrm{C}(\mathrm{n}, \gamma),{ }^{12} \mathrm{C}$ elastic & \\
\hline & & Structure: ${ }^{58} \mathrm{Ni}$ elastic, ${ }^{58} \mathrm{Ni}$ inelastic, ${ }^{58} \mathrm{Ni}(\mathrm{n}, \gamma),{ }^{58} \mathrm{Ni}(\mathrm{n}, \mathrm{p})$ & \\
\hline $\begin{array}{l}\text { Fast spectrum } \\
\text { MSR }\end{array}$ & $\begin{array}{l}\text { Molten chloride } \\
\text { fast spectrum } \\
\text { reactor }\end{array}$ & $\begin{array}{l}\text { Fuel and coolant salt: } \\
{ }^{238} \mathrm{U} \text { inel., }{ }^{238} \mathrm{U}(\mathrm{n}, \gamma),{ }^{239} \mathrm{Pu}(\mathrm{n}, \gamma), \\
\bar{v} \text { and fission of }{ }^{235} \mathrm{U},{ }^{238} \mathrm{U},{ }^{239} \mathrm{Pu},{ }^{240} \mathrm{Pu},{ }^{241} \mathrm{Pu}, \\
{ }^{37} \mathrm{Cl} \text { inelastic, }{ }^{37} \mathrm{Cl} \text { elastic, }{ }^{23} \mathrm{Na} \text { inelastic, }{ }^{23} \mathrm{Na} \text { elastic, }{ }^{35} \mathrm{Cl}(\mathrm{n}, \mathrm{p}),{ }^{35} \mathrm{Cl} \\
(\mathrm{n}, \gamma)\end{array}$ & $\begin{array}{l}\text { Angular scattering distribution } \\
\text { uncertainties: limited availability and } \\
\text { usability } \\
{ }^{238} \text { U inelastic scattering uncertainty } \\
\text { ENDF/B-VII.1 vs. VIII.0 }\end{array}$ \\
\hline \multirow{3}{*}{$\begin{array}{l}\text { Fast spectrum } \\
\text { oxide and metal } \\
\text { fueled stationary } \\
\text { microreactor }\end{array}$} & \multirow{3}{*}{ Heat pipe reactor } & $\begin{array}{l}\text { Fuel: }{ }^{235} \mathrm{U} \bar{v},{ }^{235} \mathrm{U} \text { fission, }{ }^{235} \mathrm{U}(\mathrm{n}, \gamma),{ }^{238} \mathrm{U} \bar{v},{ }^{238} \mathrm{U} \text { fission, }{ }^{238} \mathrm{U} \mathrm{n}, 2 \mathrm{n},{ }^{16} \mathrm{O} \\
\text { elastic, } \\
\text { Elastic and inelastic scattering as well as }(\mathrm{n}, \gamma) \text { of }{ }^{56} \mathrm{Fe},{ }^{90} \mathrm{Zr},{ }^{91} \mathrm{Zr},{ }^{92} \mathrm{Zr} \text {, } \\
{ }^{94} \mathrm{Zr},{ }^{96} \mathrm{Zr}\end{array}$ & \multirow{3}{*}{$\begin{array}{l}\text { Angular scattering distribution } \\
\text { uncertainties: limited availability and } \\
\text { usability } \\
\text { No thermal scattering data uncertainties } \\
\text { for BeO } \\
{ }^{235} \mathrm{U}(\mathrm{n}, \gamma) \text { uncertainty ENDF/B-VII.1 vs. } \\
\text { VIII.0 }\end{array}$} \\
\hline & & Coolant: ${ }^{23} \mathrm{Na}$ elastic, ${ }^{23} \mathrm{Na}$ inelastic, ${ }^{39} \mathrm{~K}$ capture, ${ }^{39} \mathrm{~K}(\mathrm{n}, \mathrm{p}),{ }^{39} \mathrm{~K}$ elastic & \\
\hline & & $\begin{array}{l}\text { Structure: }{ }^{56} \mathrm{Fe}(\mathrm{n}, \gamma),{ }^{56} \mathrm{Fe} \text { elastic, }{ }^{56} \mathrm{Fe} \text { inelastic, }{ }^{27} \mathrm{Al} \text { elastic, }{ }^{9} \mathrm{Be} \\
\text { elastic, }{ }^{16} \mathrm{O} \text { elastic, }{ }^{10} \mathrm{~B}(\mathrm{n}, \gamma),{ }^{10} \mathrm{~B}(\mathrm{n}, \alpha)\end{array}$ & \\
\hline
\end{tabular}


Table 5. Overview of key nuclear data uncertainties for the selected advanced reactor concepts (continued)

\begin{tabular}{|c|c|c|c|}
\hline Reactor type & $\begin{array}{c}\text { Reactor } \\
\text { technology }\end{array}$ & Key nuclear data & $\begin{array}{l}\text { Missing/discrepant data, important } \\
\text { data changes, caveats }\end{array}$ \\
\hline \multirow{3}{*}{$\begin{array}{l}\text { Fast-spectrum } \\
\text { metal and oxide } \\
\text { fueled SFR }\end{array}$} & \multirow{3}{*}{ SFR } & $\begin{array}{l}\text { Fuel: } \bar{v} \text { and fission of }{ }^{238} \mathrm{U},{ }^{238} \mathrm{Pu},{ }^{239} \mathrm{Pu},{ }^{240} \mathrm{Pu},{ }^{241} \mathrm{Pu},{ }^{242} \mathrm{Pu},{ }^{241} \mathrm{Am}, \\
{ }^{242 \mathrm{Am}},{ }^{243} \mathrm{Am},{ }^{245} \mathrm{Cm} \text {; } \\
{ }^{238} \mathrm{U}(\mathrm{n}, \gamma),{ }^{238} \mathrm{U} \text { inelastic, }{ }^{239} \mathrm{Pu}(\mathrm{n}, \gamma),{ }^{241} \mathrm{Am}(\mathrm{n}, \gamma),{ }^{243} \mathrm{Am}(\mathrm{n}, \gamma),{ }^{16} \mathrm{O} \text { elastic }\end{array}$ & \multirow{3}{*}{$\begin{array}{l}\text { Angular scattering distribution } \\
\text { uncertainties: limited availability and } \\
\text { usability } \\
{ }^{238} \mathrm{U} \text { inelastic scattering uncertainty } \\
\text { between ENDF/B releases }\end{array}$} \\
\hline & & Coolant: ${ }^{23} \mathrm{Na}$ elastic, ${ }^{23} \mathrm{Na}$ inelastic & \\
\hline & & $\begin{array}{l}\text { Structure: }{ }^{52} \mathrm{Cr} \text { elastic } \\
\text { Elastic and inelastic scattering as well as }(\mathrm{n}, \gamma) \text { of }{ }^{56} \mathrm{Fe},{ }^{90} \mathrm{Zr},{ }^{91} \mathrm{Zr},{ }^{92} \mathrm{Zr} \text {, } \\
{ }^{94} \mathrm{Zr},{ }^{96} \mathrm{Zr}\end{array}$ & \\
\hline All concepts & & $\begin{array}{l}\text { Fission yields, decay constants, branching ratios, energy release per } \\
\text { fission, fission spectra, fission products (e.g., Xe, Sm, Gd), fission and } \\
\text { capture of actinides that build up during depletion }\end{array}$ & $\begin{array}{l}\text { Missing correlations between } \bar{v} \text {, fission } \\
\text { and } \chi \\
{ }^{235} \mathrm{U} /{ }^{239} \mathrm{Pu} \bar{v} \text { and fission uncertainty } \\
\mathrm{ENDF} / \mathrm{B}-\mathrm{VII} .1 \text { vs. VIII. } 0 \\
\text { Missing } \bar{v} \text { uncertainty for }{ }^{242} \mathrm{Am},{ }^{244} \mathrm{Am} \text {, } \\
{ }^{244 \mathrm{~m}} \mathrm{Am},{ }^{243} \mathrm{Pu},{ }^{237} \mathrm{U},{ }^{239} \mathrm{U},{ }^{240} \mathrm{U},{ }^{241} \mathrm{U}\end{array}$ \\
\hline
\end{tabular}



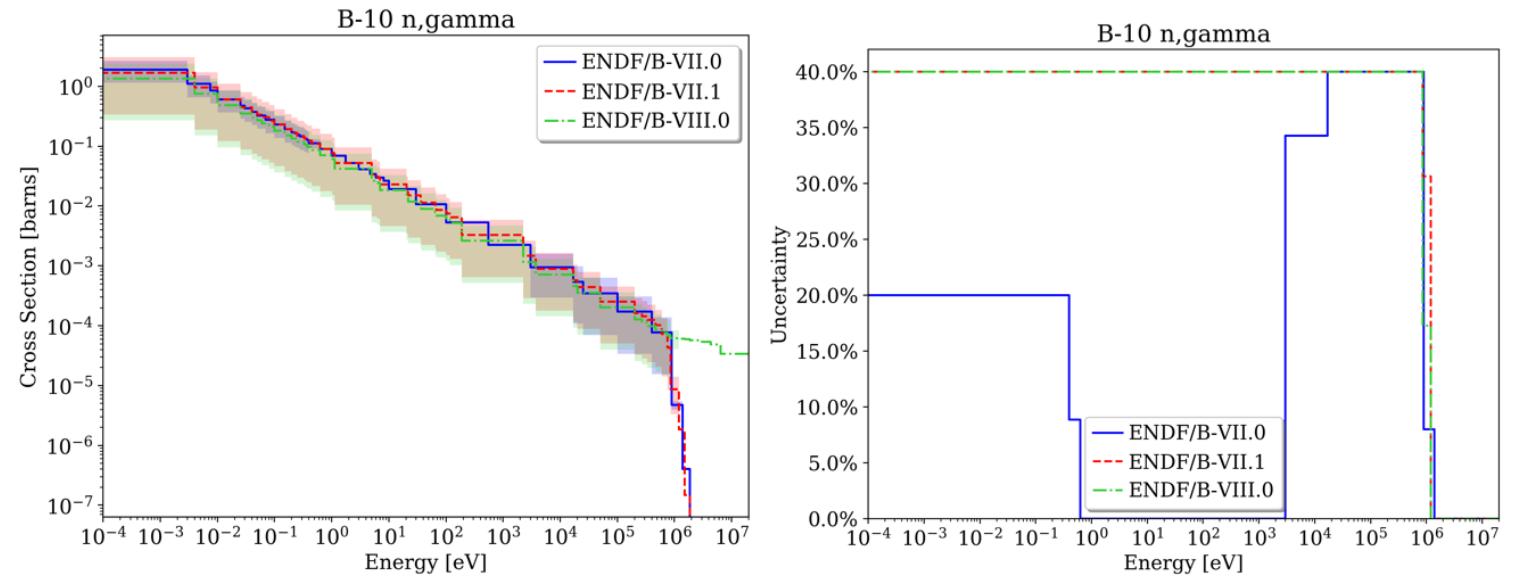

Figure 36. ${ }^{10} \mathrm{~B}(\mathrm{n}, \gamma)$ cross section and uncertainty.
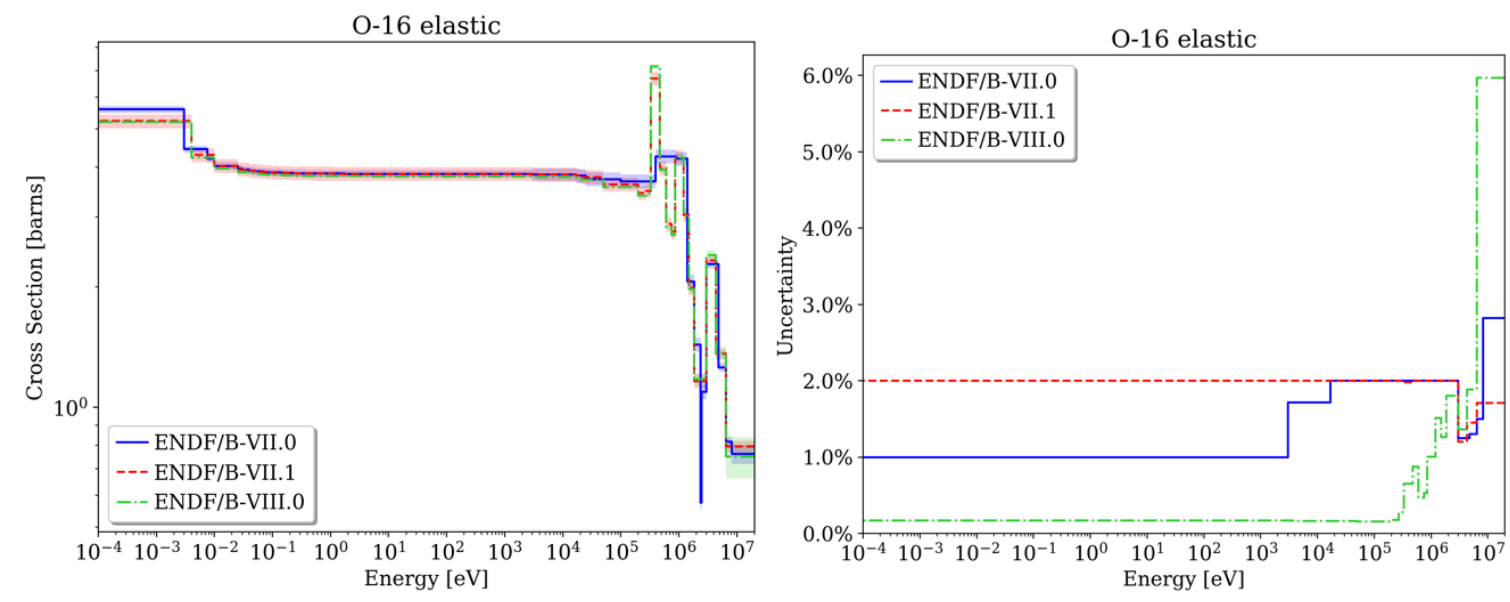

Figure 37. ${ }^{16} \mathrm{O}$ elastic scattering cross section and uncertainty.
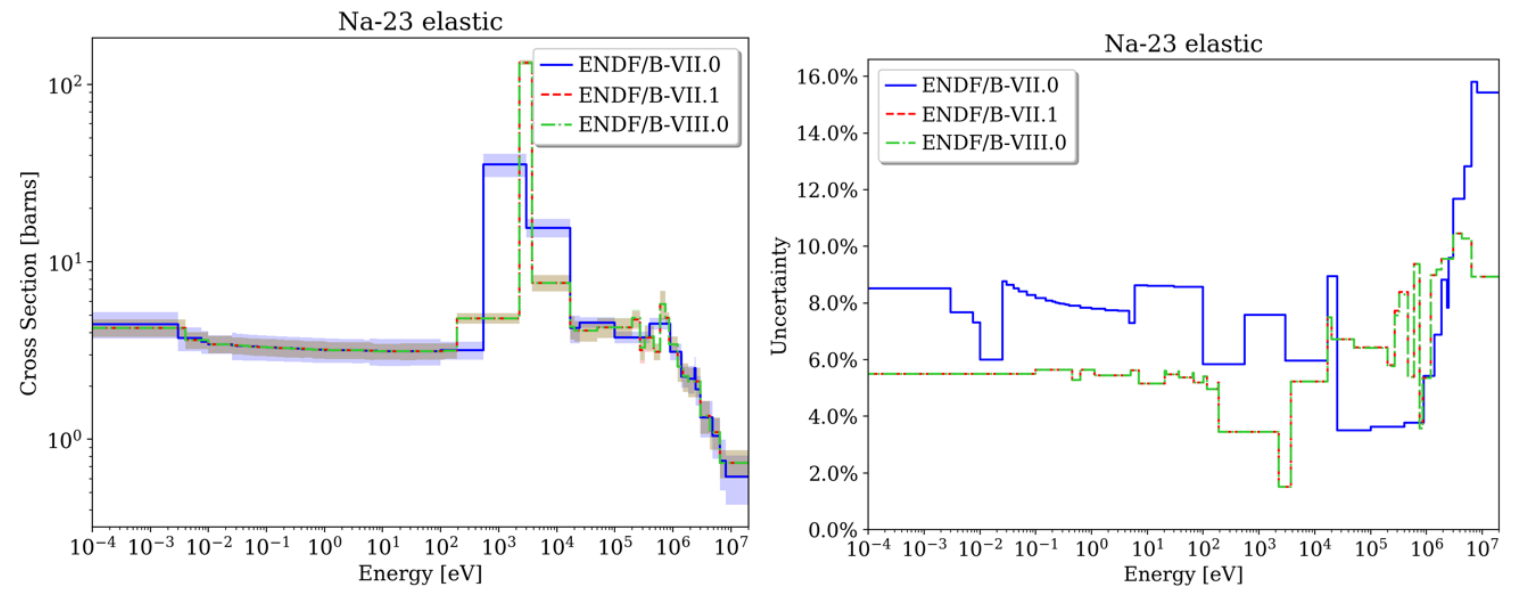

Figure 38. ${ }^{23} \mathrm{Na}$ elastic scattering cross section and uncertainty. 

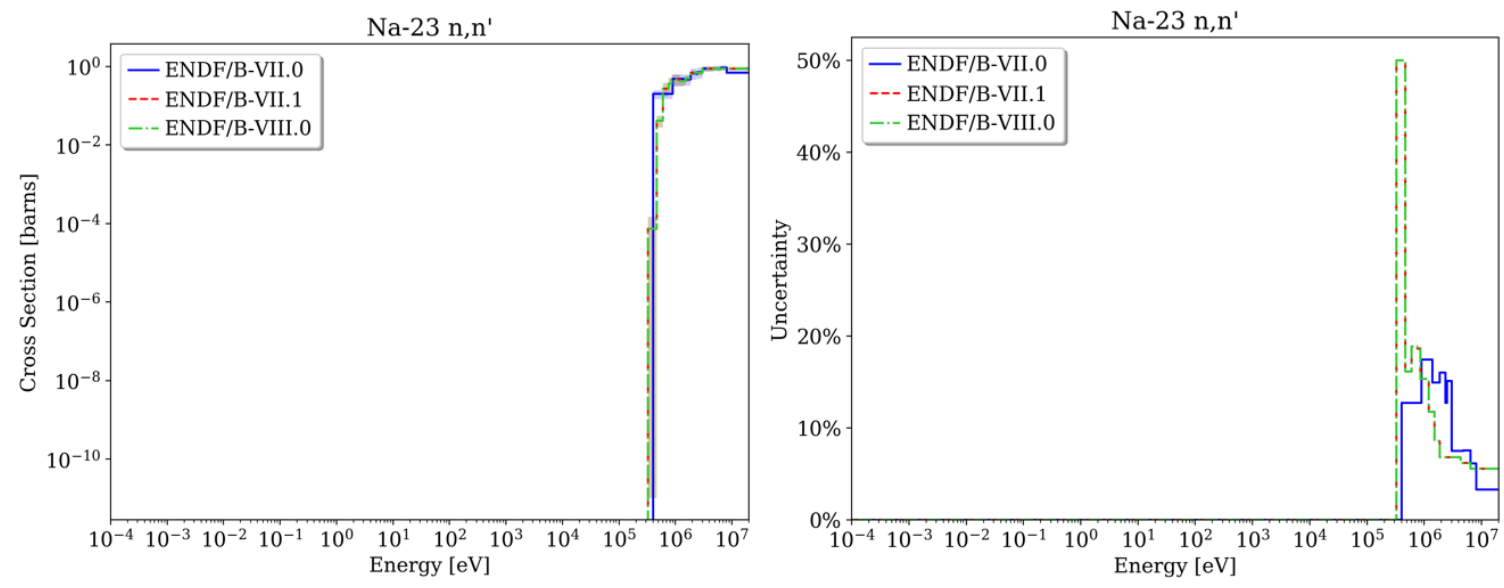

Figure 39. ${ }^{23} \mathrm{Na}$ inelastic scattering cross section and uncertainty.
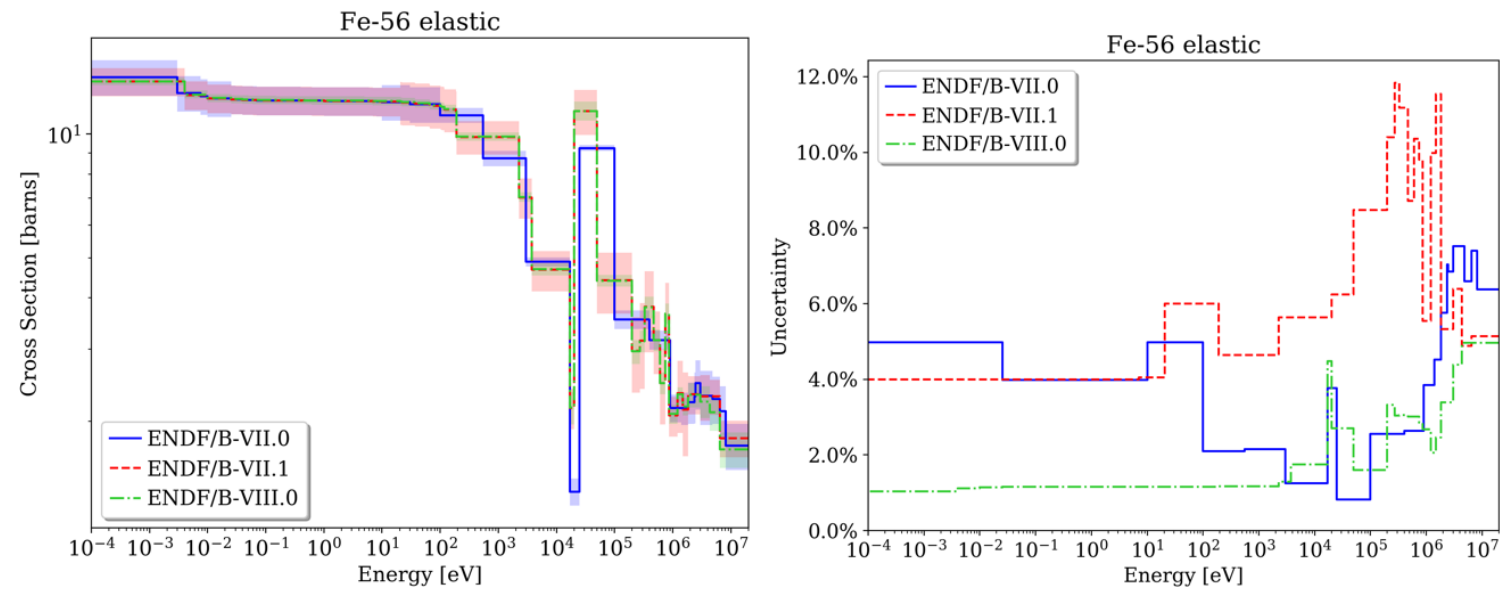

Figure 40. ${ }^{56} \mathrm{Fe}$ elastic scattering cross section and uncertainty.
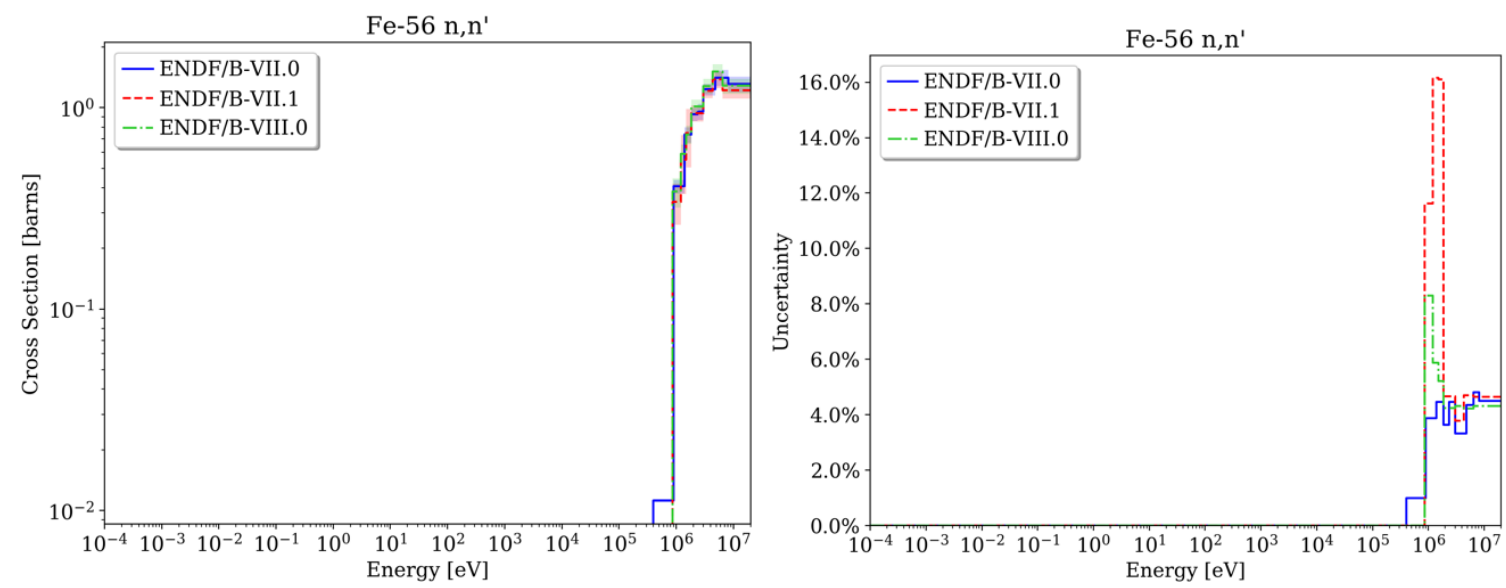

Figure 41. ${ }^{56} \mathrm{Fe}$ inelastic scattering cross section and uncertainty. 

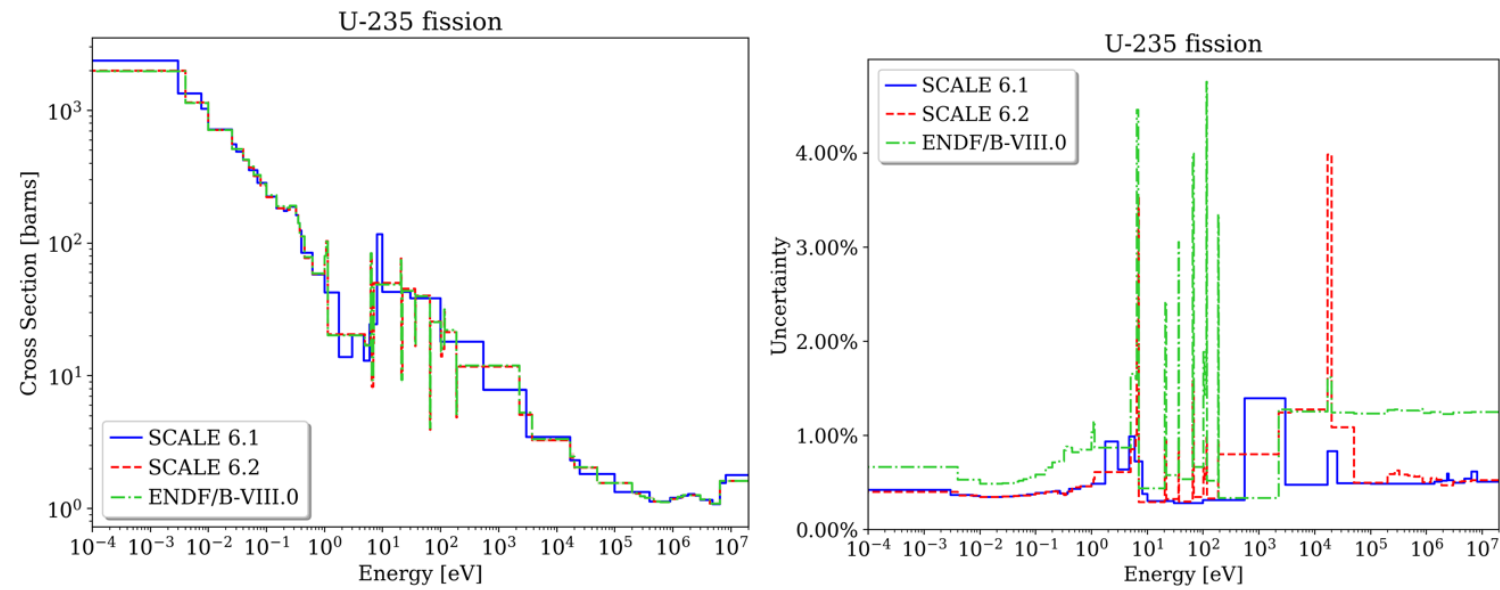

Figure 42. ${ }^{235} \mathrm{U}$ fission cross section and uncertainty.
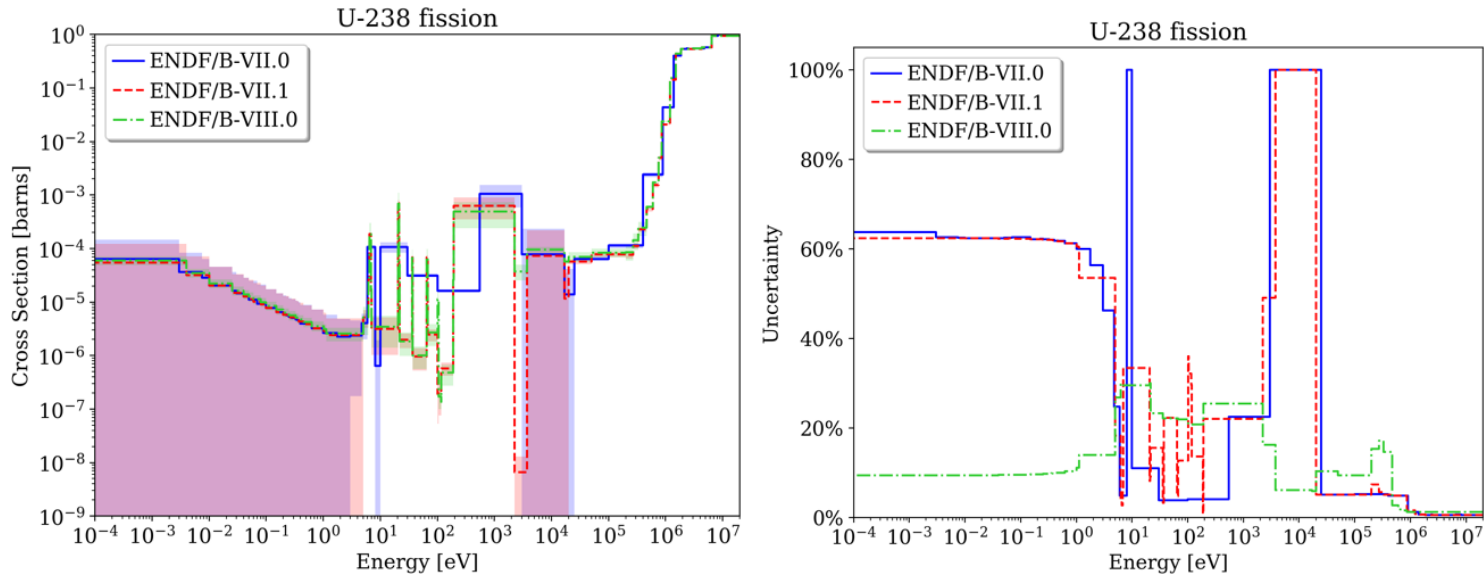

Figure 43. ${ }^{238} \mathrm{U}$ fission cross section and uncertainty.
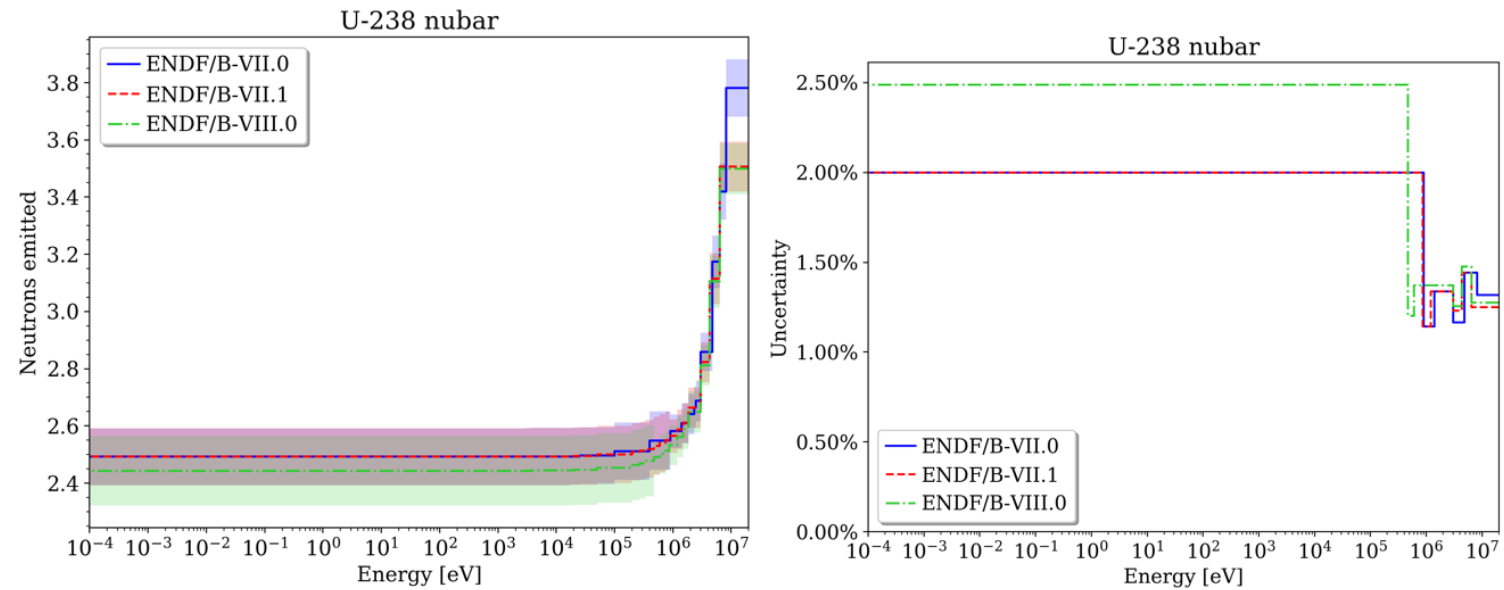

Figure 44. ${ }^{238} \mathrm{U}$ nubar nominal data and uncertainty. 

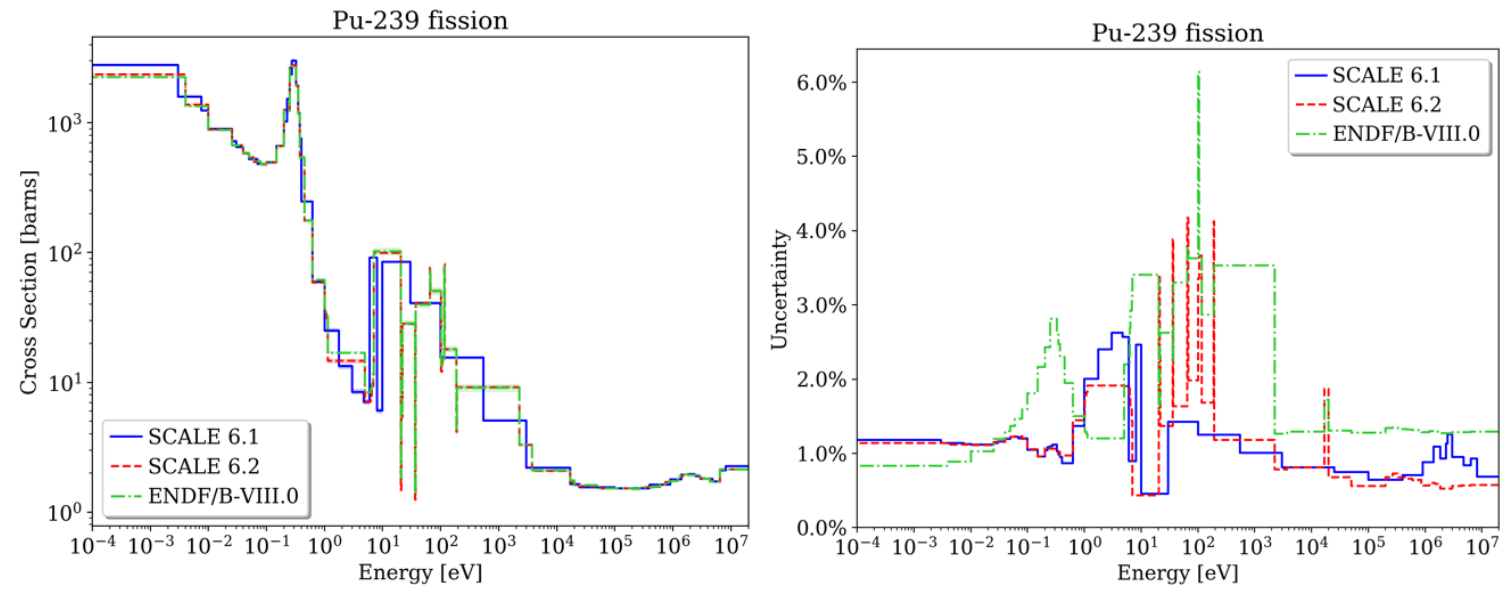

Figure $45 .{ }^{239} \mathrm{Pu}$ fission cross section and uncertainty.
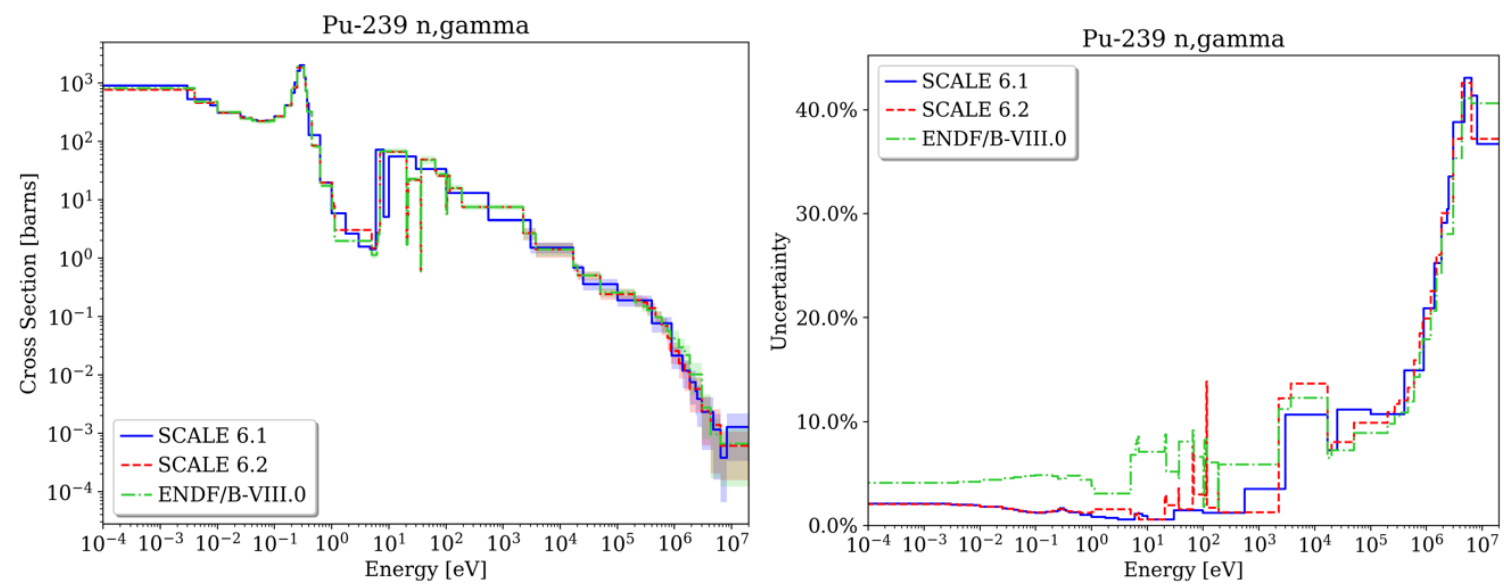

Figure 46. ${ }^{239} \mathrm{Pu}(\mathrm{n}, \gamma)$ cross section and uncertainty. 


\section{CONCLUSIONS}

Key nuclear data relevant for reactor safety analysis in selected advanced reactor technologies were identified, and their impact on important key figures of merit was assessed based on a review of available advanced reactor specifications, analysis of previous studies performed at ORNL and other research institutions, and examination of available evaluated nuclear data libraries. The most important findings are summarized herein for each considered advanced reactor concept.

For the graphite-rich pebble-bed HTGRs, the update of the carbon neutron capture cross section from the ENDF/B-VII.0 to the ENDF/B-VII.1 release led to reactivity differences greater than $1,000 \mathrm{pcm}$. With the release of ENDF/B-VIII.0, graphite can now be considered at different porosities, and the use of these different options can lead to differences in predicted reactivities. Apart from the capture and scattering reactions for graphite, the identified key nuclide reactions impacting reactivity in HTGRs are the neutron multiplicity, fission reaction, and neutron capture reaction for ${ }^{235} U$ and ${ }^{238} U$. There is a significant gap in the availability of uncertainty for graphite thermal scattering data. Significant differences between the different ENDF/B evaluations for both the nominal cross section data and the uncertainty data can cause significant differences in reactivity calculations that use these different evaluated data.

FHRs are graphite moderated and are similarly impacted by library differences for carbon and graphite as they apply to HTGRs. Key nuclear data include the neutron multiplicity, fission reaction, and neutron capture for ${ }^{235} \mathrm{U}$ and ${ }^{238} \mathrm{U}$. Additionally, the impact of the update from the ENDF/B-VII.0 to the ENDF/BVII.1 release of the tritium production cross section for ${ }^{6} \mathrm{Li}$ is significant given the large amount of FLiBe salt present in this type of reactor. Thermal scattering data uncertainties for both graphite and FLiBe are not yet available for consideration in uncertainty analyses. The impact of such uncertainties, where available, is expected to be significant for reactivity uncertainty calculations.

Reactivity in heat pipe reactors with enriched uranium fuel are significantly affected by the neutron multiplicity, fission, capture, and scattering cross sections for ${ }^{235} \mathrm{U}$ and ${ }^{238} \mathrm{U}$, as well as scattering cross sections for nuclides in coolant and structural materials. Large reactivity uncertainties in such fast spectrum system calculations are caused by large uncertainties for the ${ }^{235} U$ capture cross section in the fast energy range. Moreover, as a significant change of this uncertainty was made in the ENDF/B-VIII.0 release, the use of different evaluated libraries is expected to have a large impact on uncertainty analyses for this reactor type. A gap identified in the data of importance for fast spectrum systems analysis is the unavailability of angular scattering data uncertainties.

For graphite-moderated MSRs, the important nuclide reactions impacting reactivity are similar to those identified for FHRs for graphite, FLiBe salt, and fissile nuclides in the fuel. Additionally, because the fuel is circulating through the reactor during operation, the importance of short-lived fission products is significantly increased. An identified nuclear data gap for analysis of MSRs is the data missing for ${ }^{135 \mathrm{~m}} \mathrm{Xe}$, which can have a large impact on the calculation of the xenon worth.

Given the fast neutron spectrum and fuel composition characteristics, the reactivity uncertainty for the molten chloride fast spectrum reactor is mainly driven by the large uncertainty of the ${ }^{238} \mathrm{U}$ inelastic scattering. A major change in uncertainty data for this inelastic scattering from ENDF/B-VII.1 to ENDF/B-VIII.0 affects uncertainty analyses for this reactor concept. Other key nuclear data are for fission and capture reactions of the fissile nuclides, as well as for scattering reactions of the materials within the salt (e.g. ${ }^{23} \mathrm{Na}$ ). Notably, a significant update of the ${ }^{35} \mathrm{Cl}(\mathrm{n}, \mathrm{p})$ reaction cross section from ENDF/B-VII.0 to $\mathrm{ENDF} / \mathrm{B}-\mathrm{VII} .1$ was shown to cause reactivity changes greater than $1,000 \mathrm{pcm}$. 
The key nuclear data identified for sodium-cooled fast reactors is similar to that identified for the heat pipe reactor and the fast spectrum MSR. For uncertainty analyses, the ${ }^{238} \mathrm{U}$ inelastic scattering update from ENDF/B-VII.1 to ENDF/B-VIII.0 plays a major role, followed in importance by scattering reactions for nuclides in the coolant $\left({ }^{23} \mathrm{Na}\right)$ and structural materials (especially ${ }^{56} \mathrm{Fe}$ ). The most relevant identified gap is the missing uncertainty data for angular scattering distributions.

\section{ACKNOWLEDGMENTS}

Support for this work was provided by the US Nuclear Regulatory Commission (NRC). The authors would like to thank Tim Drzewiecki and Don Algama of the NRC for their constructive feedback. Suggestions and comments received from many of our colleagues in ORNL's Reactor and Nuclear Systems Division are greatly appreciated. 


\section{REFERENCES}

Aliberti, G., et al., 2007. "Fission Spectrum Related Uncertainties," INL/COV-07-13354.

Andreades, A., et al., 2014. Technical Description of the Mark 1 Pebble-Bed Fluoride-Salt-Cooled HighTemperature Reactor (PB-FHR) Power Plant, University of California, Berkeley, UCBTH-14-002.

Aures, A. et al., 2017a. "Benchmarking and Application of the State-of-the-Art Uncertainty Analysis Methods XSUSA and SHARK-X," Annals of Nuclear Energy, 101, pp. 262-269.

Aures, A. et al., 2017b. "Uncertainty in the delayed neutron fraction in fuel assembly depletion calculations," EPJ Web of Conferences, 146, 02052.

Bailey, T., 2020. "Impact of Unrealistic or Missing Cross Section Covariances," Workshop for Applied Nuclear Data Activities (WANDA), Washington DC, March 3-5.

Bernstein, L., et al., 2019. "Our Future Nuclear Data Needs," Annual Review of Nuclear and Particle Science, 69.

Betzler, B. R., et al., 2010. "Sensitivity and Uncertainty Analysis Capabilities and Data in SCALE," Nuclear Technology 174(2), pp. 236-288.

Betzler, B. R., et al., 2017a. "Fuel Cycle Analysis of Fast and Thermal Molten Salt Reactors," GLOBAL International Fuel Cycle Conference, Seoul, Korea, Sep. 24-29.

Betzler, B. R., et al., 2017b. "Molten Salt Reactor Neutronics and Fuel Cycle Modeling and Simulation with SCALE," Annals of Nuclear Energy, 101, pp.489-503.

Betzler, B. R., et al., 2018. "Fuel Cycle and Neutronic Performance of a Spectral Shift Molten Salt Reactor Design," Annals of Nuclear Energy, 119, pp. 396-410.

Bostelmann, F., et al., 2016. "Criticality calculations of the Very High Temperature Reactor Critical Assembly Benchmark with Serpent and SCALE/KENO-VI," Annals of Nuclear Energy, 90, pp. 343352.

Bostelmann, F., and Strydom, G., 2017. "Nuclear Data Uncertainty and Sensitivity Analysis of the VHTRC Benchmark Using SCALE,” Annals of Nuclear Energy, 110, pp. 317-329.

Bostelmann, F., et al. 2018a. Nuclear Data and Benchmarking Program: Nuclear Data Performance Assessment for Advanced Reactors, ORNL/TM-2018/1033.

Bostelmann, F., et al., 2018b. "Assessment of SCALE Capabilities for High Temperature Reactor Modeling and Simulation," Transactions of the American Nuclear Society, 119, Orlando, Florida, November 11-15.

Bostelmann, F. et al., 2019. "Impact of the ENDF/B-VIII.0 Library on Advanced Reactor Simulations," Presentation at the ANS Winter conference, November 17-21, Washington, D.C.

Bostelmann, F., 2020. Systematic Uncertainty and Sensitivity Analysis of Sodium-Cooled Fast Reactor Systems, PhD Thesis, EPFL.

Brown, D. A., et al., 2018. "ENDF/B-VIII.0: The $8^{\text {th }}$ Major Release of the Nuclear Reaction Data Library with CIELO-Project Cross Sections, New Standards and Thermal Scattering Data," Nuclear Data Sheets 148, pp. 1-142.

Chadwick, M. B., et al. 2006. "ENDF/B-VII.0: Next Generation Evaluated Nuclear Data Library for Nuclear Science and Technology," Nuclear Data Sheets 107, Issue 12, pp. 2931-3060. 
Chadwick, M. B., et al. 2011. "ENDF/B-VII.1 Nuclear Data for Science and Technology: Cross Sections, Covariances, Fission Product Yields and Decay Data," Nuclear Data Sheets 112, Issue 12, pp. 28872996.

Campbell, A. A, et al. 2016. "Property Changes of G347A Graphite Due to Neutron Irradiation," Carbon 109, pp. 860-873.

Choe, J., et al., 2018. "Fuel Cycle Flexibility of Terrestrial Energy’s Integral Molten Salt Reactor (IMSR)," $38^{\text {th }}$ Annual Conference of the Canadian Nuclear Society and $42^{\text {nd }}$ Annual CNS/CNA Student Conference, Saskatoon, SK, Canada, June 3-6.

Cisneros, A. T., 2013. Pebble Bed Reactors Design Optimization Methods and their Application to the Pebble Bed Fluoride Salt Cooled High Temperature Reactor (PB-FHR), PhD Thesis, UC Berkeley.

Clark, A., et al., 2020. “Technical and Licensing Considerations for Micro-Reactors," Sandia Report SAND2020-4609.

CSWEG, 2018. "Minutes of the 2018 Cross Section Evaluation Working Group Annual Meeting," BNL209790-2018-INRE, Brookhaven National Laboratory, November 5-7.

CSWEG, 2019. “2019 CSEWG Meeting Minutes,” BNL-213606-2020-INRE, Brookhaven National Laboratory, November 4-8.

DOE Office of Nuclear Energy, Science and Technology, 2002. A Technology Roadmap for Generation IV Nuclear Energy Systems, GIF-002-00.

Eades, M. J., et al., 2016. "The Influence of Xe-135m on Steady-State Xenon Worth in Thermal Molten Salt Reactors," Progress in Nuclear Energy, 93, pp. 397-405.

Fast Reactor Working Group, 2018. "Nuclear Metal Fuel: Characteristics, Design, Manufacturing, Testing, and Operating History," White paper 18-01.

https:/www.nrc.gov/docs/ML1816/ML18165A249.pdf

Fiorito, L., et al., 2014. "Fission Yield Covariance Generation and Uncertainty Propagation through Fission Pulse Decay Heat Calculation," Annals of Nuclear Energy, 69, pp. 331-343.

Fratoni, M., 2019. "Impact of Nuclear Data on the Design of Fluoride Cooled Reactors," Workshop for Applied Nuclear Data Activities (WANDA), Washington D.C., January 22-24.

Hawari, A., et al., 2014. "Inelastic Thermal Neutron Scattering Cross Sections for Reactor-Grade Graphite," Nuclear Data Sheets, 118, pp. 176-178.

Hill, I., 2017. "Status and Analysis of P1 Angular Scattering Sensitivity Data Available with the Database for ICSBEP (DICE),” M\&C 2017, Jeju, Korea, April 16-20.

Holcomb, D. E., et al., 2011. Fast Spectrum Molten Salt Reactor Options, Oak Ridge National Laboratory, ORNL/TM-2011/105.

IAEA, 2013. Evaluation of High Temperature Gas Cooled Reactor Performance: Benchmark Analysis Related to the PBMR-400, PBMM, GT-MHR, HTR-10 and the ASTRA Critical Facility, IAEATECDOC-1694.

Ilas, G., et al., 2012. Validation of SCALE for High Temperature Gas-Cooled Reactor Analysis, NUREG/CR-7107, US Nuclear Regulatory Commission.

International Handbook of Reactor Physics Experiments, 2007. "Evaluation of the Initial Critical Configuration of the HTR-10 Pebble-Bed Reactor," HTR10-GCR-RESR-001, NEA/NSC/DOC(2006)1, Rev. 0. 
Kodeli, I., 2013. "Sensitivity and Uncertainty in the Effective Delayed Neutron Fraction (ßeff)," Nuclear Instruments and Methods in Physics Research A, 715, pp. 70-78.

Latta, R., et al., 2019. "High Power Irradiation Testing of TRISO Particles in Miniature Fuel Specimens in HFIR," Transactions of the American Nuclear Society,121, Washington, DC, November 17-21.

Leray, O., et al., 2017. "Uncertainty Propagation of Fission Product Yields to Nuclide Composition and Decay Heat for a LWR UO 2 fuel assembly," Progress in Nuclear Energy, 101, pp. 486-495.

Little, R. et al., 2008. Low-Fidelity Covariance Project. Nuclear Data Sheets, 109(12), pp. 2828-2833.

Lum, E. S., et al., 2006. Evaluation of Run 138B at Experimental Breeder Reactor II, a Prototypic Liquid Metal Reactor, EBR2-LMFR-RESR-001, CRIT, NEA/NSC/DOC(2006)1.

Maoioli, A., et al., 2019. Westinghouse eVinci Micro-Reactor Licensing Modernization Project Demonstration, Southern Company, SC-29980-202.

Martines, J. S., et al., 2014. "Propagation of Neutron Cross Section, Fission Yield, and Decay Data Uncertainties in Depletion Calculations," Nuclear Data Sheets 118, pp. 480-483.

Matthews, C., et al., 2019. Evaluation of the MOOSE Tool-set for Analysis of Thermo-MechanicalNeutronics Coupling in Micro-Reactors," Los Alamos National Laboratory, LA-UR-19-31443.

Mei, L., et al., 2013. "The Investigation of Thermal Neutron Scattering Data for Molten Salt FLiBe," Journal of Nuclear Science and Technology, 50(7), pp. 682-688.

Mulder, E. J., and Boyes, W. A., 2020. "Neutronics Characteristics of a $165 \mathrm{MW}_{\text {th }}$ Xe-100 Reactor," Nuclear Engineering and Design, 357, 110415.

Neudecker, D., et al., 2020. "Building a Long-Range AI/ML Vision," Workshop for Applied Nuclear Data Activities (WANDA), Washington DC, March 3-5.

OECD/NEA, 2016, Benchmark for Neutronic Analysis of Sodium-Cooled Fast Reactor Cores with Various Fuel Types and Core Sizes, NEA/NSC/R(2015)9.

Otuka, N., et al., 2014. "Towards a More Complete and Accurate Experimental Nuclear Reaction Data Library (EXFOR): International Collaboration Between Nuclear Reaction Data Centres (NRDC)," Nuclear Data Sheets, 120, pp. 272-276.

Pigni, M., et al., 2015. "Investigation of Inconsistent ENDF/B-VII.1 Independent and Cumulative Fission Product Yields with Proposed Revisions," Nuclear Data Sheets, 123, pp. 231-236.

Powers, J. J., et al., 2018. "Sensitivity/Uncertainty Analyses Comparing LR-0 Reactor Experiments Containing FLiBe Salt with Models for Molten-Salt-Cooled and Molten-Salt-Fueled Reactors," Annals of Nuclear Energy, 120, pp.319-332.

Qualls, A. L., et al., 2017. "Preconceptual Design of a Fluoride High Temperature Salt-Cooled Engineering Demonstration Reactor: Motivation and Overview," Annals of Nuclear Energy, 107, pp. $144-155$.

Radaideh, M., et al., 2019. "A New Framework for Sampling-Based Uncertainty Quantification of the Six-Group Reactor Kinetic Parameters," Annals of Nuclear Energy, 127, pp. 1-11.

Rearden, B. T., and Jessee, M. A., Eds, 2016. "SCALE Code System," ORNL/TM-2005/39, Version 6.2. Oak Ridge National Laboratory, Oak Ridge, TN. Available from Radiation Safety Information Computational Center as CCC-834, 2016. https://www.ornl.gov/sites/default/files/SCALE_6.2.3.pdf.

Rochman, D., et al. 2017. "Nuclear Data Uncertainties for Typical LWR Fuel Assemblies and a Simple Reactor Core," Nuclear Data Sheets, 139, pp. 1-76. 
Salvatores, M., 2002. "Future Nuclear Power Systems and Nuclear Data Needs," Journal of Nuclear Science and Technology, 39, pp. 4-12.

Salvatores, M., et al., 2013. "Methods and Issues for the Combined Use of Integral Experiments and Covariance Data NEA/WPEC-33,” NEA/WPEC-33.

Shen, D., et al., 2006. Molten-Salt Reactor Experiment (MSRE) Zero-Power First Critical Experiment with ${ }^{235} U$, MSRE-MSR-EXP-001, CRIT, NEA/NSC/DOC(2006)1.

Shibata, K., et al., 2012. “JENDL-4.0: A New Library for Nuclear Science and Engineering," Journal of Nuclear Science and Technology, 48(1), pp. 1-30.

Sobes, V. et al., 2018. "ENDF/B-VIII.0 Covariance Data Development and Testing for Advanced Reactors," ORNL/TM-2018/1037.

Sterbentz, J. W., et al., 2018. Preliminary Assessment of Two Alternative Core Design Concepts for the Special Purpose Reactor, INL/EXT-17-43212, Rev. 1.

Sublet, J.-C., et al., 2013. "The JEFF-3.0/A Neutron Activation File - EAF-2003 into ENDF-6 Format," JEFDOC-982, CEA, France, 2003.

Terrapower, 2020. Terrapower's Molten Chloride Fast Reactor Technology: Retooling Nuclear for a Changing Energy Sector, https://www.terrapower.com/wp-content/uploads/2020/01/TP 2020_MCFR Technology.pdf

Van Rooijen, W. F. G., et al., 2015. "Criticality Uncertainty Dependence on Nuclear Data Library in Fast Molten Salt Reactors," Energy Procedia, 71, 3-13.

Wiarda, D. et al., 2016. "AMPX-6: A Modular Code System for Processing ENDF/B, ORNL/TM2016/43”, Oak Ridge National Laboratory, Oak Ridge, TN. Available from Radiation Safety Information Computational Center as CCC-834, 2016. https://www.ornl.gov/sites/default/files/AMPX-6.pdf.

Wiarda, D., et al., 2018. "ENDF/B-VIII.0 covariance testing at Oak Ridge National Laboratory," CSEWG meeting 2018, Brookhaven National Laboratory, November 5-7.

Williams, M. L., et al., 2013. "A Statistical Sampling Method for Uncertainty Analysis with SCALE and XSUSA,” Nuclear Technology, 183, pp. 515-526.

Williams, M. L., et al., 2017. "Consistency between ENDF/B Cross Sections and Covariances," CSEWG Meeting, Brookhaven National Laboratory, October 31 - November 9.

Yan, B. H., et al., 2020. The Technology of Micro Heat Pipe Cooled Reactor: A Review. Annals of Nuclear Energy, 135, 106948.

Yang, W., 2012. "Fast Reactor Physics and Computational Methods," Nuclear Engineering and Technology, 44(2), pp. 177-198.

Zhang, Z., et al., 2006. "Design Aspects of the Chinese Modular High-Temperature Gas-Cooled Reactor HTR-PM,” Nuclear Engineering and Design, 236, pp.485-490.

Zhang, L., et al., 2020. "Influence of graphitization degree of nuclear graphite on HTGR reactor physics calculation," Annals of Nuclear Energy, 143, 107458.

Zhu, Y., and Hawari, A., 2017. "Thermal Neutron Scattering Cross Section of Liquid FLiBe," Progress in Nuclear Energy, 101, pp. 468-475. 